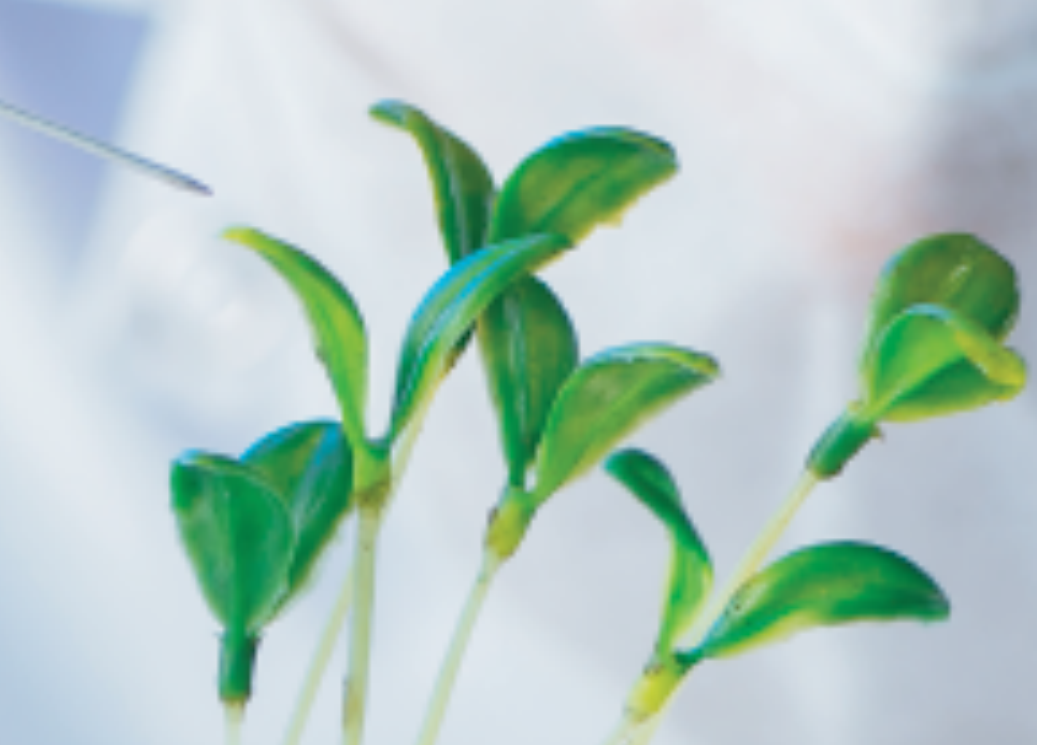

\title{
Modelo de estrategias de enseñanza para fortalecer el aprendizaje significativo en Ciencias Naturales
}

Milton Doroteo Cayambe Guachilema Manuel Jesús Sánchez Chero Jaime Amado Rosero Rojas Manuel Valentín Bermúdez Pacheco Savez
editorial Walter Geovanni Valero Zambrano Danette Pintado García 


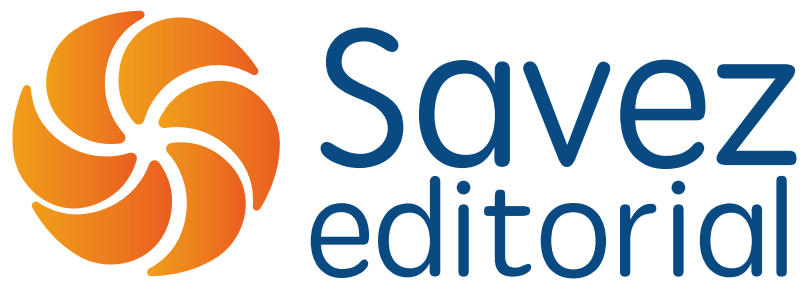

Modelo de estrategias de enseñanza para fortalecer el aprendizaje significativo en Ciencias Naturales 
Modelo de estrategias de enseñanza para fortalecer el aprendizaje significativo en Ciencias Naturales

Milton Doroteo Cayambe Guachilema Manuel Jesús Sánchez Chero Jaime Amado Rosero Rojas Manuel Valentín Bermúdez Pacheco Walter Geovanni Valero Zambrano Danette Pintado García

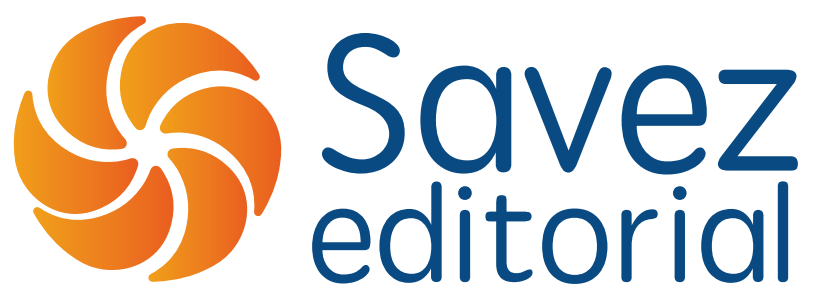


Milton Doroteo Cayambe Guachilema

Manuel Jesús Sánchez Chero

Jaime Amado Rosero Rojas

Manuel Valentín Bermúdez Pacheco

Walter Geovanni Valero Zambrano

Danette Pintado García

Modelo de estrategias de

enseñanza para fortalecer el aprendizaje

significativo en Ciencias Naturales

ISBN: 978-9942-8969-8-8

Savez editorial

Título: Modelo de estrategias de enseñanza para fortalecer el aprendizaje significativo en Ciencias Naturales

Primera Edición: Septiembre 2021

ISBN: 978-9942-8969-8-8

Obra revisada previamente por la modalidad doble par ciego, en caso de requerir información sobre el proceso comunicarse al correo electrónico editor@savezeditorial.com

Queda prohibida la reproducción total o parcial de esta obra por cualquier medio (electrónico, mecánico, fotocopia, grabación u otros), sin la previa autorización por escrito del titular de los derechos de autor, bajo las sanciones establecidas por la ley. El contenido de esta publicación puede ser reproducido citando la fuente.

El trabajo publicado expresa exclusivamente la opinión de los autores, de manera que no compromete el pensamiento ni la responsabilidad del Savez editorial 


\section{ÍNDICE}

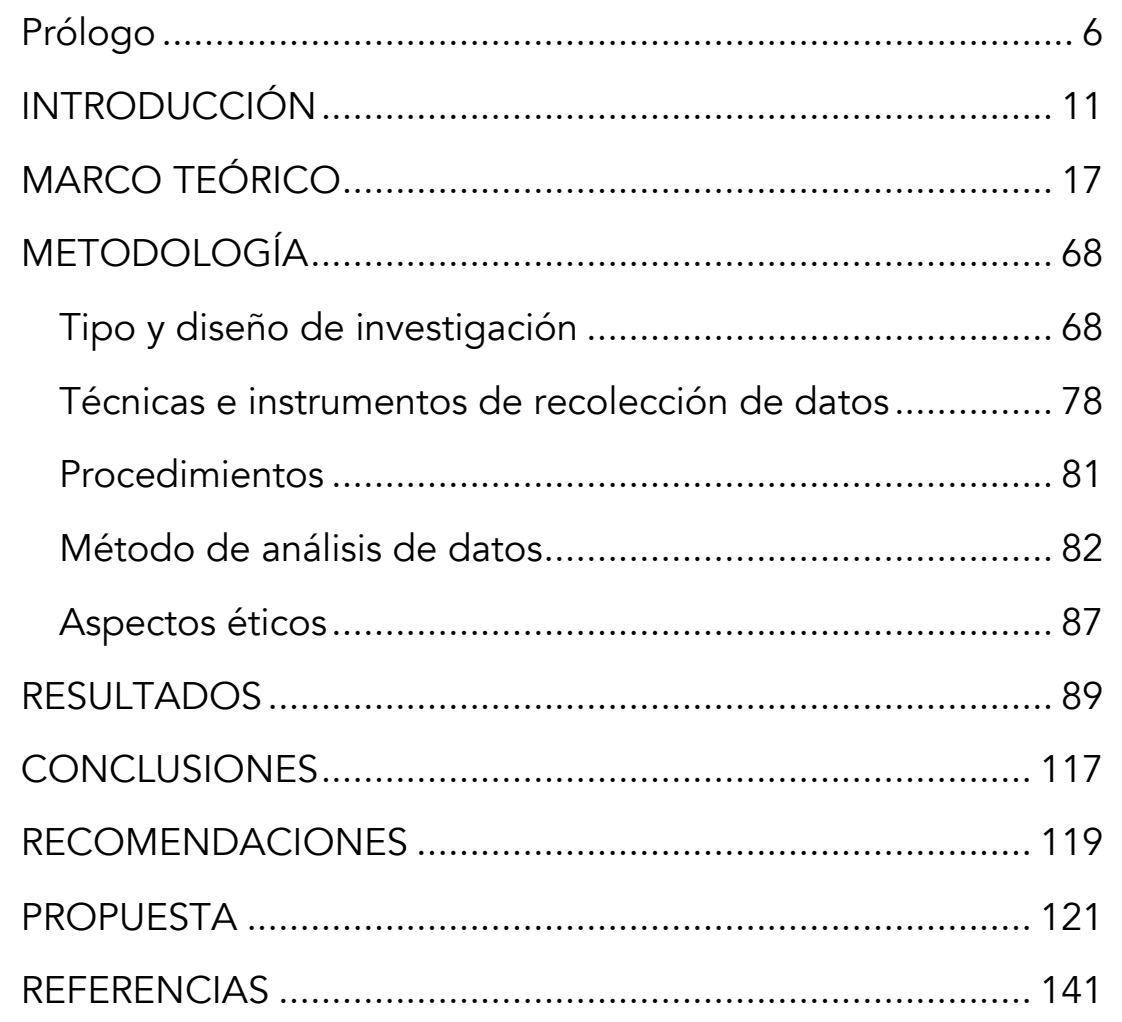




\section{Prólogo}

El libro presenta como objetivo proponer un modelo de estratégias de enseñanza para fortalecer el aprendizaje significativo de los estudiantes de Ciencias Naturales de la Unidad Educativa "Patria Ecuatoriana". Se utilizó la metodologia enfoque cuantitativo, tipo básica y con un diseño descriptivo propositivo. La técnica aplicada fue la encuesta a 170 estudiantes para conocer las dimensiones del aprendizaje significativo. Las estrategías de enseñanza empleados por los docentes se identificó mediante el analisis documental, a travez de la revisión de 32 articulos indexados de la bases de datos Scopus para ser consideradas en el diseño de la propuesta. Logrando como resultado un modelo innovador para fortalecer el aprendizaje significativo en las Ciencias Naturales; fundamentada en la teoría del aprendiaje significativo de David Ausubel, teoría cognitivista y constructivista de Jean Piaget, el método de Kolb y los enfoques tecnologicos Tic,Tac,Tep. Teniendo como conclusión que las estrategias de enseñanza fortalecerá el aprendizaje significativo; considerando al estudiante como un ser autónomo en proceso de desarrollo y que comprenda a la ciencia a su manera, según sus esquemas mentales y a las etapas de desarrollo cognitivo del educando. 


\section{INTRODUCCIONN}

Un modelo de estrategías para educar permite fortalecer el aprendizaje significativo que integra un conjunto de bases didácticas, pedagógicas y tecnológicas modernas con el propósito de alcanzar mayor eficiencia en el rendimiento académico de Ciencias Naturales en la Unidad Educativa Patria Ecuatoriana. Este aporte nos ayudara a mejorar la calidad educativa asegura el desarrollo humano y mejor futuro para los estudiantes.

Los problemas educativos del gobierno Ecuatoriano según (Rodrigo-cano, 2020) el nivel de la educación básica carece de horas de clase, se hace difícil comprender los temas, el material educativo utilizado fueron las herramientas M-learning \& TIC (Ponce, 2018) permitiendo dar mayor apoyo en la comprensión de clases, además la clase son grabada y puede ser visibles las veces que deseen de tal manera que el estudiante llegue a comprender los temas desarrollados, también (YépezReyes, 2018) consideró que esta metodología de enseñanza permite que el aprendizaje significativo tenga 
mayor impacto en la difusión del conocimiento y en el ejercicio de la vida de los estudiantes (Reinoso, 2019).

También el aporte de Uribe (2018), consideró que el aprendizaje significativo en la edad temprana no continuamente logra cumplir las metas propuestas, sin embargo, el docente utiliza medios adecuados propios de su experiencia, logrando conseguir el aumento del resulta el aprendizaje significativo de la Unidad Educativa. Dr. José Ricardo Chiriboga, en la provincia de Pichincha. Concluyó que la aplicación didáctica del juego de razonamiento como herramienta del aprendizaje significativo, permitió mejorar el pensamiento lógico y crítico en el 95\% del rendimiento académico, facilitando la resolución de problemas.

De acuerdo a las políticas del gobierno Ecuatoriano, el Ministerio de Educación, según Monserrat (2020), justificó la necesidad de urgencia sanitaria al presentar caso de contagio por coronavirus COVID-19, siendo necesario prevenir y mitigar cualquier impacto positivo perjudicando la salud y la integridad de la comunidad escolar estos cambios obligan enfrentar nuevos retos que 
con ayuda de la tecnología hacemos frente proponiendo un diseño curricular moderno con habilidades tecnológicas de fácil acceso (fijo o portátil). El programa educativo Juntos aprendemos en casa se transmite diariamente mediante frecuencia televisiva y difunde conocimiento durante el ciclo académico 2020 y 2021, esta medida evita que la comunidad educativa pierda sus clases y no se logre cumplir con las políticas educativas nacionales proyectadas para los años en curso.

Esta oportunidad ha permitido incluir metodologías activas, siendo el más adecuado el: Aprendizaje basado en proyectos, problemas y preguntas - ABP aquí se trasmite las iniciativas para el desarrollo creativo, cuyas habilidades de cada participante expresa múltiples competencias. También se identificaron dificultades trascendentales en el aprendizaje de los diversos procedimientos para el cálculo matemático, siendo una de las principales metas para el logro del razonamiento y la comprensión lógica y crítica. Para (García \& Vélez, 2015) consideró muy importante el soporte técnico de los docentes, padres de familias y apoderados fue posible el cumplimiento de logros educativos, se considera parte de las representaciones 
constructivistas. Las experiencias logradas, según Cobo (2008), Investigó sobre la implementación de un programa de aprendizaje significativo en la Escuela San José La Salle de Guayaquil, aplicó técnicas para desarrollar la asimilación del conocimiento con aprendizaje significativo para docentes quienes programaron sus clases utilizando estas técnicas.

Al principio los docentes no estuvieron de acuerdo debido a las costumbres del registro curricular, pero notaron que los estudiantes no lograban comprender sus enseñanzas con la metodología confusa que aplicaban, entonces cambiaron algunas sesiones de clases notando la diferencia de los errores pasados, esto permitió "crear estructuras cognoscitivas con las condiciones adecuadas para la inclusión y asimilación del conocimiento, se duplico el trabajo técnico, pero los resultados fueron favorables, mejorando progresivamente la enseñanza del aprendizaje" (Cobo, 2008, p. 11).

La Unidad Educativa Patria Ecuatoriana instalada en la Provincia Guayaquil, los docentes que oscilan una edad de 45 a 53 del área de Ciencias Naturales, todavian siguen 
aplicando modelos pegagógicos tradicionales con aprendizajes memorĺsticos, desconocimiento del ciclo del aprendizaje, no aplicación de herramientas tecnológicas, clase inversa, trabajo colaborativo, comunicación asertiva, estrategias de enseñanza preinstruccionales, coinstruccionales, posintruccionales y producción, dando como resultados no poder desarrollar los factores cognoscitivos y afectivos-sociales que intervienen en el aprendizaje significativo en los estudiantes del subnivel la Básica Superior de octavo, noveno y décimo que tienen una edad de diez a doce años. Para utilizar esta estrategia, es necesario tener en cuenta el grado de desarrollo intelectual del estudiante, quien debe tener la capacidad de comprender a partir del lenguaje, con o sin ayudas visuales o concretas. Cuando un alumno no puede comprender contenidos que están por encima de su capacidad de abstracción, la explicación del docente no produce aprendizajes significativos (Carriazo,2009).

El problema de investigación es: ¿De qué manera el modelo de estrategias de enseñanza fortalece el aprendizaje significativo en Ciencias Naturales de la Unidad Educativa Patria Ecuatoriana, 2020? 
Hernández, et al. (2014). Consideró necesario justificar la naturaleza de la investigación de acuerdo al detalle: Justificación teórica permitió ampliar el conocimiento mediante estudios técnicos que analiza el comportamiento del problema y fundamenta alternativa de solución. La justificación práctica, busca resolver la problemática con evidencias y logros obtenidos en el desarrollo de la investigación, además ayuda a fortalecer la propuesta, cumpliendo con los estudios adecuados para su aplicación. Finalmente, la justificación metodológica, permite actuar paso a paso logrando recopilar información adecuada. El proceso de validación de resultados mostró asegurar experiencia exitosa viable para la implementación.

El objetivo general fue: Proponer un modelo de estrategias de enseñanza para fortalecer el aprendizaje significativo y los objetivos específicos establecidos fueron: 1. Identificar los tipos de estrategias de enseñanza implementado en las Ciencias Naturales. 2. Conocer las dimensiones del aprendizaje significativo en los estudiantes. 3. Diseñar el modelo de estrategias de 
enseñanza para fortalecer el aprendizaje significativo de Ciencias Naturales de la Unidad Educativa Patria Ecuatoriana, 2020 y 4. Validar la propuesta por expertos en educación.

\section{MARCO TEÓRICO}

En España, según García, et al., (2019). Las experiencias innovadoras de los maestrantes de educación primaria demostraron que el aprendizaje independiente $\mathrm{o}$ en conjunto, logra cumplir metas cuando existe colaboración entre los participantes, de lo contrario sólo uno desarrolla las tareas y es el único que puede dar explicaciones adecuadas. Sin embargo, fue necesario buscar integración y comprensión de los participantes para lograr defender el contenido del trabajo, mientras que el individual no tiene la necesidad, pero el grupal tiene que compartir dichos conocimientos y diseñan sus propias metodologías para lograr que todos los participantes expresen el desarrollo de su trabajo de manera adecuada. Es parte de la actitud individual tomar conciencia motivadora con responsabilidad para lograr superar inconveniencias que se presente. 
También el autor Simón, et al., (2018). Analizó, los diferentes modelos educativos y los roles del docente en base a la innovación pedagógica, para dar el sustento adecuado de la construcción teórica es necesario obtener resultados aceptables de las percepciones de los universitarios, la innovación didáctica en la pedagogía no logra cambiar roles tradicionales de los formadores, cada uno aplica de acuerdo a sus iniciativas. Concluyó que los docentes ofrecen y aplican herramientas pedagógicas adecuadas para lograr la formación de las actitudes que los estudiantes deben tener, la transformación o cambio son de acuerdo al impacto de las condiciones en la que se encuentra, sin embargo, las capacidades, confianza y orientaciones ayudan a superar cualquier obstáculo, además logra motivar y asignar responsabilidad durante el aprendizaje.

La Universidad de Málaga mediante la Facultad de educación, desarrolló investigación sobre aprendizaje significativo, donde los autores Sánchez, et al., (2014), manifestaron que las sesiones educativas tienen acepciones cuando los alumnos atiende y registra apuntes, pero otros intentan aprender y solo toman nota aún sin 
lograr comprender lo que se está explicando; algunos en casa vuelven a estudiar los apuntes del contenido explicado y con ayuda del libro o manual tratan de recordar la clase logrando resolver las tareas fácilmente. Posteriormente registran el cuestionario de opinión quienes de forma mayoritaria aceptan el modelo educativo implementado por el gobierno.

Bastante relación tiene con Nicaragua, según Tregón (2017), divulgó en su tesis doctoral sobre la diversidad funcional visual de la formación educativa y las deficiencias técnicas metodológicas del docente que crea la necesidad en implementar un plan formativo para docentes con base teórica y crítica actualizada mediante el aprendizaje significativo, metodología moderna que se adaptan fácilmente a los alumnos con diversidad funcional del sistema educativo manteniendo equitativamente las relaciones de cada participante. Esta implementación amplia los conocimientos del docente, mejorando los contenidos de cada sesión de clases y permitiendo las participaciones de los estudiantes tuvieron como impacto los efectos psicológicos, emocionales, culturales, laborales y ético además logrando mejorar el rendimiento educativo. 
Uno de los casos poco desarrollados en el sistema educativo en Turquía, según (Bolat, 2016; Muir, 2017), utilizó el modelo educativo del aula invertida, la educación es diferente con otros países porque buscan crear nuevas técnicas y modelos educativos para innovar con proyectos atractivos para el desarrollo y bienestar de sociedad. El resultado determino que el $90 \%$ de estudiantes logran cumplir el desarrollo de proyectos educativos, mientras que $10 \%$ se dedica a reforzar estudios desarrollados anteriores. Se concluyó que los aportes científicos permiten ofrecer al país la generación de oportunidades económicas innovadoras para el mercado europeo, retribuyendo el gobierno a otorgar mayor inversión en la educación motivando a los estudiantes a ser más creativos.

También la Universidad de Mersin, según (Hayırsever \& Orhan, 2018) aplicó aulas invertidas, también conocida como aprendizaje invertido o clase en casa. Si bien el "aula" fue el punto focal en las primeras implementaciones de este modelo, últimamente este punto focal se ha desplazado hacia el "aprendizaje". Si bien el concepto de "aulas invertidas" se había utilizado 
comúnmente en las primeras implementaciones, posteriormente este concepto se ha sustituido por "aprendizaje invertido" donde el autor principal es el estudiante quien logra resolver problemas teniendo como base las enseñanzas obtenidas.

Situación semejante sucedió según el estudio de (Say \& Yıldırım 2020) sobre el desarrollo de tecnologías digital, innova nuevos aprendizajes y se implementan enfoques de enseñanza, se profundiza en la investigación revelando nuevos modelo que son una revolución de emprendimiento para los educandos de secundaria pública de la ciudad de Konya, Turquía, durante los años 2017-2018 interactuaron cursos de ciencias y expresan la que la aplicación del aula invertida, es exitoso, su participación en la clase ha mejorado y encontraron que este método era mucho más divertido.

En México, según (Martínez-Olvera 2015). Realizó estudios para lograr la implementación del modelo constructivo. Abordan datos sobre inicio, evolución y soporte teórico, adecua el aula, para lograr aplicar cambios educativos y desarrollaron de varias sesiones educativas 
Los resultados demuestran la distante diferencia comparativa con el modelo tradicional, donde los estudios empíricos son parte de la historia educativa y el modelo constructivo transformo múltiples cambios en corto tiempo y motiva la participación escolar por lograr aprende hacer algo novedoso.

En Venezuela, La escuela de biología de la Universidad del Zulia según (Acosta \& Andrade 2014) fundamentó estudio sobre las estrategias dinámicas para lograr la comprensión del aprendizaje significativo de los docentes activos. Esta propuesta permitió cimentar bases técnicas de los autores Ausubel, et al y Orellana (1991, 2008). La exploración tuvo característica "Descriptiva", esquema "no experimental y transversal", con capacidad técnica de estudio conformada por participantes involucrados en la escuela de Biología. Las deducciones expresaron la existencia de aplicaciones estratégicas propias de cada docente, de acuerdo a la comunidad universitaria los estudiantes "aprecian o rechazan", sin embargo, estos optan por iniciativa expresar sus capacidades de acuerdo a su interés. El logro de concluido permitió demostrar que los docentes buscan motivar la 
educación aplicando técnicas adecuadas para que los estudiantes logren comprender diversas materias, construyendo sus propios conceptos coherentes y significativa.

En Estados Unidos, según Project y Flipped (2015), más de 521,865 estudiantes de K-12, maestros, administradores, representantes legales y sujetos de la comunidad participaron en la duodécima encuesta anual Speak Up en línea facilitada por la organización nacional sin fines de lucro de educación, Project Tomorrow en conjunto con Flipped Learning Network. Por tercer año consecutivo, se hicieron preguntas específicas a maestros, bibliotecarios y administradores de edificios y distritos sobre los modelos educativos y el aprendizaje significativo, los educadores y administradores que intervinieron expresaron que cada docente busca el modelo educativo para el desarrollo de clase, también, los estudiantes coordinan directamente con el docente si la metodología aplicada es adecuada o prefieren cambiara por algo mejor.

En Perú, en la Provincia de Paucarpata, Arequipa, según Salas (2019), evaluó las habilidades educativas - 
aprendizaje que aplican los maestros para mejorar el rendimiento académico del Colegio Secundario № 40177 "Divino Corazón de Jesús". La investigación aplicó encuesta a una muestra de 194 estudiantes, es una investigación explicativa - correlacional casual determinando que las estrategias de enseñanza que aplica los profesores en sus sesiones de enseñanza-aprendizaje es adecuada para el $63 \%$ mientras que el $37 \%$ no logran comprenderla desaprobando el curso. Se demuestra que las estrategias de enseñanza que utilizan los docentes no son adecuadas, siendo necesaria mejorarla.

También Medina, (2018), demostró resultados progresivos aceptables de mejoras aplicativas en metodología del aprendizaje en diversos temas referentes a matemática financiera siendo el resultado inicial $48 \%$ frente al $73 \%$ de logro final, el cambio fue significativo, sumándose la iniciativa del estudiante. Sin embargo (Gamarra, 2017), diseñó un modelo teórico destinado al Trabajo Social en la enseñanza aprendizaje escolar. El método aplicado permite la construcción interactiva de conocimientos que fortalezca las competencias, para brindar oportunidades y satisfacer su estilo de convivir. 
Las teorías sobre modelo educativos, propuestos por García-Valcárcel (2009) nos enseñanza diseñar planes estructurados con materiales educativos de acuerdo a las necesidades curriculares, estos medios facilitarán los procesos de enseñanza en las aulas. Es recomendable no limitar el potencial del estudiante se debe guiar de acuerdo a los avances, la visión nos permite calificar el potencial de aprendizaje de cada estudiante. Es necesario que los modelos educativos tengan integrado los siguientes elementos:

\begin{tabular}{ccc}
\hline 1. El & 2. La & 3. La Evaluación \\
Enfoque & Metodología & \\
¿Qué & ¿Cómo & ¿Cómo medir los objetivos \\
enseñar? & enseñar? & alcanzados? \\
\hline
\end{tabular}

Educación (2020) presenta la línea de tiempo de la educación de la última década en Ecuador siendo: 
Figura 1 Línea de tiempo de la educación en

Ecuador, Educación (2020)

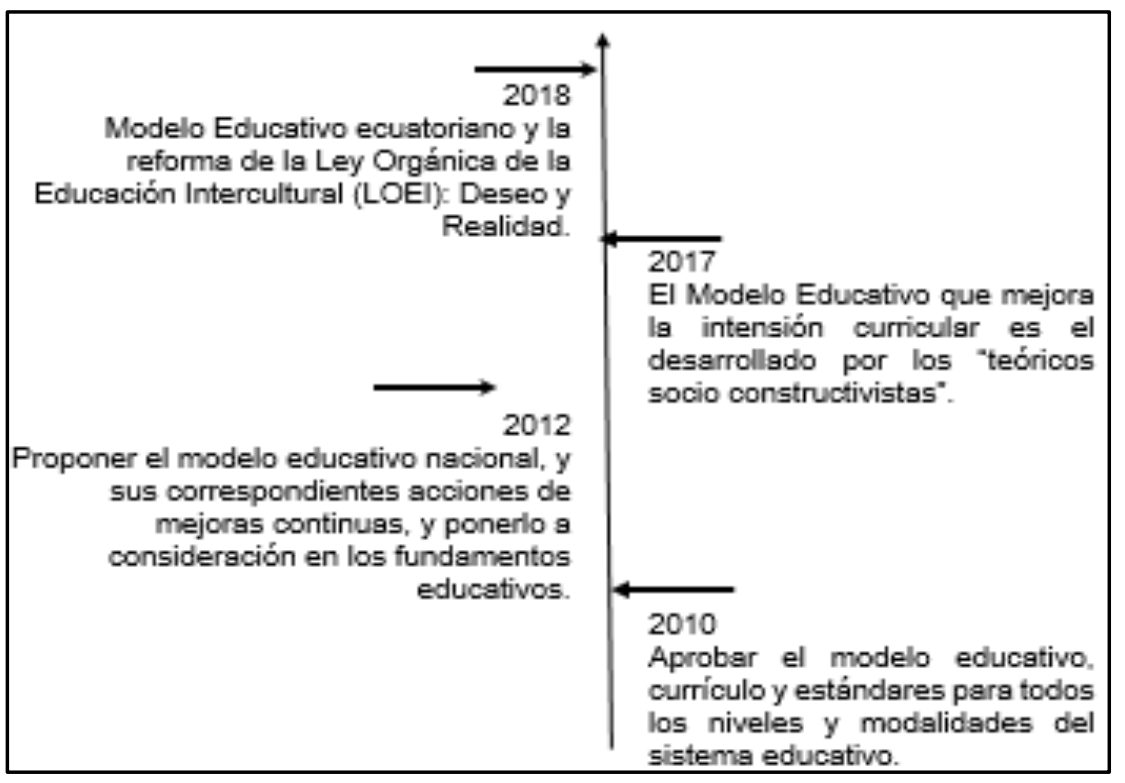

Según el Ministerio de Educación (2020). El Modelo implementado para el Sistema de Educación Intercultural Bilingüe (MOSEIB) ha permitido estandarizar los niveles ideológicos, culturales con tendencia filosófica en toda la cobertura nacional, los pueblos de poco acceso fueron integrados y adecuados para lograr dar respuesta a todos los procesos de implementación. Sin embargo, el nivel de progreso del modelo ha permitido mejorar las relaciones y condiciones educativas. Los diferentes indicadores de la realidad nacional han permitido la integración entre pueblos y globalizar las políticas públicas del estado en el 
sector educativo, también es posible resaltar el modelo MOSEIB tiene elementos que evalúa su funcionabilidad denominándose estrategias de la realidad educativa y que cumplen metas programadas siendo:

- La experiencia vivencial escolar y la integración técnica de los miembros.

- Compartir propuestas innovadoras de especialistas externos.

- Uso de información histórica de la Educación Intercultural Bilingüe.

Mejoras de las relaciones interculturales con desarrollo estratégico nacional con libre participación perfecciona las gestiones pedagógicas. 
Figura 2 Línea de tiempo de la innovación (Acosta \& Andrade, 2014)

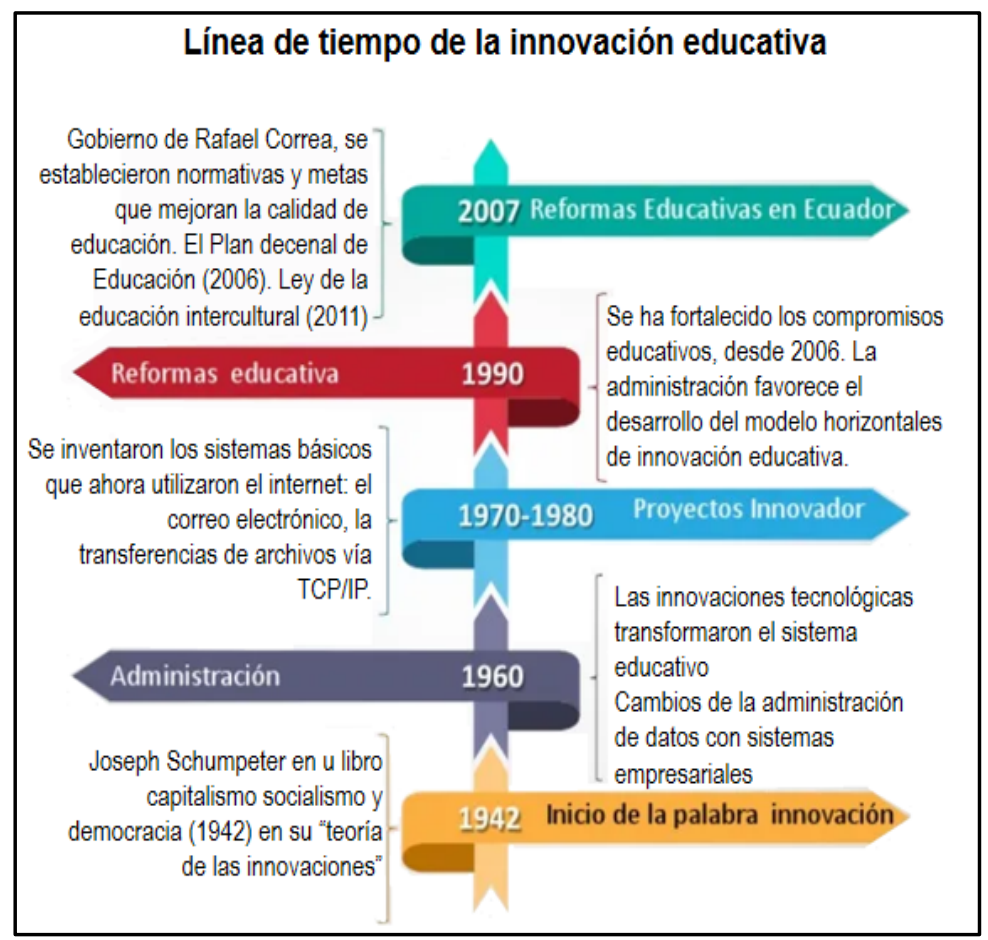

Por otra parte, teniendo presente que la didáctica, como disciplina independiente, apoya directamente a los procesos de la formación educativa (Medina \& Salvador, 2009); se puede ahora definir lo que sería un modelo didáctico como la representación esquemática de la diversidad de acciones, técnicas y medios posibles a utilizar por los educadores para habilitar el proceso de enseñanza - aprendizaje (Mayorga \& Madrid, 2010). Finalmente, Sarmiento (2017). 


\section{Tabla 1}

Comparaciones de las actuales teorías educativas

\begin{tabular}{|c|c|c|c|c|c|c|c|c|}
\hline Autor & Teoría & $\begin{array}{l}\text { Sujeto } \\
\text { que } \\
\text { aprende }\end{array}$ & Inteligencia & $\begin{array}{l}\text { Rol del } \\
\text { docente }\end{array}$ & Aprendizaje & $\begin{array}{l}\text { Términos } \\
\text { específicos }\end{array}$ & $\begin{array}{l}\text { Papel de los } \\
\text { contenidos }\end{array}$ & Evaluación \\
\hline Piaget & $\begin{array}{l}\text { Constr } \\
\text { uctivis } \\
\text { mo } \\
\text { genéti } \\
\text { co }\end{array}$ & $\begin{array}{l}\text { Epistémi } \\
\text { co- } \\
\text { activo }\end{array}$ & $\begin{array}{l}\text { La } \\
\text { asimilación } \\
\text { de nuevos } \\
\text { aprendizajes } \\
\text { es } \\
\text { permanente } \\
\text {, depende } \\
\text { de las } \\
\text { estructuras } \\
\text { cognoscitiva } \\
\text { s. }\end{array}$ & $\begin{array}{l}\text { Facilitador } \\
\text { del } \\
\text { aprendizaj } \\
\text { e, motiva } \\
\text { a los } \\
\text { estudiante } \\
\text { s, } \\
\text { respetand } \\
\text { o sus } \\
\text { experienci } \\
\text { as y su } \\
\text { desarrollo } \\
\text { biopsicos } \\
\text { ocial. }\end{array}$ & $\begin{array}{l}\text { Construcción } \\
\text { constante de } \\
\text { nuevos } \\
\text { conocimiento } \\
\text { s a partir de } \\
\text { los previos a } \\
\text { través de } \\
\text { procesos de } \\
\text { asimilación, } \\
\text { acomodación } \\
\text { y adaptación } \\
\text { que implica } \\
\text { cambios } \\
\text { cualitativos. }\end{array}$ & $\begin{array}{l}\text { Estructura, } \\
\text { esquema, } \\
\text { función, } \\
\text { asimilación, } \\
\text { acomodació } \\
\text { n y } \\
\text { adaptación. }\end{array}$ & $\begin{array}{l}\text { Es hilo } \\
\text { conductor } \\
\text { de reflexión } \\
\text { y cambio } \\
\text { didáctico, } \\
\text { que se } \\
\text { utiliza para } \\
\text { optimizar la } \\
\text { ejecución } \\
\text { de } \\
\text { habilidades } \\
\text { y destrezas. }\end{array}$ & $\begin{array}{l}\text { Evalúa los } \\
\text { procesos } \\
\text { sobre los } \\
\text { resultados. }\end{array}$ \\
\hline $\begin{array}{l}\text { Vygots } \\
\text { ky }\end{array}$ & $\begin{array}{l}\text { Históri } \\
\text { co- } \\
\text { cultura } \\
\text { I }\end{array}$ & $\begin{array}{l}\text { Constru } \\
\text { ye sus } \\
\text { proceso } \\
\text { s } \\
\text { psicológ } \\
\text { icos } \\
\text { superior } \\
\text { es en la } \\
\text { interacci } \\
\text { ón con } \\
\text { lo social } \\
\text { en un } \\
\text { proceso } \\
\text { interper } \\
\text { sonal } \\
\text { interioriz } \\
\text { ar al } \\
\text { proceso } \\
\text { intraper } \\
\text { sonal. }\end{array}$ & $\begin{array}{l}\text { Se } \\
\text { desarrolla el } \\
\text { pensamient } \\
\text { o, la } \\
\text { capacidad } \\
\text { de } \\
\text { argumentaci } \\
\text { ón, los } \\
\text { efectos y la } \\
\text { voluntad. }\end{array}$ & $\begin{array}{l}\text { Docente- } \\
\text { mediador } \\
\text { de la } \\
\text { cultura a } \\
\text { través de } \\
\text { lenguaje } \\
\text { oral y } \\
\text { escrito en } \\
\text { un } \\
\text { contexto } \\
\text { inicial de } \\
\text { diálogo, } \\
\text { conversaci } \\
\text { ón y } \\
\text { debate. }\end{array}$ & $\begin{array}{l}\text { El aprendizaje } \\
\text { debe iniciar } \\
\text { reconociendo } \\
\text { el significado } \\
\text { y la } \\
\text { importancia } \\
\text { social y } \\
\text { cultural que } \\
\text { tiene el } \\
\text { contenido } \\
\text { que se } \\
\text { pretende } \\
\text { enseñar y } \\
\text { aprender. }\end{array}$ & $\begin{array}{l}\text { Docente- } \\
\text { Mediador, } \\
\text { zona de } \\
\text { desarrollo } \\
\text { próximo. }\end{array}$ & $\begin{array}{l}\text { Desarrollo } \\
\text { de } \\
\text { destrezas } \\
\text { (saber } \\
\text { hacer), } \\
\text { procedimie } \\
\text { ntos, } \\
\text { procesos } \\
\text { mentales } \\
\text { (observar, } \\
\text { buscar } \\
\text { información, } \\
\text { analizar, } \\
\text { clasificar y } \\
\text { responder a } \\
\text { los interese } \\
\text { de los } \\
\text { estudiantes) } \\
\text { • }\end{array}$ & $\begin{array}{l}\text { Todo es } \\
\text { valioso y } \\
\text { correcto, se } \\
\text { evalúa } \\
\text { procedimie } \\
\text { ntos } \\
\text { (portafolio) } \\
\text { de acuerdo } \\
\text { al ritmo de } \\
\text { aprendizaje } \\
\text { del } \\
\text { alumno.. }\end{array}$ \\
\hline
\end{tabular}




\begin{tabular}{|c|c|c|c|c|c|c|c|c|}
\hline $\begin{array}{l}\text { Ausub } \\
\text { el }\end{array}$ & $\begin{array}{l}\text { Apren } \\
\text { dizaje } \\
\text { signific } \\
\text { ativo }\end{array}$ & $\begin{array}{l}\text { Posee } \\
\text { un } \\
\text { conjunt } \\
\text { o de } \\
\text { concept } \\
\text { os, } \\
\text { ideas, y } \\
\text { saberes } \\
\text { previos } \\
\text { que son } \\
\text { propios } \\
\text { de la } \\
\text { cultura } \\
\text { en la } \\
\text { que se } \\
\text { desenvu } \\
\text { elve. }\end{array}$ & $\begin{array}{l}\text { Posibilidad } \\
\text { de construir } \\
\text { conocimient } \\
\text { os y } \\
\text { aptitudes } \\
\text { sobre otros } \\
\text { conocimient } \\
\text { os previos. }\end{array}$ & $\begin{array}{l}\text { Introducir } \\
\text { de los } \\
\text { saberes } \\
\text { significativ } \\
\text { os, que } \\
\text { investiga } \\
\text { acerca de } \\
\text { los } \\
\text { saberes } \\
\text { previos y } \\
\text { las } \\
\text { motivacio } \\
\text { nes de sus } \\
\text { alumnos. }\end{array}$ & $\begin{array}{l}\text { Proceso } \\
\text { cognitivo que } \\
\text { tiene lugar } \\
\text { cuando las } \\
\text { personas } \\
\text { interactúan } \\
\text { con su } \\
\text { entorno } \\
\text { tratando de } \\
\text { dar sentido al } \\
\text { mundo que } \\
\text { perciben. }\end{array}$ & $\begin{array}{l}\text { Estructura } \\
\text { cognitiva. }\end{array}$ & $\begin{array}{l}\text { Posibilitado } \\
\text { res del } \\
\text { encadenami } \\
\text { ento de los } \\
\text { saberes } \\
\text { nuevos con } \\
\text { los previos } \\
\text { por su } \\
\text { significativid } \\
\text { ad. }\end{array}$ & $\begin{array}{l}\text { Se focaliza } \\
\text { en los } \\
\text { cambios } \\
\text { cualitativos } \\
\text { las } \\
\text { apropiacion } \\
\text { es } \\
\text { significativa } \\
\text { s que } \\
\text { realizan los } \\
\text { estudiantes. }\end{array}$ \\
\hline
\end{tabular}

Fuente: (Sarmiento, 2017)

Los modelos pedagógicos permiten trasmitir conocimientos desarrollando destrezas con criterio operativos para el buen desempeño educativo. Actualmente las políticas educativas aplican a los autores: Verónica Edwards, Ángel Díaz Barriga, Paulo Freire, Lev Vygotsky. Los modelos educativos, tratan de explicar procesos internos para desarrollar el aprendizaje, adquiriendo habilidades intelectuales con destrezas motoras eficientes. Los modelos de estudios son el conductismo, cognitivismo y constructivismo. 
Tabla 2. Comparaciones de las teorías educativas

\begin{tabular}{|c|c|c|c|}
\hline $\begin{array}{c}\text { Aspectos } \\
\text { diferenciales }\end{array}$ & Conductismo & Cognitivismo & Constructivismo \\
\hline $\begin{array}{l}\text { - Supuestos } \\
\text { teóricos } \\
\text { - Aprendizaje } \\
\text { por } \\
\text { contenidos. }\end{array}$ & $\begin{array}{l}\text { - Modelo E-R y } \\
\text { reflejos } \\
\text { condicionados. } \\
\text { - Asociación } \\
\text { - Pre- } \\
\text { especificados. }\end{array}$ & $\begin{array}{l}\text { - Modelos de } \\
\text { procedimiento de } \\
\text { la información. } \\
\text { - Transmisión } \\
\text { - Pre-especificados. }\end{array}$ & $\begin{array}{l}\text { - Teoría } \\
\text { constructivista del } \\
\text { conocimiento. } \\
\text { - Reestructuración } \\
\text { - Rechazan la pre- } \\
\text { especificación. }\end{array}$ \\
\hline $\begin{array}{l}\text { - Conocimien } \\
\text { to. }\end{array}$ & $\begin{array}{l}\text { - Respuesta } \\
\text { pasiva y } \\
\text { automática a } \\
\text { estímulos } \\
\text { externos. }\end{array}$ & $\begin{array}{l}\text { - Representaciones } \\
\text { simbólicas en la } \\
\text { mente del } \\
\text { aprendiz. }\end{array}$ & $\begin{array}{l}\text { - Construcción } \\
\text { individual por } \\
\text { interacciones entre } \\
\text { sujeto y objeto. }\end{array}$ \\
\hline $\begin{array}{l}\text { - Aprendizaje } \\
\text { Activo y } \\
\text { Colaborativ } \\
\text { o }\end{array}$ & $\begin{array}{l}\text { - Aprendizaje } \\
\text { pasivo y no } \\
\text { negociado. }\end{array}$ & $\begin{array}{l}\text { - Aprendizaje activo } \\
\text { y no } \\
\text { necesariamente } \\
\text { negociado. }\end{array}$ & $\begin{array}{l}\text { - Aprendizaje activo } \\
\text { y negociado. }\end{array}$ \\
\hline • Evaluación & $\begin{array}{l}\text { - En función de } \\
\text { los objetivos } \\
\text { terminales. }\end{array}$ & $\begin{array}{l}\text { - Considera su } \\
\text { separación del } \\
\text { contexto. }\end{array}$ & $\begin{array}{l}\text { - Evaluación dentro } \\
\text { del contexto. }\end{array}$ \\
\hline $\begin{array}{l}\text { - Contexto } \\
\text { del } \\
\text { aprendizaje }\end{array}$ & $\begin{array}{l}\text { - Ambientalista } \\
\text { (Aprendizaje } \\
\text { controlado). }\end{array}$ & $\begin{array}{l}\text { - Reales y permiten } \\
\text { aislarse } \\
\text { (Aprendizaje por } \\
\text { instrucción). }\end{array}$ & $\begin{array}{l}\text { - Realistas } \\
\text { (Aprendizaje por } \\
\text { experiencia). }\end{array}$ \\
\hline $\begin{array}{l}\text { - Metodologí } \\
\text { a de } \\
\text { estudio }\end{array}$ & $\begin{array}{l}\text { - Métodos: } \\
\text { Observación y } \\
\text { experimentació } \\
\text { n. }\end{array}$ & $\begin{array}{l}\text { - Técnicas: Análisis } \\
\text { de tareas. }\end{array}$ & $\begin{array}{l}\text { - Método: Histórico, } \\
\text { crítico, de análisis y } \\
\text { psicogenético. }\end{array}$ \\
\hline - Sujeto & - Pasivo & - Activo & - Dinámico \\
\hline
\end{tabular}




\begin{tabular}{|c|c|c|c|}
\hline $\begin{array}{l}\text { - Estrategias } \\
\text { de } \\
\text { aprendizaje. }\end{array}$ & $\begin{array}{l}\text { - Son controladas } \\
\text { por el } \\
\text { ambiente. }\end{array}$ & $\begin{array}{l}\text { - Unas son } \\
\text { específicas y otras } \\
\text { son consensuadas. }\end{array}$ & $\begin{array}{l}\text { - Individuales y } \\
\text { grupales; los } \\
\text { alumnos controlan } \\
\text { su propia } \\
\text { instrucción. } \\
\end{array}$ \\
\hline $\begin{array}{l}\text { - Interpretaci } \\
\text { ón } \\
\text { personal. }\end{array}$ & $\begin{array}{l}\text { - Otros deciden } \\
\text { lo que él } \\
\text { alumno debe } \\
\text { saber. }\end{array}$ & $\begin{array}{l}\text { - La estructura del } \\
\text { aprendizaje no es } \\
\text { única. }\end{array}$ & $\begin{array}{l}\text { - Cada estudiante } \\
\text { tiene una } \\
\text { interpretación } \\
\text { personal. }\end{array}$ \\
\hline $\begin{array}{l}\text { - Construcció } \\
\text { n del } \\
\text { aprendizaje. }\end{array}$ & $\begin{array}{l}\text { - La experiencia } \\
\text { produce errores } \\
\text { en la } \\
\text { comprensión } \\
\text { de la realidad. }\end{array}$ & $\begin{array}{l}\text { - Él alumno necesita } \\
\text { muchas } \\
\text { experiencias. }\end{array}$ & $\begin{array}{l}\text { - A través de la } \\
\text { experiencia. }\end{array}$ \\
\hline
\end{tabular}

Fuente: (Sarmiento, 2017).

La teoría conductista es una concepción empirista del conocimiento, actúa de manera primaria al adquirir conocimiento, no logra desarrollar la visión humana, está compuesta de tres elementos que son: Estímulo discriminativo, respuesta operante y estímulo reforzante. Para Bartolomé (2016) está teoría es poco aceptada, pero la práctica consecuente permite el aprendizaje y las destrezas ocupan espacio intelectual en el contexto general del alumno, también Gros, (2010) estableció que el diseño de los materiales educativos debe ser didácticos para el autoaprendizaje. 
Figura 3. Estrategias Conductista (Guerrero \& Flores, 2009)

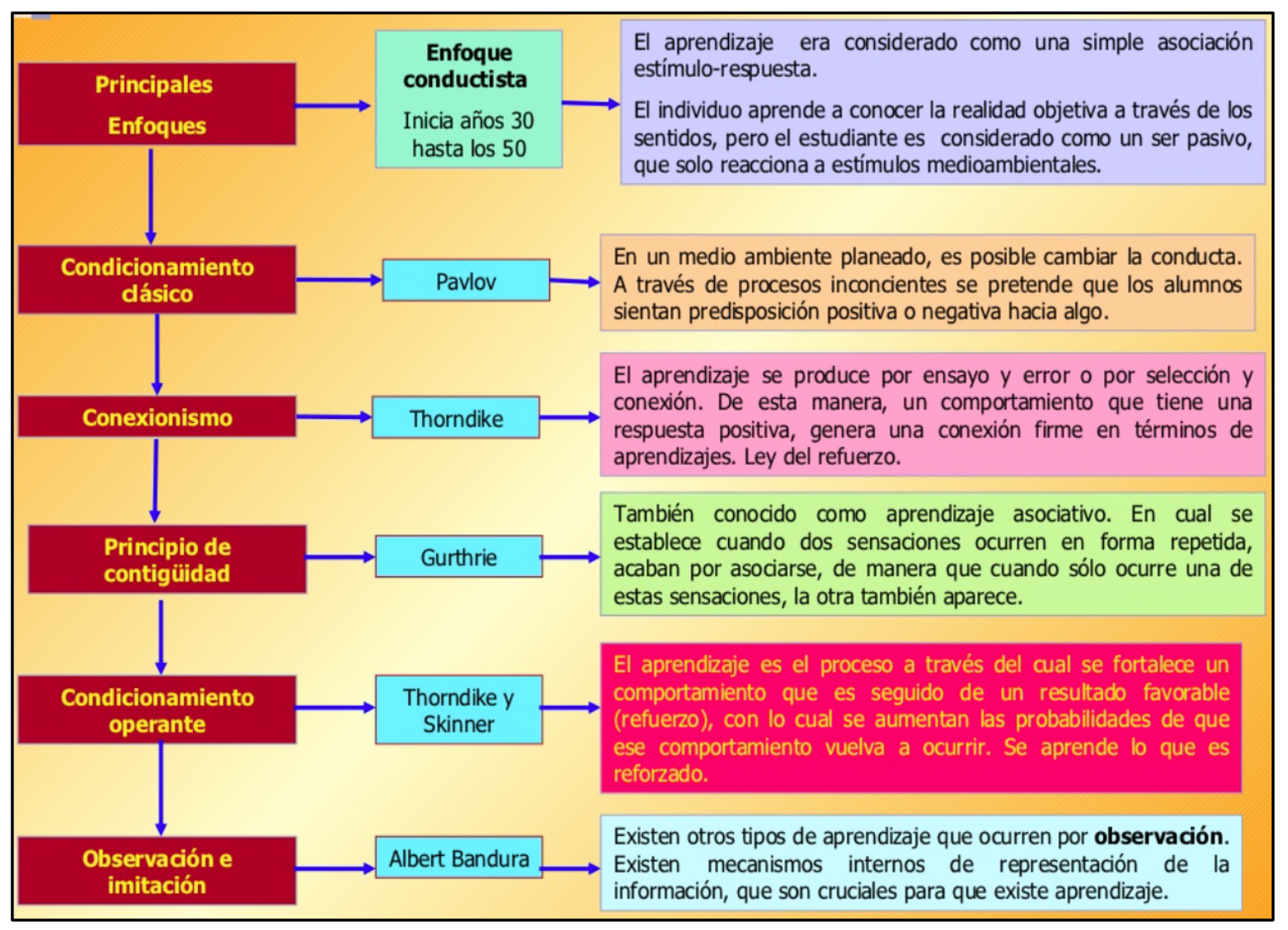

La teoría cognitivista relaciona los conocimientos adquiridos para desarrollar una nueva idea. Permite mejorar el aprendizaje y obtener nuevos productos (Gallego, 2017). El desarrollo de competencias permite mejorar las habilidades cognitivas y crear nuevas 
alternativas para maximizar el aprendizaje con superiores iniciativas.

“La configuración cognoscitiva de cada individuo establece su potencial mental, que será aplicado en los procesos de su aprendizaje, a cambio el profesor buscará desarrollar estrategias favorables para lograr el aprendizaje" (Hernández, et al., 2010). Las diferencias entre teorías conductistas y cognitivas se presentan de acuerdo al medio como se logra interpretar el conocimiento. Está demostrado que lo cognitivismo representa la mente individual, la inteligencia, con capacidad creativa. La memoria tiene buena percepción y suficiente competencia para lograr hacer algo.

La perspectiva de la teoría constructivista es organizar y estructurar el conocimiento, según De-Pablos (2018), consideró que, el estudio detallado de aquellos cambios que se generan en la organización y características de contenidos mentales es consecuencia de la interrelación y su aplicación. El investigador Piaget y otros seguidores consideran que el aprendizaje construye medidas organizativas para la información, aplica sus 
capacidades competitivas para solucionar problemas de aprendizaje.

Figura 4. Estrategias Cognitivas (Barrón, 2009)

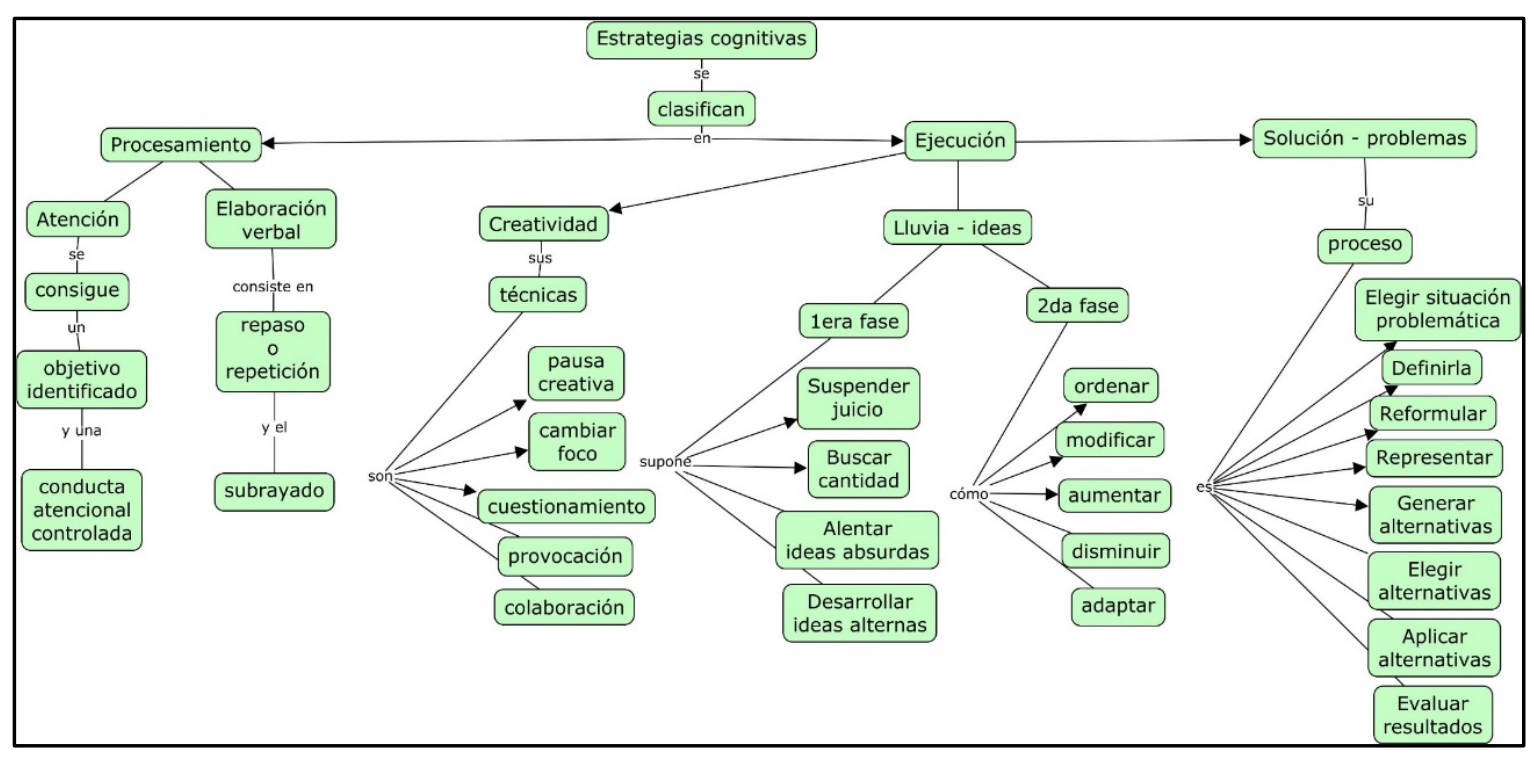

Piaget estableció progresos educativos mediante estructuras mentales, que construye la inteligencia basándose a los principios naturales y las necesidades para lograr aprender y resolver nuestros propios problemas. Todas las representaciones metodológicas son estructuras basado a la realidad y al juicio por lograr aprender (Gallego, 2017). 
Gutiérrez (2019), considera que, la participación de Piaget asegura que las estructuras educativas no logran el horizonte esperado para el desarrollo intelectual del estudiante, el mismo construye gradualmente las opciones operativas para lograr entender los saberes. Existen 3 "períodos psico evolutivos" para el desarrollo del niño, tales como la etapa sensorial motora integrada por niños hasta los 2 años, la pre operacional compuesta por niños hasta 7 años) y la tercera etapa de operaciones concretas considera a los niños de 7 hasta 11 años y las formales hasta más de 11 años. Las inclusiones teóricas piagetiana, mencionadas por (Silva y Ávila, 2018) las clasifica como: "El desarrollo intelectual, mejoramiento de la actividad cognitiva y sistema de gestión en las transformaciones. 
Figura 5. Estrategias de constructivismo (Guerrero \& Flores, 2009)

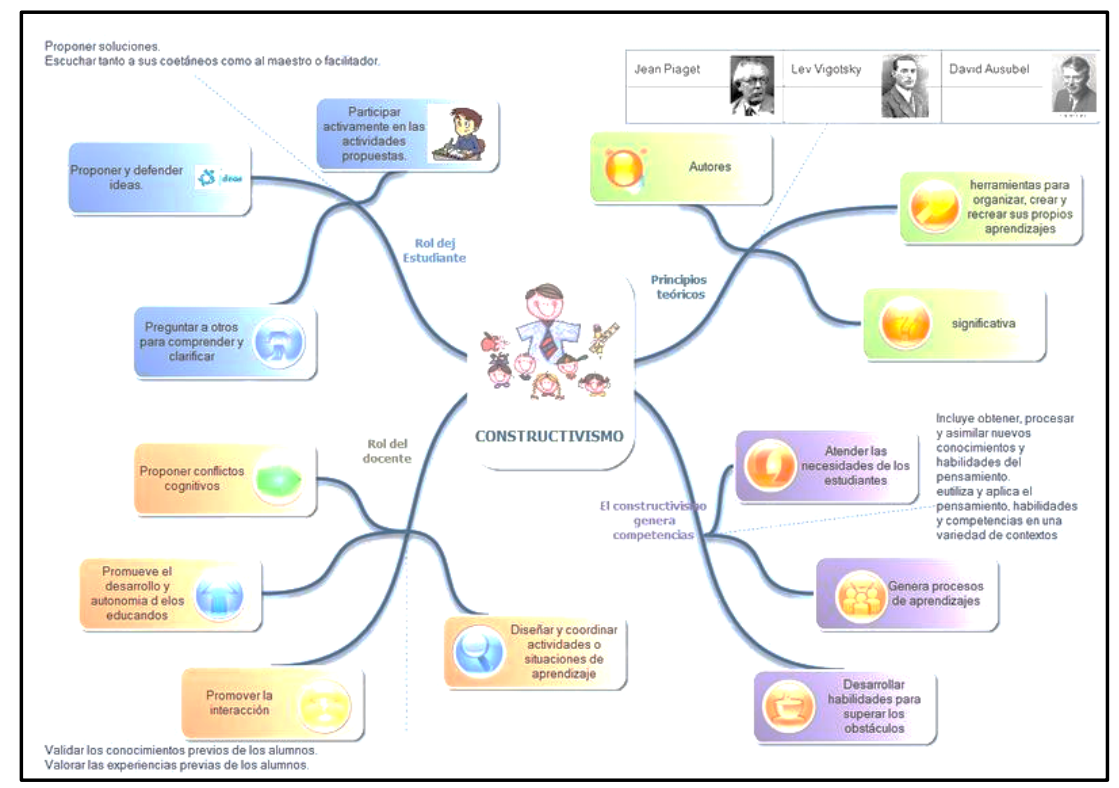

Estrategias del aprendizaje significativo por recepción, el que se genera cuando los contenidos y cuadros mentales son asimilados al ser recibidos y comparados con experiencias ya adquiridas por cada alumno en el salón de clases. Así, el aprendizaje se produce en la interrelación de aquellos saberes ya adquiridos y vinculados con los nuevos, lo que va más allá de solo conceptualizarlos, sino que crean nuevos saberes que facilitan la enseñanza - aprendizaje en el estudiante. 
David Ausubel, consideró que, el concepto inclusor funciona como medio vinculante entre los saberes previos y los nuevos.

Los principios de aprendizaje establecen un diseño de herramientas metacognitivas que facilitan identificar el ensamblaje de la organización cognitiva. Por tal razón, la labor docente no parte de cero, al iniciar la actividad educativa sustentada en aquellas experiencias y conocimientos que inciden en el aprendizaje y benefician al estudiante; implicando se adquiera un nuevo significado de la información, a partir de los conceptos y aprendizajes con los que cuenta cada discente. 
Figura 6. Estrategias del aprendizaje significativo (Guerrero \& Flores, 2009)

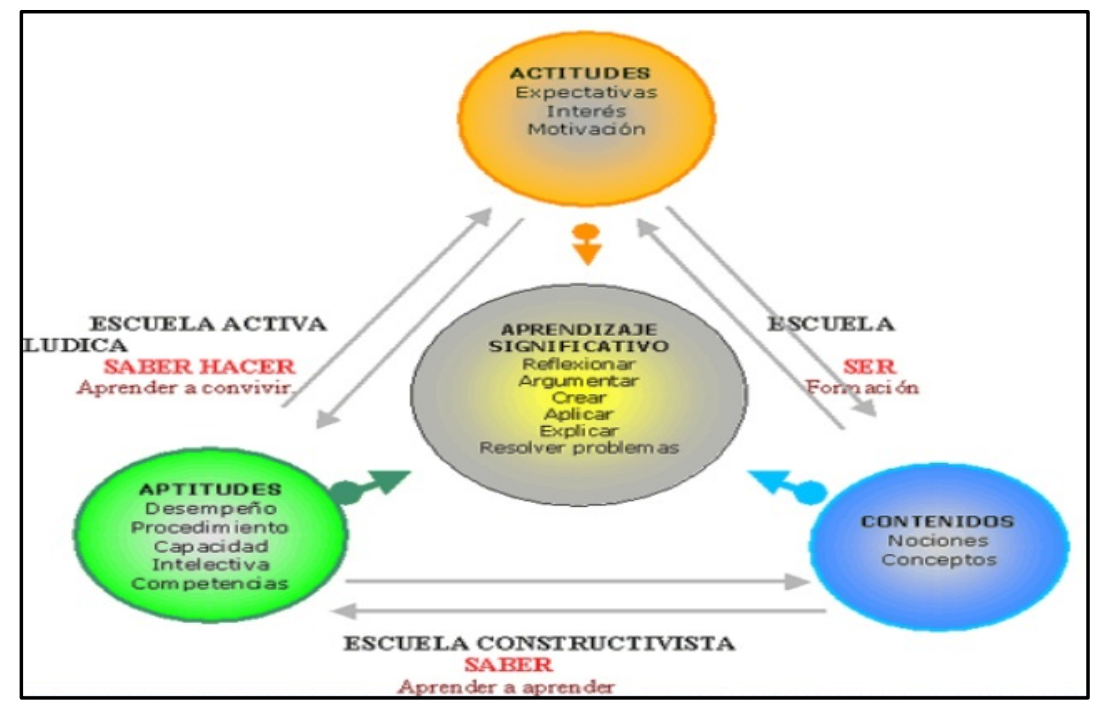

Las experiencias del aprendizaje significativo son identificables con los nuevos conocimientos adaptados a la actividad constructiva y la interacción que desarrolle con los diferentes saberes adquiridos por el estudiante. En este proceso se involucra el aspecto afectivo o la generación del interés que el alumno demuestre por aquellos nuevos conocimientos que se determinen como de mucha importancia para su crecimiento intelectual. 
El modelo de estrategias de enseñanza, según Hernández, et al. (2014). Discurrieron en aportes que ofrecen las capacidades técnicas y operativas de los docentes permiten mejorar las teorías metodológico con disciplinas y con iniciativa innovadoras. Los investigadores (Aquino, Ortiz \& Yanes, 2013) consideraron que los docentes en Ciencias Naturales poseen alto conocimiento y deben articular las teorías con la práctica; de tal manera que logre mayor interés al desarrollo de las prácticas, estas actividades exigen al estudiante ofrecer mayor tiempo y dedicación al desarrollo del curso.

También es necesario referir que los procesos de reforzamiento de la enseñanza-aprendizaje deben guiarse de acuerdo a la metodología del docente de curso, para evitar confundir con diferentes procedimientos al estudiante. Las evaluaciones del aprendizaje deben demostrar acción didáctica y no memorística para lograr mayor razonamiento con la suficiente capacidad de responder a las consultas (Ponce, 2018). Actualmente los maestros buscan métodos innovadores para mejorar la enseñanza y ganar mayor confianza de la audiencia. La 
facilidad de las herramientas tecnológicas ofrece múltiples recursos que se combinan con las prácticas rutinarias.

Las enseñanzas cruzadas, no incluye tecnología, es una experiencia enriquecedora tanto para el estudiante como para el profesorado. Aquí, el aprendizaje ocurre en un entorno informal. El docente puede vincular el contenido educativo con las experiencias que están teniendo los alumnos. Esta enseñanza se mejora y profundiza aún más al agregar preguntas relacionadas con el tema. Luego, los estudiantes pueden agregar a las discusiones en el aula a través de notas de la excursión, proyectos fotográficos y otras asignaciones grupales relacionadas con la excursión.

Enseñar a través de pizarrones inteligentes, son una forma eficaz de dar vida al aula y, al mismo tiempo, apoya al aprendiz a experimentar el nivel máximo de participación y comprensión. Esto se hace haciendo que el contenido del curso sea interactivo y visual. Los pizarrones inteligentes transforman la experiencia de enseñanza en una experiencia interactiva y colaborativa, ya que los profesores utilizan contenido multimedia dinámico para 
ayudar a transmitir el tema de manera más eficaz a los estudiantes y convertirlo en una experiencia visual y atractiva.

Para enseñar a través de salones de clase invertidos, dar la vuelta al aula se está convirtiendo en un método de enseñanza eficaz cada vez más popular. En esta técnica, los estudiantes logran mayor actividad en sus participaciones mejorando el aprendizaje al darle la responsabilidad de aprender, requiere que los docentes releguen al papel de proveedores de recursos y los estudiantes asuman la responsabilidad de recopilar información sobre conceptos. Mediante el uso de diversas herramientas de tecnología, se alienta a todos los escolares a edificar culturas, llenar los vacíos de información y hacer inferencias por sí mismos cuando sea necesario.

"Si otorgar a los estudiantes la responsabilidad de aprender, los maestros de han visto que cuando se le pone a cargo de su propio aprendizaje, se sumergen más en la materia, se interesan más y aprenden mejor". Este método es eficiente para sentar bases del aprendizaje independiente. 
La enseñanza mediante la colaboración, otro método innovador de enseñanza consiste en fomentar la colaboración de los estudiantes en varios proyectos. Hoy vivimos en un mundo globalizado y la colaboración es una habilidad esencial para la vida que es importante para todas las carreras y empresas. Los maestros pueden ayudar a fomentar esta habilidad en el aula al permitir que los estudiantes aprendan, estudien y trabajen en grupos. La asignación de trabajos grupales permite ofrecer colaboración de los participantes y logran compartir la enseñanza siendo aceptada como una poderosa herramienta de enseñanza donde una vez más la responsabilidad está en el grupo de estudiantes y los educadores juegan el papel de guías, mentores, supervisores de los estudiantes. También les enseña a los estudiantes empatía, destrezas, integración en trabajo grupal y resolución de problemas.

La enseñanza con la realidad virtual, implica apoyar a los aprendices a través de interacciones con un mundo 3D. Ejemplo, en lugar de llevar a los estudiantes a través de una clase de historia aburrida, los profesores pueden 
utilizar la tecnología 3D para explorar civilizaciones antiguas, viajar a países distantes para una clase de geografía o incluso hacer un viaje al espacio exterior durante una clase de ciencias. Esta tecnología ofrece una valiosa oportunidad para aprender de manera inmersiva (crea una visión real en un campo virtual). Aquí el aprendizaje es divertido y ayuda a los estudiantes a retener el material durante más tiempo, todos los puntos esenciales al considerar métodos de enseñanza efectivos en el aula.

La enseñanza mediante la tecnología de impresión $3 \mathrm{D}$, este método innovador de enseñanza ha ganado rápidamente aceptación mundial, especialmente en la educación superior donde se utilizan impresoras de última generación que utiliza las impresiones 3D para crear prototipos y hacer que conceptos complejos sean fáciles de entender.

La enseñanza a través de la informática en la nube, es uno de los métodos seguros para guardar recursos vitales del aula, como planes de lecciones, notas, lecciones en audio, videos y detalles de las tareas en la nube del 
aula. Luego, los estudiantes pueden acceder a ella desde la comodidad de sus hogares, cuando sea necesario, devolviendo el aula a los estudiantes con un clic del mouse. También asegura que los estudiantes que han faltado a clases se mantengan actualizados. Este método elimina los libros físicos y permite aprender de acuerdo a la comodidad de cada estudiante.

Método Kolb y el Aprendizaje ERCA (Stavenga et al., 2006). El método de Kolb aplicada a estudiantes convergentes logra utilidad práctica de ideas y teorías. Aquí el estudiante establece su estilo adecuado para lograr solucionar problemas y tomar decisiones adecuadamente. Sin embargo cuando se aplica a estudiantes divergentes logra producir múltiples ideas alternas para solucionar problemas. Pero si se aplica a los estudiantes asimiladores este logran aprender con criterio lógico - práctico orientadas para las carreras científicas. $Y$ para los estudiantes adaptadores logran aprenden basado en la experiencia y de acuerdo a las situaciones técnicas presentadas.

La práctica metodológica Kolb se presenta en cuatro pasos didácticos: 1. La capacidad de experiencia concreta (EC) activa los conocimientos previos de los estudiantes, comparte experiencias vividas, observaciones de mapas cognitivos, fotos, videos; utiliza preguntas como: 
quién, dónde y cuándo. 2. La capacidad de observación reflexiva (OR) relaciona lo que los alumnos saben con el nuevo conocimiento; se presentan un mapa conceptual de partida, se genera hipótesis para provocar desequilibrio cognitivo a través de cuestionamientos, escribir y concluir sobre indagaciones e investigaciones realizadas; se utiliza preguntas como: qué, por qué, que significa. 3. La capacidad de conceptualización abstracta (CA) aquí se negocia ideas, discutir sobre lo que es y no es un concepto; argumentación de ideas; se utiliza preguntas como: qué significa, cuáles son las semejanzas y diferencias. 4. Capacidad de experimentación activa (EA) aplica el conocimiento en una nueva situación y relaciona dinámicamente los fundamentos teóricos para tomar decisiones planteando alterativas de solución para los problemas presentados; utiliza expresiones como: identifique, explique, seleccione, ilustre, dramatice, etc.

El Aprendizaje ERCA, considera la experiencia, reflexión, conceptualización y la aplicación como metodología experiencial activo interpersonal y transpersonal desarrollando nuevas experiencias concretas, favoreciendo las competencias del saber: 
conocer, hacer, ser y convivir en el estudiante. La experiencia actúa de manera concreta reflexionar de manera emotiva. La reflexión, formar las ideas, identificar el proceso de la experimentación durante el ciclo del aprendizaje, sacar conclusiones de los temas tratados. La conceptualización, puntualizar los conceptos de un argumento, Finalmente la aplicación, se ejecuta de acuerdo a los conceptos y conocimientos propuestos (Clark \& White, 2010).

La descripción de las dimensiones y los indicadores de las variables de estudio, relacionado al tema y al problema son las siguientes:

Dimensión Didácticas del aprendizaje: Constituye técnicas y métodos de estudio planificados para desarrollar el proceso de enseñanza-aprendizaje de las Ciencias Naturales es necesario evidenciar sistemas científicos, identificamos el espacio científico y experimentamos los cambios físicos, químicos y biológicos que pueden sufrir por efecto natural o por acción del hombre. Netamente el aprendizaje es llevado a cabo por el alumno; necesariamente esta actividad requiere de tiempo y 
esfuerzo, porque brinda diversos conceptos y habilidades al estudiante (Guerrero \& Flores, 2009). El aprendizaje es complejo, el conocimiento básico ayuda a iniciar. El manejo adecuado de la información ofrece seguridad en el uso. También las habilidades y dificultades van ligadas al funcionamiento neuropsicológico. Sin embargo, aprender requiere asimilar información es un requisito para responder a los problemas y prácticas profesionales. Finalmente se aprende a convivir en los distintos ámbitos vida.

Sus indicadores son: Las teorías educativas, las competencias académicas, habilidades comunicativas, las técnicas y los instrumentos de evaluación. Luego, las teorías educativas de acuerdo a nuestra investigación se clasifican en: Teoría conductista, compuesto por la Trasmisión-recepción. La teoría cognitivista, integra los aprendizajes asistidos por el tutor y por procesos mentales de acuerdo al desarrollo bilógico del estudiante, también plantea solución a los problemas identificados, que se desarrollan de acuerdo a la práctica de hábitos con técnicas de estudios tradicionales. Los encargos intelectuales consienten alcanzar, agrupar y redimir 
información las diligencias mentales que proponen los aprendices puede comprender y mejorar la perspicacia de la expresión, la memoria y el uso adecuado de sus acciones. La teoría constructivista generar aprendizaje y conocimiento construyendo o reconstruyendo nuevas ideas, este aprendizaje no es simple se transmite y se reconstruye nuevas experiencias y finalmente el aprendizaje significativo, representa, conceptos y proposiciones educativas que desarrolla el estudiante con capacidad y destreza.

Las capacidades que se adquieren son conocimiento que permite lograr la interpretación adecuadamente de las competencias académicas que deben desarrollar cuando el estudiante tiene interés por mejorar (Lacerda, 2019). También se conceptualiza como la capacidad para saber, hacer, ser y convivir cumpliendo con los objetivos establecidos. Obtener sapiencias sin tener que memorizar y aplicarlo adecuadamente demuestra la madurez intelectual del aprendiz (Coll, 2007). Los aprendices comparten sus capacidades intelectuales combinando destrezas, actitudes, valores éticos, con seguridad logran ganarse la confianza y el interés de 
muchos. Para Santos-Guevara (2010) las Ciencias Naturales, es un área del conocimiento científico, relacionado al estudio de los fenómenos presentes en todos los aspectos referidos a la vida, el ser, la naturaleza y el cosmos.

Las habilidades comunicativas, es clave en el aula, generalmente se considera que la enseñanza exitosa requiere solo un $50 \%$ de conocimientos y un $50 \%$ de habilidades de comunicación. Todo docente debe ser competente en cuatro formas de comunicación: escuchar, hablar, leer y escribir, y debe saber cómo utilizar esta competencia de manera efectiva en un entorno escolar. Se ha demostrado que ser capaz de hacer esto tiene un impacto en el éxito que los estudiantes logran en sus vidas académicas, así como en el éxito profesional del docente. La oportunidad de comunicación para la enseñanza de Ciencias Naturales nos permite divulgar detalladamente sobre los avances científico encontrados, además el docente aplica estrategias de comunicación adecuada para lograr mayor atención y comprensión durante el desarrollo de clases (Gabriela, 2015). La comunicación en la educación se desarrolla en tres áreas diferentes siendo: 
cuando se comunican con los estudiantes, con los padres y con los colegas.

Comunicarse con los estudiantes: Son más vitales para las interacciones con los estudiantes, porque el acto de enseñar en sí las requiere. En su rol, usted es responsable de comprender y desglosar información compleja, transmitir esta información claramente a sus estudiantes (tanto verbalmente como en recursos escritos), presentar de una manera que mantenga su atención y escuchar y resolver sus preguntas o problemas (Santelices et al., 2013).

También debe adaptar el contenido a los tipos de inteligencias múltiples, motivar a los educandos para que aprendan, construir relaciones de apoyo utilizando el estímulo y la empatía, administrar el aula y dar retroalimentación, haciendo de su aula un entorno de aprendizaje seguro y de apoyo. Todas estas cosas requieren buenas habilidades de comunicación.

Cuanto mejores sean sus habilidades de comunicación, más eficazmente podrá realizar estas tareas. 
A su vez, sus estudiantes progresarán más académicamente. Los estudios han encontrado que el rendimiento de los alumnos está vinculado con entornos de enseñanza interactivos y atractivos formados por profesores capaces (Mashburn et al., 2008). Además, la forma en que se comunica con sus estudiantes puede afectar positivamente sus percepciones de la escuela, su papel en el aula, ellos mismos y sus habilidades, y su motivación para tener éxito (Dobbs-Oates y Arnold, 2009).

Sin embargo, esto funciona en ambos sentidos: las habilidades de comunicación deficientes y, por lo tanto, los métodos de enseñanza deficientes, hacen que la altura de comprensión de los alumnos disminuyan y afecte su progreso académico de manera negativa. También podría llevar a que los estudiantes carezcan de motivación, no les guste la escuela y se sientan incapaces de lograrlo. Esto podría tener consecuencias para el resto de sus vidas.

Por lo tanto, la comunicación asertiva entre profesores y estudiantes es extremadamente importante. Te permite realizar bien tu trabajo, con resultados positivos para tus alumnos. Un beneficio adicional es que su clase 
puede usarlo como modelo para mejorar sus propias habilidades de comunicación, que son críticas para su desarrollo y aprendizaje futuro.

Comunicarse con los padres, es necesario de manera efectiva. Podría llevarse a cabo a través de una variedad de medios, incluidas Ilamadas telefónicas, correos electrónicos y reuniones en persona, por lo que debe ser hábil con el lenguaje verbal y escrito. Esto es particularmente importante porque a menudo tendrá que discutir temas delicados, como problemas de comportamiento, problemas de aprendizaje y las fortalezas y debilidades del estudiante, sin que los padres se sientan confundidos o a la defensiva. Es vital que sea claro, pero con tacto, en todo momento. No comunicarse bien con los padres podría generar dudas de su parte sobre su capacidad para enseñar y posibles quejas, así como una falta de comprensión del desempeño y las necesidades educativas de su hijo.

Comunicarse con colegas, la docencia no siempre implica un trabajo independiente, también requiere colaboración. Ya sea que estén planeando lecciones juntas, actualizando a sus colegas sobre el progreso de 
ciertos estudiantes o compartiendo consejos sobre cómo manejar los problemas en el aula, las buenas habilidades de comunicación le serán de utilidad.

Técnicas e instrumentos de evaluación: según (Caballero \& Recio, 2017), consideró que la evaluación educativa es el proceso que determina los medios utilizados para evaluar los conocimientos, habilidades y destrezas. Un docente puede emplear cualquiera de las herramientas educativas disponibles. Existen diversas herramientas y técnicas de evaluación. Generalmente se clasifican en dos categorías: Técnica cuantitativa y cualitativa.

El examen oral, es una práctica en muchas escuelas y disciplinas, donde un examinador plantea preguntas al estudiante en forma hablada. El alumno debe responder a la pregunta de forma que demuestre un conocimiento suficiente de la materia para aprobar el examen. Muchos programas requieren que los estudiantes terminen el programa tomando un examen oral o una combinación de exámenes orales para mostrar qué tan bien el estudiante ha comprendido el material estudiado en el programa. 
Figura 7. Análisis de las técnicas de evaluación Caballero \& Recio (2017).

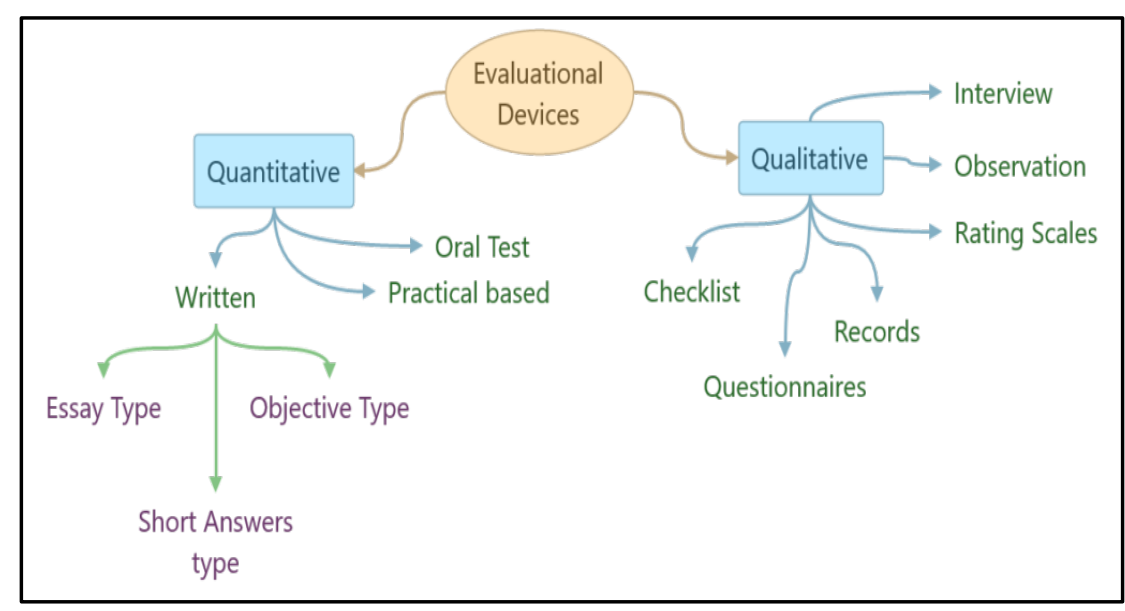

Actualmente los profesores en las unidades educativas usan exámenes orales, solo para medir el conocimiento, pero la capacidad de responder es negativa. Mientras que la evaluación escrita, es la herramienta de evaluación más utilizada. Se llevan a cabo varios tipos de pruebas escritas a lo largo de la sesión académica. Las pruebas escritas se realizan en papel o en un ordenador. En este caso, el alumno que se presente a la prueba escrita deberá proporcionar las respuestas escribiendo en el espacio indicado. Existen formatos de pruebas que los docentes utilizan para medir los conocimientos y verificar el progreso del aprendizaje. 
Como consecuencias, las pruebas se pueden diseñar con un solo tipo de formato de elementos como: pruebas orales (base estructurada y no estructurada), pruebas prácticas (informes), pruebas de tipo ensayo, pruebas de tipo objetivo, pruebas de tipo de respuesta corta, y la prueba de opción múltiple incluye varios tipos formato: cuestionamiento directo, emparejamiento, de relación, de ordenamiento y jerarquía. En la actualidad los sistemas virtuales aplican diversas técnicas como: La observación, Medición, Autoevaluación y la Co-evaluación, todas tienen un registro y las rubricas que configura el proceso de la evaluación.

Figura 8. Caballero \& Recio (2017) técnicas de evaluación

\begin{tabular}{|c|c|c|c|}
\hline \multicolumn{4}{|c|}{ ¿Cómo? (TÉCNICAS) } \\
\hline OBSERVACIÓN & MEDICIÓN & AUTOEVALUACIÓN & COEVALUACIÓN \\
\hline $\begin{array}{c}\text { Instrumentos: } \\
\text { - Registros } \\
\text { - Rúbricas }\end{array}$ & $\begin{array}{c}\text { Instrumentos: } \\
\text { - Registros } \\
\text { - Rúbricas }\end{array}$ & $\begin{array}{l}\text { Instrumentos: } \\
\text { - Rúbricas } \\
\text { - Portfolios }\end{array}$ & $\begin{array}{c}\text { Instrumentos: } \\
\text { - Rúbricas }\end{array}$ \\
\hline \multicolumn{4}{|c|}{ ¿Dónde? (Contextos de aplicación) } \\
\hline $\begin{array}{l}\text { Contextos: } \\
: \quad \text { Cuaderno/Informes } \\
: \quad \text { T. Coop. } \\
\text { Experimentos } \\
\text { : Res.problemas } \\
: \quad \text { Comprensión } \\
: \quad \text { Exposiciones orales } \\
\end{array}$ & $\begin{array}{l}\text { Contextos: } \\
\text { - Prueba oral } \\
\text { - Prueba } \\
\text { escrita } \\
\text { - Test } \\
\end{array}$ & $\begin{array}{l}\text { Contextos: } \\
: \quad \text { Cuaderno/Informes } \\
: \quad \text { T. Coop. } \\
: \quad \text { Experimentos } \\
: \quad \text { Res.problemas } \\
: \quad \text { Comprensión } \\
: \quad \text { Exposiciones orales } \\
\text { (...) }\end{array}$ & $\begin{array}{l}\text { Contextos: } \\
: \quad \text { Cuaderno/Infomes } \\
: \quad \text { T. Cooo. } \\
: \quad \text { Experimentos } \\
: \quad \text { Res.problemas } \\
: \quad \text { Comprensión } \\
: \quad \text { Exposiciones orales } \\
\text { (...) }\end{array}$ \\
\hline
\end{tabular}


"Los objetivos para lograr el aprendizaje, requieren estar inmersos en un eficiente sistema educativo donde se encuentren alineados la enseñanza y la gestión de evaluación al estudiante" (Biggs, 2007, p.29).

Dimensión enfoques tecnológicos educativos: Son procedimientos que utilizan la información a través de los medios electrónicos orientados en el desarrollo educativo. Entre ellos tenemos:

Las Tecnologías de la información y comunicación (TIC), comentada por la UNESCO (2015) fundamentó que, el aprendizaje de los estudiantes depende de las capacidades tecnológicas de los profesores este conocimiento está vinculado en el currículo de estudios. Los colegios utilizan instrumentos tecnológicos TIC para comunicar, crear, difundir, almacenar y gestionar información. 
Figura 9. TIC: La UNESCO (2015)

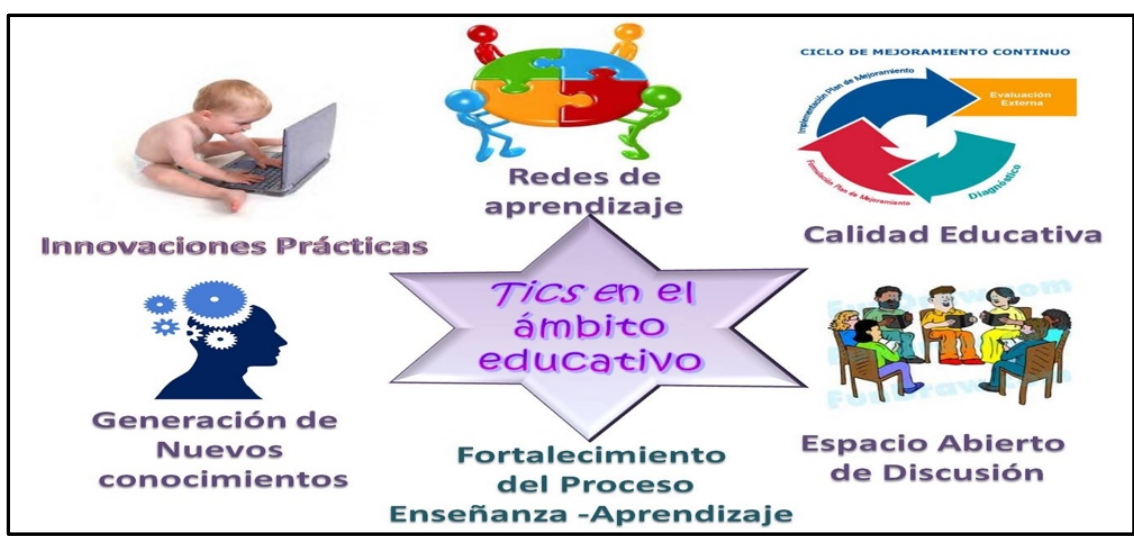

Para Blurton (2000), Las TIC en la actualidad es un recurso adecuado para la interacción en el ciclo del aprendizaje, mediante el uso de los pizarrones electrónicos interactivos, también llamado pizarrones digitales. Es necesario utilizar algunos recursos celulares portátiles que los estudiantes disponen. Durante el periodo de clase los estudiantes logran comprender las materias de estudio, sin embargo, muchos en su hogar hacen replica en las tareas y repasan las clases como se indica en el aula invertida. Cuando los profesores utilizan las TIC, facilita las condiciones para expresar nuestra creatividad y despertar ideas de los estudiantes de tal manera que logren desafiar 
las deficiencias y proponga mejoras constructivas para el bienestar educativo. (Goodwin, 2012) Las cuestiones relacionadas con las $\mathrm{TIC}$ donde los planificadores deben considerar el costo-beneficio, la infraestructura, el suministro de información con el apoyo de las directrices, supervisiones a los docentes, todo aquello que sea beneficioso al uso de la tecnología para el desarrollo educativo.

Las Tecnologías de Aprendizaje y Conocimiento (TAC), Según Parra, et al. (2019) la tecnología es herramienta principal que permite crear nuevas perspectivas en la educación, utilizar TAC permite mejorar las capacidades técnicas del usuario. Las (Unesco, 2013) recomienda el uso de las herramientas tecnológica en la escuela para emprender e innovar nuevos horizontes educativos y productivos para el desarrollo social. Prieto et al. (2016), los avances tecnológicos han permitido llevar las clases presenciales a línea virtual, aquí las competencias de los docentes se demuestran trasmitiendo didácticamente sus conocimientos. (García et al., 2018), el objetivo productivo se enfoca al aprendizaje colectivo, todos participan y buscan desarrollar las tareas compartiendo el 
conocimiento entre participante, la enseñanza virtual adopta ventajas digitales como el material educativo, juegos y aplicativos educativos.

Introducir las TAC de manera práctica, requiere del docente aplique estrategias convencionales para la enseñanza que genere satisfactoriamente la comprensión y entendimiento de los contenidos (Salinas, 2004). Así, cambiar a un escenario tecnológico, obliga al docente reestructurar sus actividades, tareas y competencias. Una de las transformaciones en sus actividades y responsabilidades, es desarrollar el dominio como asesor, facilitador, mediador y dejar a segundo plano el de instructor. De igual manera, al estudiante le implica explorar sobre el buen uso de los instrumentos tecnológicos, demostrando suficiente interés en adquirir destrezas para el aprendizaje a través de esta nueva modalidad educativa.

Las nuevas habilidades a ser desarrolladas para la manipulación y uso de plataformas virtuales en las sesiones de clases tanto por estudiante y profesor, necesitan reflejar el pensamiento crítico para la búsqueda y obtención de 
información, así como, su procesamiento para ser convertida en conocimiento útil para su aplicación bajo este nuevo paradigma educativo.

La tecnología del empoderamiento y la participación (TEP); son aplicaciones que contribuye la participación de los ciudadanos en diversos temas educativos su enfoque con la comunidad educativa es despertar interés interno de los participantes logrando conseguir igualdad del trato dentro de un entorno educativo. (Zambrano \& Balladares, 2017), definieron la TEP como la tecnología participativa donde el término Empoderar, es conceder poder para que, la autogestión, perfeccione sus estilos de vida. Las características que permiten la actividad pedagógica de empoderamiento de los aprendientes son:

Autonomía: Implementar las estrategias de empoderamiento personal, mediante de las herramientas tecnológicas que desarrollen un estilo de independencia y confianza y autoeficacia que asume la responsabilidad de su autoaprendizaje y cuestiona libremente lo que aprende. El uso de las herramientas tecnológicas, se convierten en 
fundamentales elementos para la enseñanza y el aprendizaje con capacidad de dar solución a diversidad de conflictos presentes en el día a día de la convivencia social.

Construcción social del conocimiento: Se direcciona a la elaboración y construcción del conocimiento bajo un entorno social, donde la participación grupal constituye el pilar del desarrollo y crecimiento de los formatos del aprendizaje.

Para Serrano (2010), el aprendizaje significativo, consiste en la adquisición del conocimiento de una manera integral, donde prevalecen dos dimensiones conocida como repetición- aprendizaje significativo y recepcióndescubrimiento fundamentadas en la enseñanza por recepción y repetición. De igual manera, Ausubel, con su teoría de aprendizaje significativo, manifestó que, es el resultado de la interrelación autogestionada por el individuo de aquellos conocimientos previos que posee en su intelecto y los nuevos conocimientos expuestos, generando un cuadro mental o simbología fácil de entender y asimilar en su archivo cognitivo. 
Según O'Connor (2015), Los estudiantes que aportan con ideas creativas e innovadoras para discutir sobre posibles soluciones trabajando de forma colaborativa y grupal, por lo general son aquellos que no toman nota de manera mecánica o metódica. Es una teoría fundamentada en tres dimensiones. La primera dimensión se direcciona al docente. Según (Adame, 2017), en el proceso educativo hay tres elementos: emisor, mensaje y receptor. Se busca optimizar la explicación de contenidos en la cátedra, los procesos complejos, actitudes, destrezas en las estrategias educativas, que generen motivación e interés en la población estudiantil a su cargo con apoyo de la tecnología. Los nuevos parámetros relacionados con las Tics, son en la actualidad el medio referente exigido para desarrollar los procesos educativos pertinentes y vigentes.

El segundo el Conocimiento Pedagógico, (DeConti, 2018), el estudio formativo del docente permite que cuente con las capacidades adecuadas para el desarrollo pedagógico de las clases, además puede analizar y brindar nuevos aportes a la gestión educativa de acuerdo al 
tiempo y la experiencia académica. Es necesario mantener fluida las actualizaciones pedagógicas que permiten ofrecer diversas herramientas educativas ayudando a desarrollar la enseñanza-aprendizaje de manera más atractiva y logrando cumplir los objetivos propuestos de la malla curricular.

El tercero, el rendimiento académico, (Lamas, 2016), enfoca que el producto del aprendizaje se demuestra a través del rendimiento académico, sin embargo, el nivel de impacto inicial llega a un determinado grupo de estudiantes, muchos logran comprender el contenido de las clases después de una evaluación o del repaso (conductista y cognitivista). (Rojas, 2005), la evaluación pedagógica es un conjunto de procedimientos que mide el nivel de aprendizaje, mediante los conocimientos, dando resultados globales sobre el avance escolar. El Nivel de comprensión constituye los principios elementales de los hechos donde el estudiante logra obtener el perfil calificativo de acuerdo a los niveles de esfuerzo. Las operaciones del pensamiento, se construyen con las operaciones del pensamiento, la utilización de estrategias de aprendizajes, optimización de la memoria y 
concentración mediante los hemisferios cerebrales. Otros factores incidentes están centrados en generar un entorno armónico, donde la interacción con los discentes sea proactiva.

Las dimensiones inmersas en el aprendizaje significativo son:

Dimensión de Factores cognoscitivos del aprendizaje: entre los procesos que se definen, la observación, desarrollo, generalización, análisis, percepción, asociación, interpretación, comparación, clasificación, expresión, deducción, retención, evaluación, que permiten dar significado a las vivencias mediante el lenguaje y materiales empleados en la formación educativa. Sus indicadores son:

Nivel de conocimiento de datos: Almacenamiento e información de contenidos en la memoria.

Capacidad de comprensión: Capacidad de expresión y resumen con propio criterio.

Habilidad en la aplicación: Capacidad de comprensión y claridad para detallar casos específicos utilizando conceptos abstractos. 
Capacidad de análisis: Identificación y clasificación los componentes de los contenidos informativos, reconociendo principios para direccionar la organización de los elementos de manera coherente y ordenada.

Capacidad para organizar y relacionar (Síntesis): Conectar los elementos componentes de los contenidos tratados de manera innovadora.

Capacidad para emitir juicios: Capacidad de determinar criterios para la valoración y evaluación del estudiante.

Dimensión Factores afectivos - sociales: Elementos que se relacionan de manera directa con la comunicación, permite generar un motivador estado emocional y actitudes interpersonales amistosas. Los indicadores que miden su eficiencia son:

Capacidad receptiva: se demuestra según la habilidad del docente durante el proceso de enseñanza, si logra transmitir conocimiento de manera práctica que los estudiantes logran comprender 
Capacidad de respuesta: Son acciones que reflejan los estudiantes frente a consultas propuestas. Estas formas permiten demostrar conocimiento de cada estudiante. Es necesario contar con facilidad comunicativa para expresar respuestas coherentes. Capacidad para valorar: El alumno aprecia de forma responsable su esfuerzo y de los demás, su convivencia permite influir mediante la confianza tomar acto de apreció de cada miembro. Esta valorización se expresa mediante la aceptación o el rechazo.

Capacidad para organizar: Comprende establecer una escala de valores como la justicia, la innovación y la solidaridad con fines de evaluación de los diferentes aspectos y actitudes de su vida. 


\section{METODOLOGÍA}

Tipo y diseño de investigación

(Hernández et al, 2014), considera que la investigación desarrollada fue de tipo "Cuantitativo y descriptivo", por evaluar el estado de cada variable según los indicadores identificados, y describir sus condiciones sin producir cambios en la variable (p. 95).

Nieto, (2018), consideró que, "la investigación básica, se sustenta en la exploración, la curiosidad por el encuentro de nuevos conocimientos para adquirir sabiduría" (p. 1). El autor, hace referencia a la pasión que investigadores y filósofos tienen por adquirir sabiduría a través del conocimiento, curiosidad por la ciencia, la observación por los fenómenos naturales, y constante actividad del pensamiento. Se considera además como el cimiento para el desarrollo de la investigación tecnológica o aplicada.

Con el fin de obtener información primaria, se desarrolló una investigación descriptiva y propositiva, con modalidad virtual y de corte transversal, que permita 
recopilar datos válidos y confiables mediante la aplicación del cuestionario, en el centro educativo donde se realiza la investigación, cuyo resultado será tabulado estadísticamente para determinar mediante análisis un diagnóstico de la situación. Previamente se desarrollará una prueba piloto y cuyo cuestionario o ítems deben ser validados mediante el sistema Alfa de Cronbach para su correcta aplicación.

El diseño de investigación según (Hernández, et al., 2014), es "Descriptivo y propositivo". Se analizó el contenidos de las variables identificadas, los resultados permitieron establecer la solución del problema identificado (p. 174). El gráfico del diseño de la investigación es la siguiente: 
Figura 10. Diseño de investigación según (Hernández, et al., 2014)

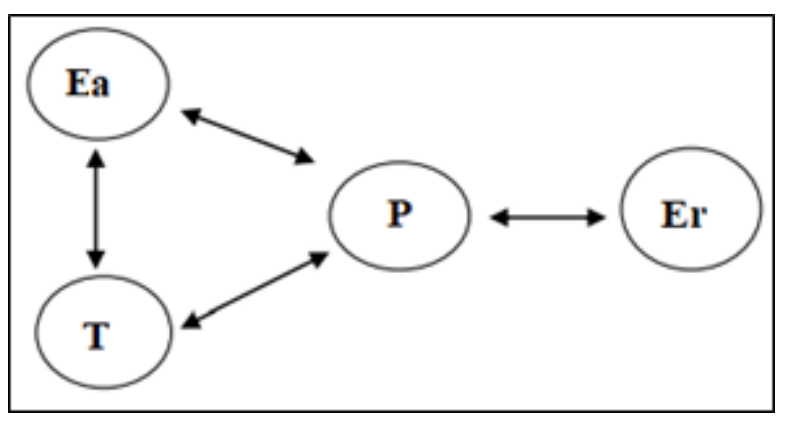

Donde:

$$
\begin{aligned}
& \mathrm{Ea}=\text { Escenario educativo actual } \\
& \mathrm{T}=\text { Bases teóricas } \\
& \mathrm{P} \quad=\text { Propuesta con fundamento teórico } \\
& \mathrm{Er} \quad=\text { Escenario educativo reformado }
\end{aligned}
$$

\section{Estrategias de enseñanza}

\section{Definición conceptual.}

Las estrategias de enseñanza, "son procedimientos o recursos (organizadores del conocimiento) utilizados por el docente, a fin de promover aprendizajes significativos". (Mendoza \& Mamani, 2012, p.59). Las estrategías estan representadas por un cunjunto de métodos, técnicas, procedimientos didacticos y demás acciones pegagógicos 
organizados de manera secuencial y lógica que aplican los profesores.

\section{Definición Operacional}

Para medir la variable independiente del modelo innovador de estrategias de enseñanza, se utilizó según (Tamayo et al, 2015) refirió que: "El instrumento del análisis de documental es la Ficha de Análisis que sirva para anotar información alcanzada, la cual nos ayudará a conocer los detalles del problema y es fuente principal para dar la solución adecuada" (p. 251).

\section{Aprendizaje Significativo}

\section{Definición Conceptual}

Aprendizaje significativo es, cuando la nueva información que se adquiere, puede relacionarse de modo sustantivo y no arbitrario con el conocimiento previamente asimilado por el individuo. Se construyen significados cuando hay capacidad de establecer relación sustantiva entre lo aprendido con lo que ya se sabe. (Iglesias \& Sánchez, 2007) 


\section{Definición Operacional}

Para conocer las dimensiones del aprendizaje significativo en los estudiantes, se utilizó la técnica de la encuesta con su instrumento del cuestionario; según (Hernández, Fernández, \& Baptista, 2014) considera que: El instrumento de la encuesta, es el cuestionario, con preguntas integrada al tema de investigación con la finalidad de encontrar respuesta al problema.

Para (Reguant \& Martinez, 2014) La operacionalización de variables, es un proceso lógico que consiste en la separación de los elementos teóricos (abstractos), para llegar a una realidad (concretos), los cuales pueden ser observables y valorables, que conforman los indicadores. Se requiere establecer los conceptos, determinando las dimensiones e indicadores, así como, sus índices para la medición de la incidencia entre las variables a través de los instrumentos de las técnicas como encuestas.

Entre las dimensiones relacionadas a las estrategias de enseñanza se consideró: La dimensión didáctica del aprendizaje con sus indicadores, teorías educativas, 
competencias académicas, habilidades comunicativas, técnicas e instrumentos de evaluación. El enfoque tecnológico, con sus indicadores, aplicaciones de las TIC, aplicaciones de la TAC y aplicaciones de la TEP. En relación al aprendizaje significativo, se cuenta con las dimensiones: Factores cognoscitivos, sus indicadores, nivel de conocimientos de datos, capacidad de comprensión, habilidad en la aplicación, capacidad de análisis, capacidad de organizar y relacionar, capacidad de emitir juicio. La dimensión Factores Sociales y sus indicadores, capacidad receptiva, capacidad de respuesta, capacidad de valorar, capacidad de organizar. 


\section{Tabla 3}

Matriz de operacionalización de variables

\begin{tabular}{|c|c|c|c|c|c|}
\hline Variable & Definición Conceptual & Definición Operacional & Dimensiones & Indicadores & ĺtems \\
\hline \multirow{7}{*}{ 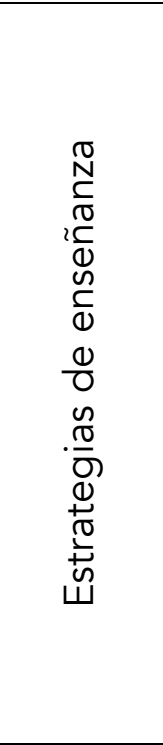 } & \multirow{7}{*}{$\begin{array}{l}\text { Las estrategias de } \\
\text { enseñanza, son } \\
\text { procedimientos o } \\
\text { recursos (organizadores } \\
\text { del conocimiento) } \\
\text { utilizados por el } \\
\text { docente, a fin de } \\
\text { promover aprendizajes } \\
\text { significativos } \\
\text { (Mendoza \& Mamani, } \\
\text { 2012) }\end{array}$} & \multirow{7}{*}{$\begin{array}{l}\text { Para medir la variable } \\
\text { independiente del } \\
\text { modelo innovador de } \\
\text { estrategias de } \\
\text { enseñanza, se utilizara } \\
\text { según (Tamayo, Zona, \& } \\
\text { Loaiza, 2015) refirió } \\
\text { que: El instrumento del } \\
\text { análisis documental es } \\
\text { la ficha de análisis que } \\
\text { sirva para anotar } \\
\text { información alcanzada, } \\
\text { la cual nos ayudará a }\end{array}$} & \multirow{4}{*}{$\begin{array}{l}\text { Didácticas del } \\
\text { Aprendizaje }\end{array}$} & Teorías educativas & \\
\hline & & & & $\begin{array}{l}\text { Competencias } \\
\text { Académicas }\end{array}$ & \\
\hline & & & & $\begin{array}{l}\text { Habilidades } \\
\text { Comunicativas }\end{array}$ & \\
\hline & & & & $\begin{array}{l}\text { Técnicas e instrumentos } \\
\text { de evaluación }\end{array}$ & \\
\hline & & & \multirow[b]{3}{*}{$\begin{array}{l}\text { Enfoques } \\
\text { tecnológicos }\end{array}$} & Aplicaciones de las TIC & \\
\hline & & & & Aplicaciones de las TAC & \\
\hline & & & & Aplicaciones de los TEP & \\
\hline
\end{tabular}




\begin{tabular}{|c|c|c|c|c|c|}
\hline & & $\begin{array}{l}\text { conocer los detalles del } \\
\text { problema y es fuente } \\
\text { principal para dar la } \\
\text { solución adecuada" (p. } \\
\text { 251). }\end{array}$ & & & \\
\hline \multirow{9}{*}{ 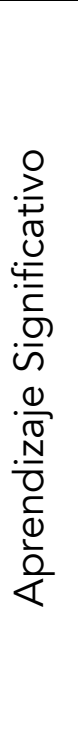 } & \multirow{9}{*}{$\begin{array}{l}\text { Aprendizaje significativo } \\
\text { es, cuando la nueva } \\
\text { información que se } \\
\text { adquiere, puede } \\
\text { relacionarse de modo } \\
\text { sustantivo y no arbitrario } \\
\text { con el conocimiento } \\
\text { previamente asimilado } \\
\text { por el individuo. Se } \\
\text { construyen significados } \\
\text { cuando hay capacidad } \\
\text { de establecer relación } \\
\text { sustantiva entre lo }\end{array}$} & \multirow{9}{*}{$\begin{array}{l}\text { Será aplicado un } \\
\text { cuestionario con escala } \\
\text { de Likert como } \\
\text { instrumento de } \\
\text { investigación para } \\
\text { recolectar información } \\
\text { pertinente sobre las } \\
\text { dimensiones del } \\
\text { aprendizaje significativo } \\
\text { actualmente generado } \\
\text { en el estudiante. El } \\
\text { aprendizaje es } \\
\text { representacional, }\end{array}$} & \multirow{6}{*}{$\begin{array}{l}\text { Factores } \\
\text { Cognoscitivos }\end{array}$} & $\begin{array}{l}\text { Nivel de conocimiento de } \\
\text { datos }\end{array}$ & 1 \\
\hline & & & & $\begin{array}{l}\text { Capacidad de } \\
\text { comprensión }\end{array}$ & 2 \\
\hline & & & & Habilidad en la aplicación & 3 \\
\hline & & & & Capacidad de análisis & 4 \\
\hline & & & & $\begin{array}{l}\text { Capacidad para organizar } \\
\text { y relacionar }\end{array}$ & 5 \\
\hline & & & & $\begin{array}{l}\text { Capacidad para emitir } \\
\text { juicio }\end{array}$ & 6 \\
\hline & & & \multirow{3}{*}{$\begin{array}{l}\text { Factores } \\
\text { Afectivos - } \\
\text { Sociales }\end{array}$} & Capacidad receptiva & 7 \\
\hline & & & & Capacidad de respuesta & 8 \\
\hline & & & & Capacidad para valorar & 9 \\
\hline
\end{tabular}




\begin{tabular}{|l|l|l|l|l|}
\hline $\begin{array}{l}\text { aprendido con lo que ya } \\
\text { se sabe. (Iglesias \& } \\
\text { Sánchez, 2007) }\end{array}$ & $\begin{array}{l}\text { cuando se le otorga un } \\
\text { significado a los } \\
\text { símbolos. (Bresneider \& } \\
\text { Soto, 2016). }\end{array}$ & Capacidad para organizar & 10 \\
\hline
\end{tabular}


La delimitación del estudio comprende la Unidad Educativa Patria Ecuatoriana, código AMIE 09H00289, ubicado en la calle cuarenta entre Camilo Destrugue y Portete de la parroquia Febres Cordero en la ciudad de Guayaquil, su régimen escolar es Costa, con jornadas de estudio matutino y vespertino, niveles de Educación Básica Superior y Bachillerato General Unificado, con tipo de educación Regular.

Población: Cuenta con una población de la EGB de 304 estudiantes y 87 docentes. La población seleccionada para la investigación comprende 8 paralelos de décimo grado, constituidos por 38 estudiantes de cada paralelo y seis docentes del área de Ciencias Naturales. Según Álvarez (2017), "Población estadística comprende una agrupación bien definida de elementos accesibles para una investigación a partir de la selección de una muestra" ( $p$. 221).

Muestra: Para calcular la muestra poblacional, fue utilizada la fórmula aplicada para población finita en la población estudiantil, resultando un total de 170 estudiantes a quienes se aplicó un cuestionario de preguntas. 


$$
n=N * k^{2 *} P * Q /\left(E^{2 *}(N-1)\right)+K^{2 * P * Q}
$$

Donde, el significado de la siguiente simbología es:

$$
\begin{array}{ll}
\mathbf{N}=\text { tamaño de la Población } & =304 \text { estudiantes } \\
\mathrm{n}=\text { Muestra a calcular }(\mathrm{x}) \text { estudiantes } & =(0,05) \\
\mathrm{E}=\text { error admisible } 5 \% & =(1,96) \\
\mathrm{K}=\text { constante estadística } & =0,5 \\
\mathrm{P}=\text { Nivel de éxito } 95 \% & =0,5 \\
\mathbf{q}=\text { Nivel de fracaso al } 5 \% & =\frac{0.9604}{1.96 \wedge 2^{*}\left(0.5^{*} 0.5\right)}=170 \\
\mathrm{n}=\frac{0.05 \wedge 2\left(1.96 \wedge 2^{*}\left(0.5^{*} 0.5\right)\right) / 304}{0.0057}
\end{array}
$$

La muestra poblacional según el cálculo es de 170 alumnos.

Muestreo: Probabilístico aleatorio simple.

\section{Técnicas e instrumentos de recolección de}

\section{datos}

Para la recolección de datos se utilizó como técnicas e instrumentos de investigación: El análisis documental será aplicada por el responsable de la investigación siendo el instrumento la ficha de análisis que nos permitirá identificar los tipos de estrategias de enseñanza 
implementado en las Ciencias Naturales en los centros educativos.

\section{FICHA DE ANÁLISIS DOCUMENTAL}

Datos de la Aplicación

Responsable: Mag. Milton Doroteo Cayambe Guachilema

Análisis: Unidad Educativa Patria-Ecuatoriana, 2020

De acuerdo al análisis documentario de las publicaciones encontradas determinaran las estrategias: Conductista (Cd), Cognitivas (Cg), Constructivismo (Co), Aprendizaje significativo (As) que se desarrollan en la educación básica, siendo las estrategias a relacionar:

\section{Estrategias de enseñanza \\ Didácticas del Aprendizaje}

1. Teorías educativas

- Cd1: Condicionamiento clásico

- Cd2: Conexionismo

- Cd3: Principio de contigüidad

- Cd4: Condicionamiento operante

- Cd5: Observación e imitación

- Cg1: Creatividad

- Cg2: Lluvia - ideas

- Co1: Participa activamente en clases

- Co2: Propone y defiende ideas

- As1: Reflexiona, argumenta, crea

- As2: Aplica, explica y resuelve problemas

2. Competencias Académicas 
3. Habilidades Comunicativas

4. Técnicas e instrumentos de educación

Enfoques tecnológicos (Aplicaciones de las TIC, TAC Y TEP

Es INDISPENSABLE consultar a una base de datos de revistas indexada y filtrar diversas publicaciones considerando desde el año 2016 - 2021, se aplica la relación de estrategias educativas por grupos y se graficar de acuerdo al nivel de ocurrencias.

El fundamento teórico se considera que la Encuesta se denomina a la técnica de recopilación de datos para la investigación social (Maxwell, 2019). La palabra proviene del francés enquête, que significa investigación.

La otra técnica que se utilizó fue la encuesta, direccionada a los estudiantes del décimo grado de Educación General Básica de la Unidad Educativa Patria Ecuatoriana. Mediante el cuestionario de preguntas para conocer las dimensiones del aprendizaje significativo como variable dependiente que determina la problemática de la investigación. Esta será medida mediante la aplicación de la escala Likert el mismo que estará representada por un valor 
siendo: Totalmente desacuerdo $=1$; Desacuerdo $=$ $2 ;$ Indiferente $=3 ;$ De acuerdo $=4$ y Totalmente de acuerdo $=5$, la sumatoria de respuestas en cada encuesta será considerada como puntaje (desde 7 hasta 35 puntos) el mismo que se evaluará el nivel de rango de la dimensión cognoscitiva determinándose que siendo "Deficiente" el puntaje que oscila entre: 07 a 14, mientras que se denomina "Medio o incertidumbre" al puntaje que oscila entre 15 a 21 y se considera que la dimensión cognoscitiva es "Alto" cuando el puntaje esta entre 22 a 35. Para la dimensión afectivo - social el nivel de rango de acuerdo al puntaje es: 03 a 06 "Deficiente", 07 a 10 "Medio o incertidumbre" y 11 a 13 "Alto".

\section{Procedimientos}

Luego de establecer el formato y elaboración del cuestionario, se validó mediante juicio de experto luego se aplicó vía internet siendo la dirección electrónica: https://forms.office.com/Pages/ResponsePage.aspx?id=D 
QSIkWdsW0yxEjajBLZtrQAAAAAAAAAAAAZAANBxIxdU RFhXSEFHWVVNOURDWUNKRzhMUUIFMDlyUS4u.

La prueba piloto de la encuesta con la participación de 170 estudiantes, cuyo resultado fue sometida a la prueba Alfa Cronbach. Luego, se compartió los datos en el sistema SPSS. Además, se desarrolló una matriz de validación de las variables que fueron certificadas por los especialistas. El instrumento fue aplicado, previo a la autorización de las autoridades del plantel a través de Microsoft Forms, donde los datos e información obtenida reflejaran un determinado diagnóstico de la situación en el escenario investigado.

\section{Método de análisis de datos}

Es necesario analizar los indicadores de la variable independiente, estrategias de enseñanza, por el cual se consultó en la base de datos de publicaciones en revistas indexadas, mediante el software Review Manager v. 5.3. Se realizó la búsqueda y se aplicó filtros de periodo de tiempo para reducir el nivel de números de publicaciones a revisar. Es necesario relacionar las estrategias educativas con los 
indicadores de la variable para determinar el estudio según las dimensiones propuestas: Didácticas del Aprendizaje: Teorías educativas, Competencias Académicas, Habilidades Comunicativas, Técnicas e instrumentos de evaluación. La dimensión Enfoques .tecnológicos, Aplicaciones de las TIC, TAC. Y TEP.

La estructura de la encuesta y la propuesta fue validada mediante juicio de expertos por un jurado de 5 miembros que son:

Tabla 4 Lista de jueces que validaron el instrumento de investigación

\begin{tabular}{ll}
\hline \multicolumn{1}{c}{ Juez } & \multicolumn{1}{c}{ Grado } \\
\hline Juan José Jacinto Chunga & $\begin{array}{l}\text { Doctor en Ciencias de la } \\
\text { Educación }\end{array}$ \\
$\begin{array}{l}\text { Abner Milán Barzola } \\
\text { Cárdenas }\end{array}$ & $\begin{array}{l}\text { Doctor en Gestión } \\
\text { Lilliam Enriqueta Hidalgo }\end{array}$ \\
Benites & Doctor en Ciencias de la \\
Juan Lázaro Andrade Yucra & $\begin{array}{l}\text { Educación } \\
\text { Educación }\end{array}$ \\
Manuel José Alayo Méndez Ciencias de la & $\begin{array}{l}\text { Doctor en Ciencias de la } \\
\text { Educación }\end{array}$ \\
\hline
\end{tabular}


Los datos de la encuesta permiten calcular la confiabilidad mediante el programa estadístico informático muy usado en las ciencias sociales y aplicadas (SPSS), con otros resultados de estadística descriptiva. El coeficiente del Alfa de Cronbach por dimensiones y general (variable) y el análisis factorial exploratorio, los resultados estableció la fiabilidad del instrumento, con el fin de conocer la integridad interna de la información. También el programa Excel permitió la tabulación de los datos, el diseño de las tablas y gráficos.

Fiabilidad y validez: Se relaciona con la "posibilidad de poder reproducir el resultado, indica el grado en que un procedimiento concreto de traducción de un concepto en variable, produce los mismos resultados en pruebas repetidas con el mismo instrumento de investigación o con instrumentos equivalentes". (Corbetta, 2007, p.99). La validez hace referencia al grado en que un determinado procedimiento de traducción de un concepto en variable registra efectivamente el concepto en cuestión. Está vinculada al error sistemático presente en cada una de las observaciones. La escala de fiabilidad de los instrumentos 
coeficiente de alfa de Cronbach son interpretados de la siguiente manera:

Tabla 5 Rangos de evaluación del coeficiente alfa de Cronbach

\begin{tabular}{rc}
\hline \multicolumn{1}{c}{ Rango } & Confiabilidad \\
\hline$<=0.53$ & Nula \\
$>0.54 \circ<=0.59$ & Baja \\
$>0.60 \circ<=0.65$ & Confiable \\
$>0.66 \circ<=0.71$ & Muy confiable \\
$>0.71$ a 0.99 & Excelente confiabilidad \\
1 & Confiabilidad perfecta \\
\hline
\end{tabular}

Para el cálculo manual, según el formato Excel se identificaron los siguientes indicadores:

$\mathrm{K}=$ Numero de ítems del cuestionario $\mathrm{S} 1=$ Sumatoria de las varianzas de los ítems $\mathrm{S} 2=$ Varianza de la suma total del instrumento $A=$ Coeficiente de confiabilidad del cuestionario $\left(\mathrm{k} /(\mathrm{k}-1)^{\star}(1-\mathrm{S} 1 / \mathrm{S} 2)\right.$ 
Tabla 6 Indicadores para el cálculo del coeficiente de Alfa de Cronbach

\begin{tabular}{cccc}
\hline Indicador & Dimensión & Dimensión & Variable \\
& $\mathbf{1}$ & $\mathbf{2}$ & \\
\hline $\mathrm{K}$ & $\mathbf{6}$ & 4 & 10 \\
$\mathrm{~S} 1$ & 19.06 & 6.24 & 25.31 \\
$\mathrm{~S} 2$ & 65.42 & 12.80 & 77.81 \\
$\mathrm{~A}$ & 0.83 & 0.74 & 0.75 \\
\hline
\end{tabular}

Reporte de validez y fiabilidad: El instrumento: Mide "El aprendizaje significativo", integrado por dos dimensiones (10 ítems): Dimensión 1 "Factores Cognoscitivos" (6 ítems), Dimensión "Factores Afectivos Sociales" (4 ítems) en la escala tipo Likert de 1 a 5 puntos, con el valor de fiabilidad "Excelente confiabilidad" siendo el coeficiente del Alfa de Cronbach $=0,75$ (Darren \& Mallery, 2018), los indicadores adecuados para el análisis factorial exploratorio mediante el Método de componentes principales y rotación varimax $(\mathrm{KMO}=0.770$, Prueba de esfericidad de Bartlett $=658,170$, Varianza total explicada $=70,35 \%$, Comunalidades: $0.619-0.774$, Cargas factoriales: $0.77-0.97$ ). 
La regresión lineal concluye al cálculo del R2 de Cox y Snell asegura que el grado de mejora sobre el ajuste del modelo final se logra con el cálculo logarítmico de la razón de probabilística de cambiar el modelo nulo. El valor máximo es menor a 1 , se considera como varianza de pronóstico. Sin embargo para McFadden los resultados del R2, reflejan variabilidad expuesta a la mejoras también Uhler y Cragg, indicaron que la probabilidad de mayor aceptación se presenta con R2 por lo tanto su aplicación determina al coeficiente casuística variada para mejorar resultados (Agresti, 2007; Tjur, 2009). Finalmente el R2 próximo al 1, demuestra tener mayor credibilidad probabilística a la mejora.

\section{Aspectos éticos}

El avance de la investigación se realizó considerando y cumpliendo delineamientos de la Unidad Educativa Patria Ecuatoriana de la ciudad de GuayaquilEcuador, 2020, para lo cual se obtuvo el consentimiento previo del rector, así como, de los docentes y representantes de los alumnos del décimo grado. Razón por lo cual, la encuesta y su instrumento, fue elaborado con 
el modo de escala de Likert, así, cada uno de los estudiantes encuestados aceptaron aportar con información clara y confiable. Luego, se pidió autorización a los personeros del plantel para lograr un espacio en las sesiones educativas virtuales del plantel. De igual manera, se respetó el carácter de anónimo y la confidencialidad en la aplicación de los instrumentos y en el manejo de la información recogida; con referencia a los derechos de autor y la veracidad de los datos. Los estudiantes contaron con el respaldo de sus representantes legales. 


\section{RESULTADOS}

Para identificar los tipos de estrategias de enseñanza implementado en las Ciencias Naturales mediante el análisis documental de acuerdo a los enfoques teóricos citados fueron agrupados en dos dimensiones de acuerdo a la siguiente clasificación:

Didácticas del Aprendizaje

1. Teorías educativas: Estrategias

- Conductista: Condicionamiento clásico

- Conductista: Conexionismo

- Conductista: Principio de contigüidad

- Conductista: Condicionamiento operante

- Conductista: Observación e imitación

- Cognitivas: Creatividad

- Cognitivas: Lluvia - ideas

- Constructivismo: Participa activamente en clases

- Constructivismo: Propone y defiende ideas

- Aprendizaje significativo: Reflexiona, argumenta, crea 
- Aprendizaje significativo: Aplica, explica y resuelve problemas

2. Competencias Académicas: Saber, hacer, ser y convivir

3. Habilidades Comunicativas: Leer, escribir, hablar y escuchar

4. Técnicas e instrumentos de evaluación: Pruebas escritas y orales, ensayos, informes, exposiciones, pruebas de opción múltiple.

\section{Enfoques tecnológicos}

1. Aplicaciones de las Tecnología de la Información y la Comunicación (TIC)

2. Aplicaciones de las Tecnologías del Aprendizaje y del Conocimiento (TAC)

3. Aplicaciones de los Tecnologías para el Empoderamiento y la Participación (TEP) 
Figura 11 Diagrama de flujo de revisión de artículos publicados

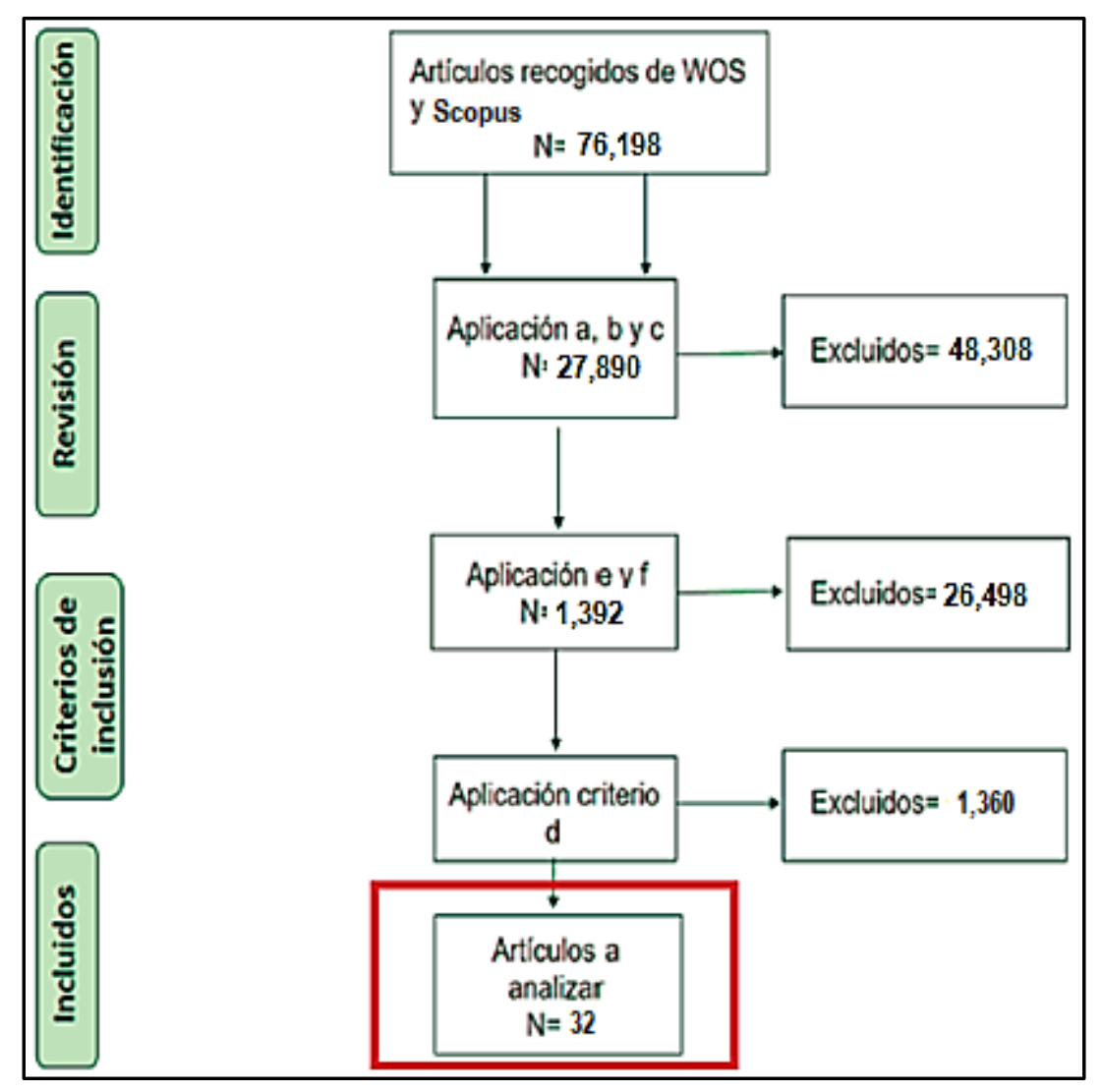

De acuerdo a la consulta de la base de datos SCOPUS se presentaron 76,198 publicaciones de artículos indexados el primer filtro se consideró el periodo 2016 hasta el 2021, logrando excluir 48, 308 artículos, el segundo filtro consideró sólo al idioma inglés se excluyó 26,498 , finalmente se hizo la relación con la estrategia 
educativa identificada y se excluyeron 1, 360 quedando 32 artículos en revisión.

El logro más importante de la educación fue divergir ideas que ofrecen cambios en las personas (Hodson, 2009). Se creía que los humanos eran parte de un universo que incluía la Tierra. Los científicos del Renacimiento rechazaron la idea de que había un propósito oculto detrás de todo. Una manzana no cayó al suelo por su propio propósito, cayó al suelo debido a la gravedad. El juicio científico tecnológico actual se basa en explicaciones confirmadas por experimentos (Taber, 2017). El objetivo de la ciencia es responder preguntas sobre nuestro mundo creando la mejor explicación posible que esté de acuerdo con los resultados experimentales. Para hacer accesibles los hallazgos a otros, los científicos informan todos los resultados experimentales y los procedimientos utilizados para obtener esos resultados. De esta forma, otros científicos pueden rehacer experimentos para ver si obtienen los mismos resultados. La naturaleza de la tecnología en la educación. Los últimos 30 años han sido un período que ha tenido un gran impacto en cómo la tecnología toma un lugar radical en la vida humana. Es 
bastante razonable decir que las tecnologías informáticas e Internet son necesarias para las personas. Los nuevos métodos basados en tecnologías de Inteligencia Artificial generan la creación de nuevas ideas en el horizonte y proponen soluciones alternativas a numerosos problemas diferentes. La tecnología implica la comprensión de qué es la tecnología, cómo y por qué se desarrolla la tecnología, cómo los individuos y la sociedad dirige, reaccionan y, a veces, cambian involuntariamente por la tecnología. Es importante enseñar ciencia y tecnología para (Taber, 2017): Mejorar la necesidad de futuros científicos, ingenieros, tecnólogos y otros que necesitarán una sólida formación científica y tecnológica para su trabajo futuro y fundamentar la importancia del aspecto cultural moderno.

Además es básico comprender cómo la tecnología interactúa con la ciencia es importante para que los estudiantes tomen decisiones personales y sociales informadas. Sin embargo, los contextos de educación STEM (ciencia, tecnología, ingeniería y matemáticas) a menudo aprenden sobre cómo la tecnología puede ser útil para que la usemos. Sin embargo, una educación tecnológica sólida exige que los esfuerzos de educación 
científica enseñen a los estudiantes sobre la naturaleza de la tecnología (Aydeniz \& Cakmakci, 2017). Principios clave en el área de la naturaleza de la tecnología es mediante: El desarrollo tecnológico implica pensamiento creativo. La tecnología está limitada por leyes de la naturaleza, como la gravedad. Los científicos se preocupan por lo que existe en la naturaleza; Los ingenieros modifican los materiales naturales para satisfacer las necesidades y deseos humanos. Las tecnologías desarrolladas para un propósito a veces se adaptan para servir a otros propósitos. El ritmo del cambio tecnológico ha ido en aumento. La educación STEM y otras disciplinas se apoyan mutuamente. Las herramientas ayudan a las personas a hacer las cosas de manera eficiente, precisa y segura. Tecnología y su relación con la naturaleza.

Tabla 7. Coincidencias publicadas según los componentes de relación

\begin{tabular}{|c|c|c|c|c|c|c|c|c|c|c|}
\hline \multirow[t]{2}{*}{ Componentes } & \multicolumn{7}{|c|}{ Didácticas estratégicas } & \multicolumn{3}{|c|}{$\begin{array}{c}\text { Enfoques } \\
\text { tecnológicos }\end{array}$} \\
\hline & 1 & 2 & 3 & 4 & 5 & 6 & 7 & 8 & 9 & 10 \\
\hline Conductista & 0 & 0 & 0 & 60 & 34 & 21 & 12 & 0 & 0 & 0 \\
\hline Cognitivas & 10 & 0 & 0 & 11 & 51 & 11 & 15 & 0 & 0 & 0 \\
\hline
\end{tabular}




\begin{tabular}{lcccccccccc}
\hline Constructivismo & 48 & 17 & 0 & 65 & 39 & 14 & 39 & 0 & 0 & 0 \\
\hline Aprendizaje significativo & 60 & 11 & 65 & 0 & 18 & 18 & 10 & 0 & 0 & 0 \\
\hline Competencias Académicas & 0 & 0 & 0 & 0 & 0 & 24 & 42 & 21 & 16 & 30 \\
\hline Habilidades Comunicativas & 0 & 0 & 0 & 0 & 24 & 0 & 11 & 19 & 21 & 26 \\
\hline $\begin{array}{l}\text { Técnicas e instrumentos de } \\
\text { educación }\end{array}$ & 0 & 0 & 0 & 0 & 42 & 11 & 0 & 26 & 18 & 18 \\
\hline $\begin{array}{l}\text { Tecnología de la Información y la } \\
\text { Comunicación }\end{array}$ & 0 & 0 & 0 & 0 & 0 & 0 & 0 & 0 & 10 & 9 \\
\hline $\begin{array}{l}\text { Tecnologías del Aprendizaje y } \\
\text { del Conocimiento }\end{array}$ & 0 & 0 & 0 & 0 & 0 & 0 & 0 & 10 & 0 & 16 \\
\hline $\begin{array}{l}\text { Tecnologías para el } \\
\begin{array}{l}\text { Empoderamiento y la } \\
\text { Participación }\end{array}\end{array}$ & 0 & 0 & 0 & 0 & 0 & 0 & 0 & 9 & 16 & 0 \\
\hline \multicolumn{1}{c}{$\begin{array}{c}\text { Total } \\
\begin{array}{c}\text { Total acumulado por } \\
\text { dimensiones }\end{array}\end{array}$} & 118 & 28 & 65 & 136 & 142 & 64 & 76 & 66 & 81 & 74 \\
\hline$\quad$ Opciones: & & & 629 & & & & 221 & \\
\hline
\end{tabular}

Opciones: Conductista (1); Cognitivas (2); Constructivismo (3); Aprendizaje significativo (4); Competencias Académicas (5) Habilidades Comunicativas (6); Técnicas e instrumentos de educación (7); Tecnología de la Información y la Comunicación (8); Tecnologías del Aprendizaje y del Conocimiento (9); Tecnologías para el Empoderamiento y la Participación (10) 
Figura 12 Relaciones de artículos filtrados

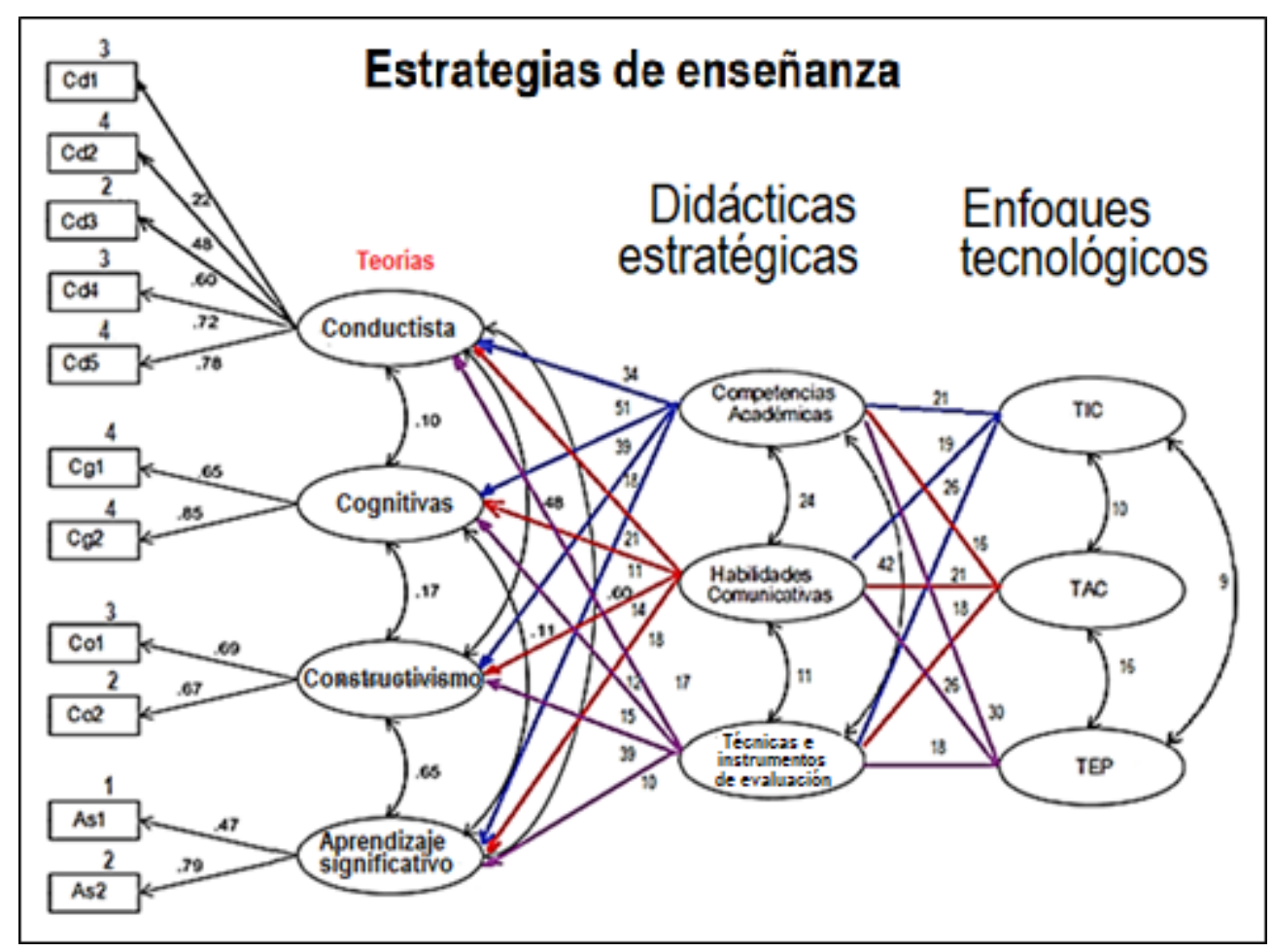

La identificación de artículos en la base de datos permitió filtrar 850 artículos indexados para el estudio de la variable didácticas del aprendizaje. Se logró filtrar 629 artículos por diferentes teorías educativas en general, las habilidades comunicativas y las técnicas e instrumento aplicados en la educación perteneciente a la dimensión que trata las didácticas estratégicas. También 221 
artículos fueron filtrados para los enfoques tecnológicos siendo sus componentes TIC, TAC, TEP. Las teorías educativas aplicadas en las Ciencias Naturales se implementan en la educación a través del método científico apoyado con los materiales bibliográficos. Esto generalmente se hace mediante la introducción paso a paso que aparentemente debe seguirse para realizar estudios científicos, de acuerdo con el plan de estudios de ciencias (Taber, 2017). Un riesgo concebible en este enfoque no es solo que el aprendizaje del método científico sea una mala construcción para los estudiantes, sino que también es bastante limitante dentro de su alcance. Por lo general, los científicos no analizan el método cronológicamente.

Tabla 8. Nivel de coincidencias publicadas según las estrategias educativas

\section{Teoría}

Estrategias educativas

Conductista Cognitivas Constructivismo significativo

Condicionamiento

clásico 3

Conexionismo 
Principio de

contigüidad

Condicionamiento

operante

Observación e imitación

Creatividad

Lluvia - ideas

Participa

activamente en

clases

Propone y

defiende ideas

Reflexiona,

argumenta, crea

Aplica, explica y

resuelve

problemas

\begin{tabular}{lllll}
\hline Total & 16 & 8 & 5 & 3 \\
\hline
\end{tabular}

Estrategias educativas en las Ciencias Naturales se desarrollan mediante actividades académicas cuyo contenido se orienta de acuerdo a la disponibilidad curricular y del material bibliográfico disponible, este condicionamiento clásico se presenta por la falta de conciencia técnica del docente y del interés institucional. Los estudiantes se familiarizan con el lenguaje simple, imágenes que reflejan la relación del estudio dando lugar al principio de contigüidad. En popular las prácticas del 
condicionamiento operante en cada estudiante, la mejor formar planteada por el docente es lograr cumplir objetivos en cada sesión académica. Los modelos de comportamientos educativos, utilizan las estrategias mediante el lenguaje científico que deben practicar los estudiantes es necesario que los procesos de enseñanza de las Ciencias Naturales consideran que observación e imitación, facilita operar por impulso del estudiante, cuando este sienta el deseo de aprender, de lo contrario tardaría más tiempo en lograr comprender las clases posteriores. Se debe participa activamente durante el desarrollo de clases para enfatizar la creatividad, la lluvia de ideas planteando múltiples contextos para que los estudiantes puedan desarrollar aportes a la ciencia con aplicabilidad de nuevas ideas para mejorar los procesos educativos. Las actividades académicas sujetas a los estudiantes permiten que apliquen y desarrollen procesos científicos autónomos ellos mismos. El funcionamiento de la ciencia en estos tiempos se enfoca desde afuera hacia adentro enfatiza el proceso de la ciencia permitiendo que los estudiantes tracen su propio camino usando herramienta interactiva de la tecnología. También es necesario incorporar relatos populares de descubrimientos 
científicos que enfatizan la naturaleza y el proceso de la ciencia. Los mitos conceptuales tratan sobre los procesos de la ciencia ficticios, además permite que los estudiantes descubran el contenido adecuado conjuntamente con los docentes quienes proporcionan información que comprometen el desarrollo de tareas educativas logrando cumplir con los objetivos del aprendizaje, esto facilita al estudiante reflexiona, argumenta, crea, aplica, explica y resuelve problemas. Muchas pruebas científicas no toman la forma de experimentos ya que se comprueba el estudio teórico. Cuando discuta la evidencia obtenida a través de estos otros tipos de pruebas científicas, asegúrese de hacer esto explícito. El uso de laboratorios y actividades que salen mal, resta importancia a la investigación o generación de ideas para promover nuevos estudios. Es necesario que los estudiantes presenten evidencia e interpretación entre sí y lleguen a un consenso sobre resultados educativos. También son necesario las reflexiones personales sobre su aprendizaje y sobre cómo se construye el conocimiento dando lugar al conexionismo físico entre estudiantes con la tecnología digital. En conclusiones la aplicación de las estrategias educativas no tienen parámetros de medición ni retroalimentación, sólo 
se aplican existiendo incertidumbre en los resultados, solo se identifica que los estudiantes poseen habilidades metódicas que se aceptan o rechazan algunas estrategias, sin embargo son pocos los que tiene acción creativa, lluvia de ideas con su defensa, participa activamente en clases para resolver problemas.

Para identificar el comportamiento de los indicadores de las dimensiones del aprendizaje significativo es necesario que los estudiantes respondan a las preguntas del instrumento el mismo que permitirá medir y concluir el estado Cognoscitivos, Afectivos y Social: Entre los factores cognoscitivos se presentan los niveles de conocimiento de datos, la capacidad de comprensión, habilidad en la aplicación técnica de lo aprendido, la capacidad de análisis para organizar, relacionar y emitir juicios. También los factores afectivos que se ofrecen en lo social demostrando la capacidad receptiva con el aprendizaje, también para dar respuesta, valorar y organizar el futuro de su vida. 
Tabla 9. Evaluación de los factores cognoscitivos

\begin{tabular}{|c|c|c|c|c|c|c|}
\hline $\begin{array}{l}\text { Alternativa de selección } \\
\text { Indicador }\end{array}$ & $\begin{array}{l}\text { Muy bajo } \\
\text { (1) }\end{array}$ & $\begin{array}{l}\text { Bajo } \\
(2)\end{array}$ & $\begin{array}{l}\text { Media } \\
\text { (3) }\end{array}$ & $\begin{array}{l}\text { Alto } \\
(4)\end{array}$ & $\begin{array}{l}\text { Muy alto } \\
\text { (5) }\end{array}$ & $\begin{array}{c}\text { Desv. } \\
\text { Estándar } \\
(6)\end{array}$ \\
\hline $\begin{array}{l}\text { Nivel de conocimiento de } \\
\text { datos }\end{array}$ & 57 & 19 & 4 & 1 & 19 & 22 \\
\hline $\begin{array}{l}\text { Capacidad de } \\
\text { comprensión }\end{array}$ & 58 & 17 & 4 & 1 & 20 & 23 \\
\hline Habilidad en la aplicación & 55 & 20 & 6 & 0 & 19 & 21 \\
\hline Capacidad de análisis & 45 & 15 & 9 & 1 & 30 & 18 \\
\hline $\begin{array}{l}\text { Capacidad para organizar } \\
\text { y relacional }\end{array}$ & 42 & 23 & 5 & 2 & 28 & 17 \\
\hline $\begin{array}{l}\text { Capacidad para emitir } \\
\text { juicios }\end{array}$ & 48 & 16 & 7 & 0 & 29 & 19 \\
\hline Promedio porcentual & 51 & 17 & 6 & 1 & 25 & 20 \\
\hline $\begin{array}{l}\text { \% Condición } \\
\text { cognoscitivos }\end{array}$ & Deficient & (68) & $\begin{array}{l}\text { Media } \\
\text { (6) }\end{array}$ & & nte (26) & No aplica \\
\hline
\end{tabular}


Se encuestaron a 170 estudiantes cuya elección aplica la escala de Likert de 5 opciones del cual se lograron los siguientes resultados. Todos los indicadores demostraron el nivel de rango como alta preferencia por la opción muy bajo siendo el promedio porcentual del 51\%, $17 \%$ en baja condición, $6 \%$ en media, $1 \%$ en alto y $25 \%$ en Muy alto.

Figura 13. Área de cobertura según las condiciones cognoscitivas

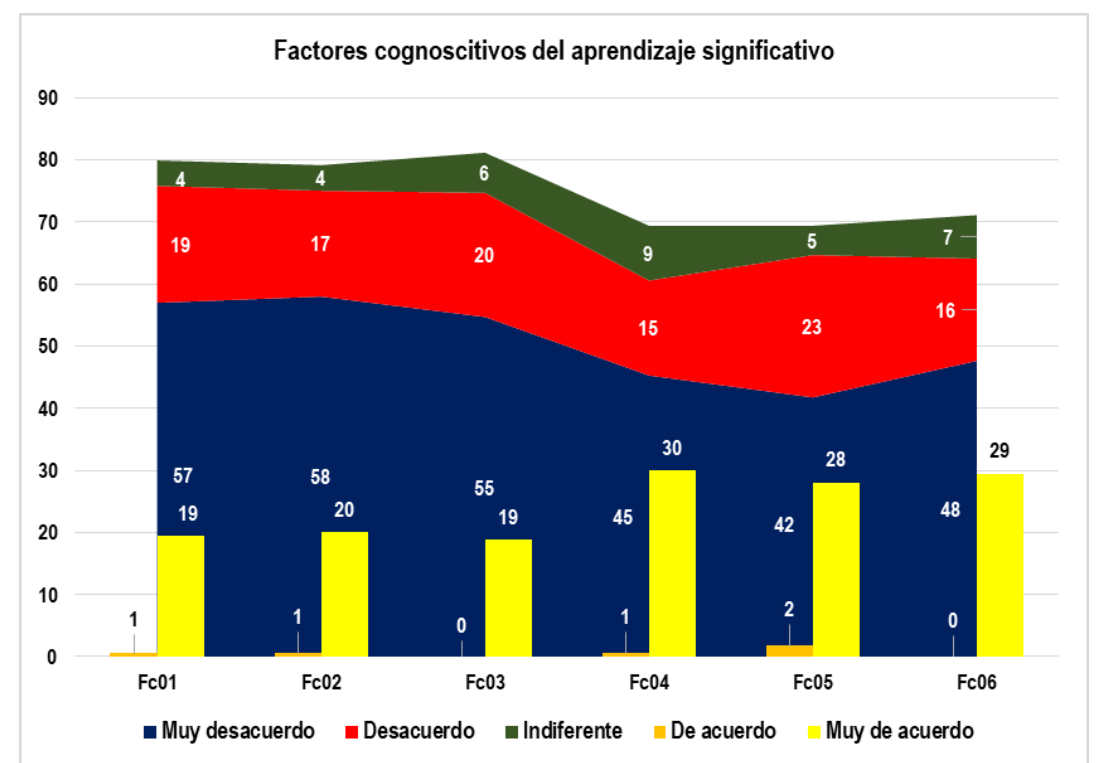

La representación gráfica de las áreas de cobertura de las condiciones cognoscitivas presenta que el $68 \%$ de 
los encuestados tienen el nivel de rango esperado como alto porcentaje en las condiciones cognoscitivas deficientes en el aprendizaje significativo, mientras que el $26 \%$ es eficiente con la incertidumbre (baja) del $6 \%$, esto significa el bajo potencial cognoscitivo del estudiante.

Figura 14. Regresión lineal de los factores cognoscitivos

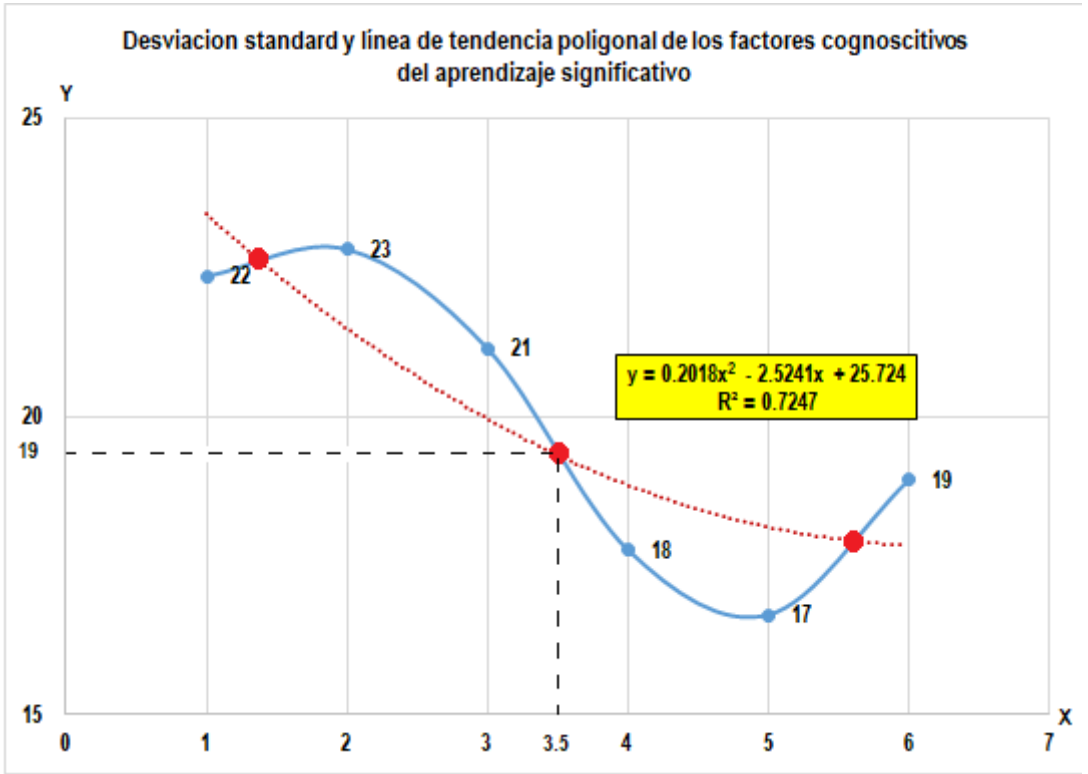

Según los resultados de la desviación estándar la escala de la distribución está dentro del margen mínimo $(5 x, 17 y)$ para margen máximo $(2 x, 23 y)$ esto representa el equilibrio ajustado entre la línea de tendencia polinómica cuya intersección central se ubica entre el 3.5 x, 19 y. Esto 
demuestra equilibrio entre ambos ejes con alta probabilidades de mejoras con aceptación del $R^{2}=0.7247$ para los factores cognoscitivos del aprendizaje significativo.

Tabla 10. Evaluación de los factores Afectivos - Social

\begin{tabular}{lcccccc}
\hline $\begin{array}{c}\text { Alternativa de } \\
\text { selección }\end{array}$ & $\begin{array}{c}\text { Muy } \\
\text { bajo (1) }\end{array}$ & $\begin{array}{c}\text { Bajo } \\
\text { (2) }\end{array}$ & $\begin{array}{c}\text { Media } \\
\text { (3) }\end{array}$ & $\begin{array}{c}\text { Alto } \\
\text { (4) }\end{array}$ & $\begin{array}{c}\text { Muy alto } \\
\text { (5) }\end{array}$ & $\begin{array}{c}\text { Desv. } \\
\text { Estándar } \\
\text { (6) }\end{array}$ \\
\hline $\begin{array}{l}\text { Capacidad } \\
\text { receptiva }\end{array}$ & 55 & 12 & 5 & 0 & 28 & 22 \\
$\begin{array}{l}\text { Capacidad de } \\
\text { respuesta }\end{array}$ & 61 & 17 & 4 & 2 & 16 & 24 \\
$\begin{array}{l}\text { Capacidad } \\
\text { para valorar }\end{array}$ & 61 & 17 & 5 & 1 & 16 & 24 \\
$\begin{array}{l}\text { Capacidad } \\
\text { para organizar }\end{array}$ & 65 & 18 & 2 & 4 & 11 & 26 \\
\hline $\begin{array}{l}\text { Promedio } \\
\text { porcentual }\end{array}$ & 60 & 16 & 4 & 2 & 18 & 24 \\
\hline $\begin{array}{l}\text { \% Condición } \\
\text { cognoscitivos }\end{array}$ & Deficiente (76) & $\begin{array}{c}\text { Media } \\
(4)\end{array}$ & Eficiente (20) & No aplica \\
\hline
\end{tabular}

Se encuestaron a 170 estudiantes cuyas opciones de elección se basan a la escala de Likert (Muy en desacuerdo: 1; Desacuerdo: 2; Indiferente: 3; De acuerdo: 4; Muy de acuerdo: 5); dando valores cualitativos de (Muy bajo: 1; Bajo: 2; Mediano: 3; Alto: 4; Muy alto: 5) del cual se lograron los siguientes resultados. Todos los indicadores 
demostraron alta preferencia por la opción muy bajo siendo el promedio porcentual fue $60 \%, 16 \%$ en baja condición, $4 \%$ en media, $2 \%$ en alto y $18 \%$ en Muy alto. Se concluye que el $76 \%$ de los encuestados tienen alto porcentaje del nivel de rango deficientes de los factores afectivos - sociales en el aprendizaje significativo, mientras que el $20 \%$ es eficiente con la incertidumbre del $4 \%$, son completamente inferiores que el primero esto significa el bajo potencial afectivo - social del estudiante.

Figura 15. Área de cobertura según las condiciones afectivas - sociales

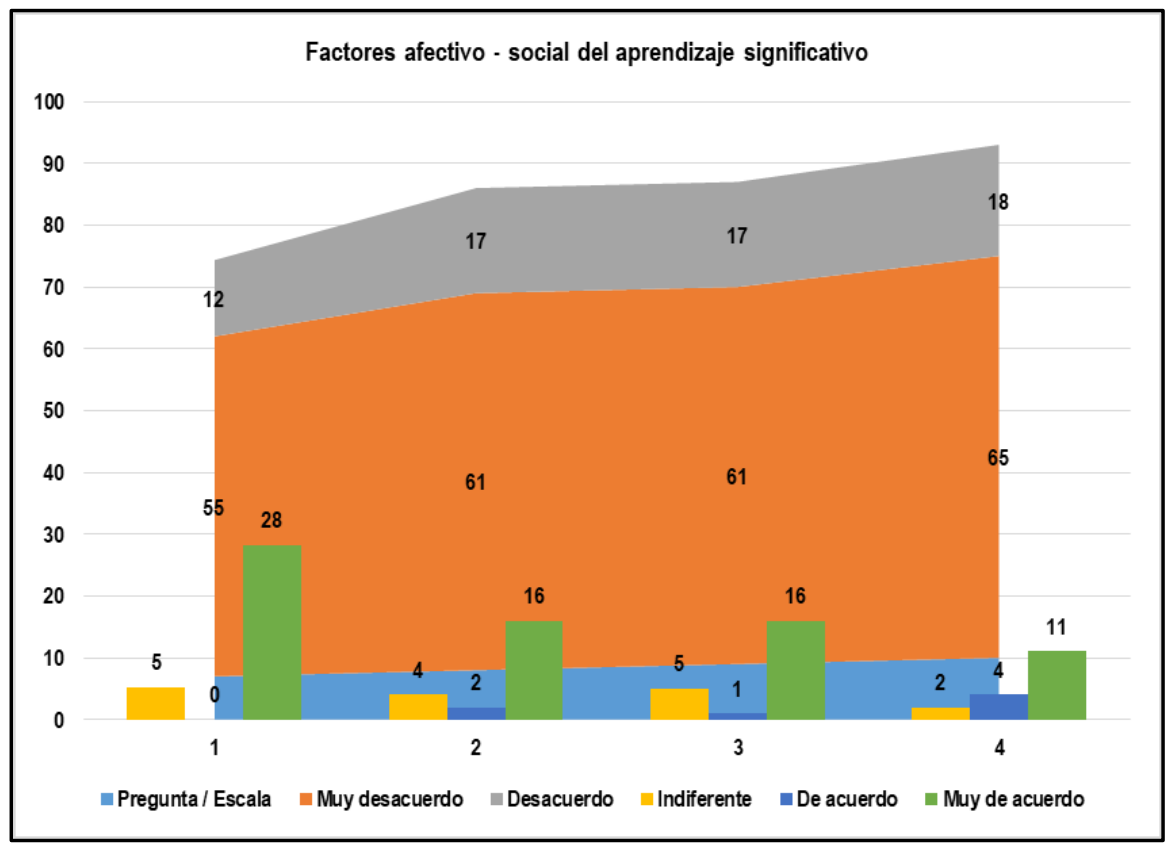


La representación gráfica de las áreas de cobertura de las condiciones afectivas - sociales presenta que el $76 \%$ de los encuestados tienen alto porcentaje en las condiciones cognoscitivos deficientes del aprendizaje significativo, mientras que el $20 \%$ es eficiente con la incertidumbre del $4 \%$, esto significa el bajo potencial afectivo - social del estudiante.

Figura 16. Regresión lineal de los factores afectivos sociales

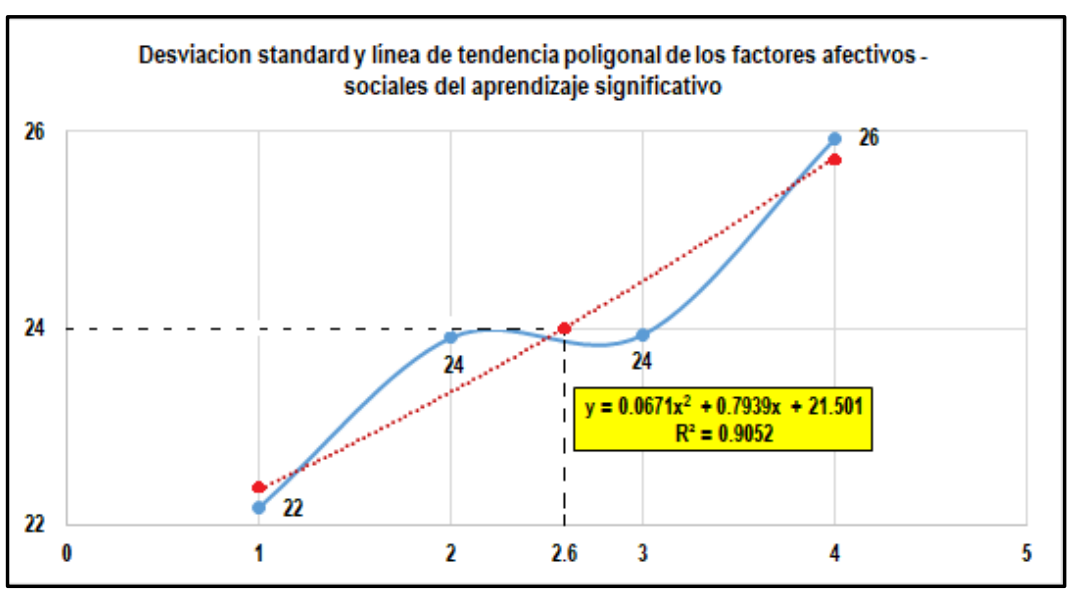

Según los resultados de la desviación estándar la escala de la distribución está dentro del margen mínimo (1 $x, 22$ y) para margen máximo (4x, 26y) esto representa el equilibrio ajustado entre la línea de tendencia polinómica 
cuya intersección central se ubica entre el $2.6 x$ x 24 y. Esto demuestra equilibrio entre ambos ejes con alta probabilidades de mejoras con aceptación del $\mathrm{R}^{2}=0.9052$ para los factores afectivos - sociales del aprendizaje significativo.

El diseño del modelo de estrategias de enseñanza para fortalecer el aprendizaje significativo de ciencias naturales de la Unidad Educativa Patria Ecuatoriana, 2020, se fundamentó en la teoría del aprendizaje de David Ausubel que explica cómo se construye el aprendizaje significativo y los momentos del proceso del aprendizaje en el aula; el método de Kolb para indicar el ciclo del aprendizaje; la teoría cognitivista - constructivista de Jean Piaget relacionado con las estrategias de enseñanza, preinstruccionales, coinstruccionales, posinstruccionales y de producción; por ultimo las herramientas tecnológicas como medios de información, comunicación, participación, producción, difusión del trabajo autónomo y colaborativo de los estudiantes. 
Figura 17. Modelo de estrategias de enseñanza para fortalecer el aprendizaje significativo en Ciencias

Naturales de la Unidad Educativa Patria-Ecuatoriana, 2020

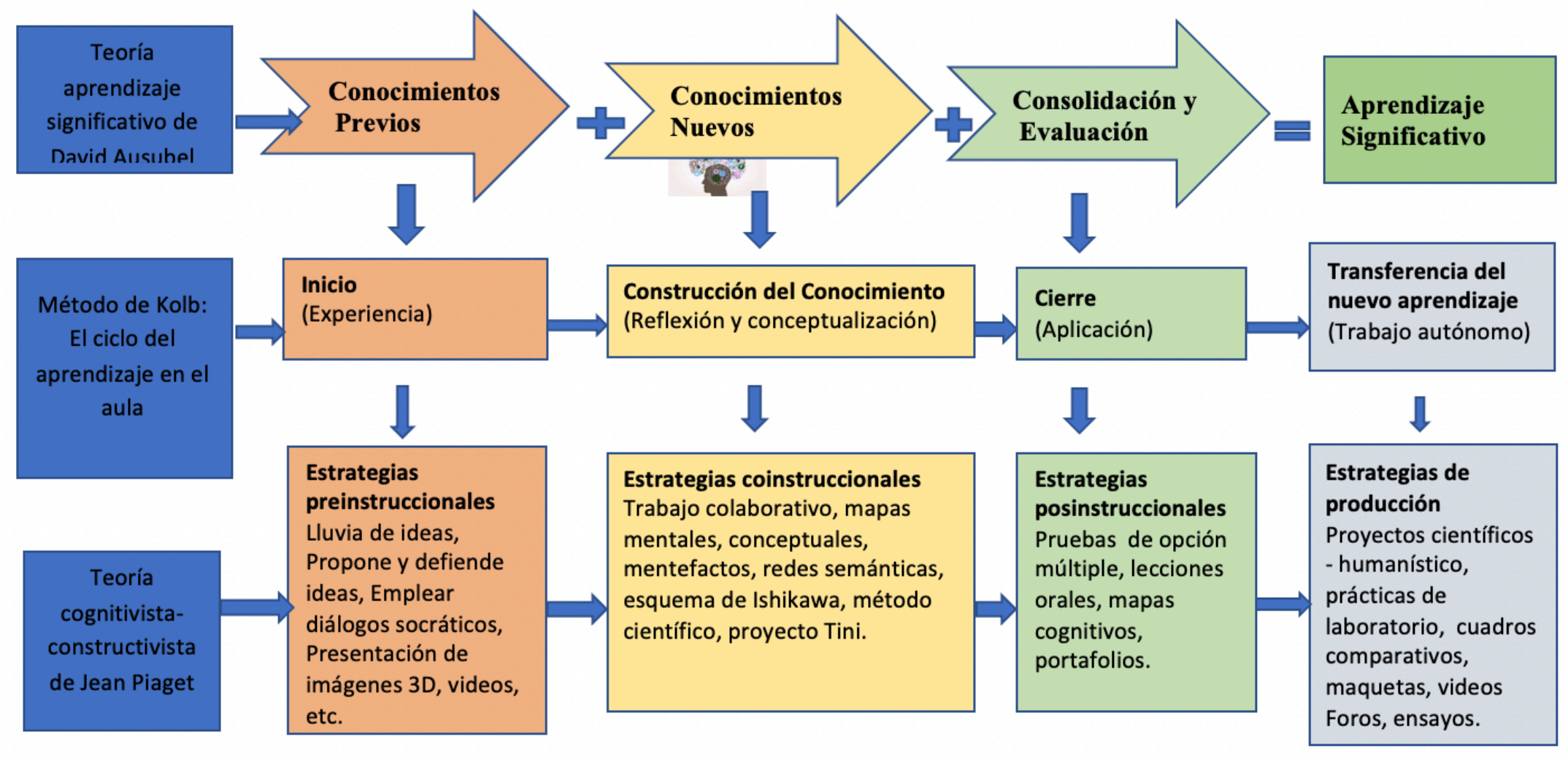

Enfoques

tecnológicas

TIC - TAC - TEP - Construir, publicar y difundir 
La validación de la propuesta fue desarrollada mediante juicios de expertos integrado por profesionales con el grado de doctor en educación. El juicio de expertos es conocido como el método de validación útil para verificar la viabilidad de la investigación se define como "una opinión informada de personas con trayectoria en el tema, que son reconocidas por otros como expertos cualificados en éste, y que pueden dar información, evidencia, juicios y valoraciones" (Escobar-Pérez \& CuervoMartínez, 2008, p.29). Tras someter la propuesta a juicio de expertos se reúne criterios de evaluación que solo el juez determina el calificativo que corresponde (Robles \& Rojas, 2015).

El registro de los expertos se presenta a continuación: 
Tabla 11 Expertos que validaron la propuesta de investigación

\begin{tabular}{llll}
\hline \multicolumn{1}{c}{ Juez } & \multicolumn{1}{c}{ Doctor } & Universidad & Experiencia \\
\hline Juan Jacinto & Ciencias de la & Nacional de & 27 \\
Chunga & Educación & Piura & \\
\hline Abner Barzola & Gestión & Nacional de & 35 \\
Cárdenas & Universitaria & Jaén & \\
\hline Lilliam & Ciencias de la & Nacional de & 41 \\
Hidalgo & Educación & Piura & \\
Benites & & & \\
\hline Juan Andrade & Ciencias de la & San Martin & 21 \\
Yucra & Educación & de Porres & \\
\hline Manuel Alayo & Ciencias de la & Sto. Toribio & \\
Méndez & Educación & de & 29 \\
\hline
\end{tabular}


La educación en España, García, et al., (2019) demuestra que el aprendizaje independiente o colectivo tiene mayor probabilidades de cumplir metas además buscan integrar la comprensión de los participantes para lograr su expresión creativa. Sin embargo Simón, et al., (2018). Considera que los docente son guía iniciales quienes identifican a los estudiantes que tiene capacidades adecuadas para innovar y mejorar los métodos educativos apoyándose de múltiples herramientas educativas y la de mayor impulso en estos tiempos son los programas tecnológicos en nuestro caso se evidencia que los estudiantes carecen de confianza y capacidad para expresar la necesidad de ayuda con orientaciones para superar obstáculo que limitan el buen desarrollo educativo, el docente aplica estrategias de motivación logrando aprendizajes de las Ciencias Naturales con responsabilidad, sin embargo se deja de lado la aplicación del conocimiento ofrecido. Resultados parecidos se presenta en el estudio desadorado por los autores Sánchez, et al., (2014), quienes expresaron que los estudiantes necesitan establecer vínculos de confianza con todos los autores para lograr captar las enseñanzas ofrecidas. 
La educación básica en Nicaragua, (Tregón, 2017), resaltó sobre las deficiencias técnicas metodológicas del docente que busca crear alternativas pedagógica para implementar el aprendizaje significativo de manera independiente ya que el sistema educativo solo se enfoca a evaluar el rendimiento educativo sin tener en cuenta el sistema metodológica que se haya aplicado. Sin embargo, el sistema educativo de Turquía demuestra ser diferente (Bolat, 2016; Muir, 2017), ellos realizan seguimiento a la metodología de aprendizaje que utiliza el docente por iniciativa apoyan a mejorarla dando oportunidad a la innovación y creatividad de esta manera los estudiantes logran aplicar el aprendizaje significativo con lluvias de ideas y trabajos creativos propios de su iniciativa. Modelo ejemplar que ayuda a relacionar compromisos entre los actores que promueven la educación estado, docente y familia. Situación contraria a la realidad de nuestra donde solo se interesa desarrollar los enfoques educativos mediante la programación curricular y los docentes exclusivamente desarrollan sus clases de acuerdo al tema programado, si desea incluir algunos materiales adicionales para mejorar su buen entendimiento, el docente invierte sus propios recursos de los cuales el 
sistema educativo público está lejos de apoyarlo. Por eso apreciamos que la tecnología digital ha crecido enormemente, (Say \& Yıldırım 2020), el nivel de innovación ha permitido nuevos aprendizajes con enfoques enseñanza autodidácticas revolucionado el emprendimiento mundial. Turquía, es uno de los países que aplica aula invertida, dando ejemplo y mayor impacto educativo, el éxito educativo asegura el bienestar y el futuro del estudiante, la influencia en desarrollar conciencia responsable del estudiante es el primer factor del éxito.

Los resultados de aplicación de la metodología de aulas invertidas desarrollada en la Universidad de Mersin, (Hayırsever \& Orhan, 2018) demuestra que los estudiantes logran resolver problemas teniendo como base los enfoques analíticos de los casos y con habilidad plantean alternativas de solución. Situación poco parecida a la investigación presentada por Project y Flipped (2015), donde los estudiantes de 12 años, maestros, administradores, progenitores y personal de la comunidad participaron en el desarrollo de problemas, los cuales cada grupo buscaron el modelo educativo más adecuado para dar solución al enfoque del problema, sin embargo la 
mayor propuesta fue dada por estudiantes cuyo nivel de análisis fue razonable y crítico, sólo se enfoca a la solución de problema, la participación de los padres fue significativa, sin embargo los maestros comprendieron con facilidad y lograron orientar a los estudiantes al planteamiento de alternativas adecuadas. En nuestro caso los estudiantes tienen mayor aceptación al uso de las herramientas tecnológicas de los cuales están bastante familiarizados y desarrollan aplicaciones de fácil manejo, es importante fortalecer esta competencias académicas mediante el método de aula invertida con la aplicación de las herramientas tecnológicas, donde el nivel educativo ofrecido sea un reflejo repetitivo en el aprendizaje dentro del hogar para ello es necesario preparara al entorno para ofrecer los recursos necesarios que pueda fortalecer el conocimiento recibido de tal manera que su nivel creativo impacte al desarrollo educativo del niño y de la sociedad.

En Perú, según Salas (2019), evaluó las habilidades educativas - aprendizaje que aplican los profesores para mejorar la calidad de educación, se logró determinar que sólo el $63 \%$ de los estudiantes logró aprobar el curso mientras que el $37 \%$ no logran comprenderla 
desaprobando la asignatura. Es preocupante la situación que busca el docente mejorar la metodología educativa. Sin embargo Medina, (2018), demostró resultados más alentadores con la aplicación de múltiples metodologías del aprendizaje dada por iniciativa del docente el $73 \%$ de los estudiante logran tener buenas calificaciones. Nuestra propuesta busca recuperar las deficiencias académicas desde el punto de vista metodológico para lograr mayor eficiencia educativa en el aprendizaje. La implementación del aprendizaje significativo para la ciencias naturales nos ayuda comprender la interrelación de la vida humana con relación a la naturaleza y el medio que nos rodea, se busca una metodología accesible a la comprensión y al buen desarrollo cognitivo, afectivo y social del estudiante. En México, Martínez-Olvera (2015). Implementaron el modelo del constructivismo, desarrollaron grandes cambios educativos, pero los resultados demostraron diferencia comparativa con el modelo tradicional donde los estudios empíricos practicados por los docentes (autodidactas) fortalecen el nivel de conocimiento. En Venezuela, (Acosta \& Andrade, 2014) optaron por aplicar estrategias dinámicas para lograr la comprensión metodológica del aprendizaje significativo demostrando la necesidad de 
motivar a los estudiantes mediante talleres con diversas técnicas educativas, dando espacio para que el estudiante construya sus propios conceptos coherentes en su contenido, dando lugar al aprendizaje significativo resultado alentadores.

\section{CONCLUSIONES}

Se identificó los tipos de estrategias de enseñanza implementado en las Ciencias Naturales mediante el análisis documental de 32 artículos indexados (Tabla 8) se identificaron que las estrategias educativas de la teoría conductista de mayor practica corresponde al conexionismo y la observación, también se presenta las estrategias cognitivas siendo la creatividad y la lluvia de ideas destacaron en los modelos educativos actuales, sin embargo las estrategias de aprendizaje significativo fueron de poca aceptación.

Se identificaron el comportamiento de las dimensiones del aprendizaje significativo en los estudiantes por medio de una encuesta de 170 estudiantes (Tabla 9) los cuales demostraron alto nivel deficientes en capacidad 
cognoscitiva del aprendizaje significativo con el 68\%, sin embargo el $26 \%$ responde a las competencias eficientemente y $6 \%$ carece en tomar decisiones, siempre necesita de alguien que lo ayude (Figura 13). De acuerdo a las capacidades afectivas - sociales (Tabla 10) el 76\% le gusta trabajar de manera independiente, no comparte sus deberes educativos. Mientras que el 20\% muestra ser más eficiente y responsable con sus deberes educativos, sin embargo el $4 \%$ siempre necesita ayuda para resolver sus obligaciones educativos (Figura 14).

Se diseñó el modelo de estrategias de enseñanza para fortalecer el aprendizaje significativo de Ciencias Naturales de la Unidad Educativa Patria Ecuatoriana, 2020. (Propuesta). Las estrategias de enseñanza cognitivas y constructivas fortalecerá el aprendizaje significativo; considerando al estudiante como un ser autónomo en proceso de desarrollo y que comprenda a la ciencia a su manera, según sus esquemas mentales y a las etapas de desarrollo cognitivo del educando. 
La enseñanza debe secuenciar, organizar y adecuar a los temas de aprendizaje a las etapas de desarrollo biopsicosocial del alumno.

Se validó la propuesta mediante la técnica de juicio de expertos. Considerando como jueces a distinguidos profesionales de prestigiosas universidades que ejercen la educación universitaria con el grado de doctor.

\section{RECOMENDACIONES}

Desarrollar los procesos de seguimiento metodológico pedagógicos dentro de la Unidad Educativa Patria Ecuatoriana, 2021 y evaluar los resultados de acuerdo al desarrollo del curso de ciencias naturales en Educación Básica Superior.

El comportamiento de las dimensiones del aprendizaje significativo en los estudiantes requiere fortalecer las capacidades cognoscitivas, afectivas -sociales capacitar a los docente mediante talleres, actividades motivacionales, prácticas de grupo entre otras acciones que permitan integrar la amistad, el conocimiento y la responsabilidad. 
Para diseñar el modelo innovador de estrategias de enseñanza se presentó ciertas dificultades en la selección y filtro de las revistas científicas indexadas que se encuentran en los repositorios a nivel mundial; se recomienda utilizar el software Review Manager v. 5.3.; que ayuda a guiar la elaboración de protocolos de revisión dentro de la colaboración con la realización de un diagrama de flujo.

A la dirección de la Unidad Educativa Patria Ecuatoriana, dar las facilidades para aplicar el modelo innovador de estrategias de enseñanza para fortalecer el aprendizaje significativo de ciencias naturales, siendo el complemento de la mejora educativa con el propósito de aumentar el aprendizaje de manera racional y con las suficientes capacidades en el desempeño del estudiante en el futuro.

También es necesario que la dirección facilite la iniciativa de los docentes del curso de ciencias naturales en Educación Básica Superior, ellos buscan aplicar metodologías adecuadas para lograr mayor comprensión de los estudiantes, no deben limitar tales acciones, es 
necesario documentar tales procesos que buscan mejorar la calidad educativa.

\section{PROPUESTA}

La tecnología facilita ampliar conocimientos en toda las ramas científicas además incluye la filosofía, estudios sociales y políticos, sus investigaciones brindan a los educadores una amplia orientación de ideas que pueden ser aceptados o rechazado. Los científicos intentan dar sentido a las observaciones de los fenómenos creando explicaciones adecuadas. Enseñanza basada en la investigación en la educación científica y tecnológica trata básicamente de que los profesores enseñen a los estudiantes a tener una mejor comprensión del mundo en el que trabajan, se comunican, aprenden y viven. Las estrategias de enseñanza que involucran activamente en indagaciones para lograr mayor probabilidades para aumentar la comprensión conceptual (Clough, 2017; Sjøberg, 2009).

El aprendizaje basado en la indagación ayuda generar conocimiento de forma eficaz (Svendsen, 2015). 
Los estudiantes deben practicar la observación para comprender durante los procesos del aprendizaje también es necesario que desarrollen investigación para lograr trasmitir lo aprendido. La enseñanza dentro del plan de estudios puede apoyarse en el hecho de que la ciencia es un proceso para generar conocimiento (Svendsen, 2015). Es importante ser consciente de la naturaleza de la ciencia que se enseña y por qué, diferentes estrategias de enseñanza, oportunidades, procesos mentales únicos y buenos resultados. Esto es desafiante, pero importante, ya que muy a menudo son los temas de ciencia que los estudiantes encuentran atractivos y que brindan una narrativa a su experiencia.

No se trata solo de hacer preguntas y discutir soluciones; está lejos de adaptar datos e información en conocimiento útil. Las estrategias de enseñanza que involucran activamente a los aprendientes en el proceso de aprendizaje mediante indagaciones tienen más probabilidades de aumentar comprensiones, y puede haber cantidades variables de dirección por parte del maestro, tanto en la investigación abierta como guiada (Svendsen, 2015; Hmelo-Silver, Duncan, \& Chinn, 2007; 
Linn, Davis, \& Bell, 2004). Cuando los estudiantes están desarrollando su comprensión del mundo natural y artificial que los rodea, entonces, como los científicos, pueden usar la indagación para llegar a ideas y teorías que les ayuden a explicar lo que observan. Los estudiantes también tienen que cambiar sus ideas a medida que encuentran evidencia nueva y contradictoria. $Y$, al igual que los científicos, no parten de cero, sino de lo que ya saben y de las ideas que ya tienen (Bybee, y otros, 2006).

El espacio profesional de la escuela da lugar a enseñanza innovadora que lleve a una mayor creatividad para los estudiantes. El espacio es un lugar de trabajo en el que los estudiantes con intereses STEM, especialmente en informática o tecnología, pueden reunirse para trabajar en proyectos mientras comparten ideas, equipos y conocimientos. La fabricación digital es una de las actividades clave en los espacios de creación de equipos, como impresoras 3D, cortadoras láser y elementos electrónicos que suelen estar disponibles (Burner, Svendsen, \& Røkenes, 2020). Una habilidad a menudo referida a los espacios de creación de espacios es la creatividad, el espacio del creador de conceptos se ha 
generalizado y ya no necesita incluir un conjunto predefinido de herramientas de fabricación, el enfoque está más bien en tener un espacio creativo, accesible al público donde es posible explorar, hacer y jugar (Bybee, y otros, 2006) (Burner, Svendsen, \& Røkenes, 2020). Alguna literatura [por ejemplo, (Bybee, y otros, 2006) menciona explícitamente la intención de los espacios de creación de estimular el interés en STEM. Makerspaces puede ser el lugar que aliente a toda una nueva generación de mentes creativas a explorar y resolver los grandes problemas. Esta oportunidad de aprendizaje brinda a los estudiantes una oportunidad innovadora de experimentar lo que pueden hacer cuando no están limitados por las reglas y respuestas del aula (Hodson, 2009).

El estudio curricular de ciencias biológicas (BSCS), en que la educación estadounidense ha desarrollado programas educativos basados en investigaciones sobre enseñanza y problema basados a la realidad, participar, explorar, explicar, elaborar y evaluar se logra la planificación, implementación y evaluación del aprendizaje y la enseñanza de manera adecuada. (Svendsen, 2015; Bybee, y otros, 2006) Definieron objetivos educativos 
claros para la enseñanza de las ciencias naturales utilizando herramientas para diseñar, planificar, implementar y evaluar sus secuencias de enseñanza de acuerdo a las iniciativas del docente con relación a la programación curricular las mismas que consideradas como aportes que fortalecen el aprendizaje.

Las mejores prácticas auténticas de la enseñanza de las ciencias naturales se presentan de acuerdo a las prácticas pedagógicas como: Involucrar ideas que aborda la comprensión inicial y las ideas preconcebidas de los estudiantes sobre los temas y su organización conceptual.

Para organizar la información puede ser una forma poderosa de aumentar la comprensión y la retención. Por ejemplo, reconocer un patrón puede ser un poderoso complemento de la recuperación. Si le pidiera a un estudiante que memoriza la siguiente lista de números, tendría dificultades a menos que el patrón de subrayado se hiciera visible: $13,7,19,10,4,1,25,16,22,28$. Si el patrón se aclara esencialmente reordenando la información, se puede establecer fácilmente una regla que facilite recordar la secuencia: 1, 4, 7, 10, 13, 16, 19, 22, 25, 
28 La regla es "Comenzando con uno, es cada tercer número hasta llegar a 28". Estas son algunas de las "grandes ideas". De manera similar, sería beneficioso para los estudiantes recibir instrucción directa para llegar a saber cómo se lleva a cabo "la solución de problemas".

Los estudiantes deben ser plenamente conscientes de lo que saben y lo que no saben. A menudo, esto se puede lograr solicitando a los estudiantes que resuman lo que han aprendido. Alternativamente, el uso de una "prueba de muestra" o una "prueba previa" se pueden utilizar, ayudando a los estudiantes a ser más conscientes de tener conocimiento o de ignorar el aprendizaje, es necesario autoevaluarse y autorregularse. La práctica del aprendizaje cooperativo mediante grupos de trabajo ayuda a participar de todos sus miembros, siendo necesario implementar liderazgo para el cumplimiento de actividades programadas. Las mejores prácticas de la enseñanza de las ciencias: Se promueven comúnmente sobre la base de la programación curricular y los hallazgos de la investigación realizada. Algunas de las principales prácticas " deseables" para la enseñanza de las Ciencias Naturales la misma que se describen para fortalecer 
aprendizajes significativos según el momento de la clase con su instrumento de evaluación:

Tabla 12. Estrategias del modelo propuesto

\begin{tabular}{|c|c|c|}
\hline $\begin{array}{l}\text { Momento de la } \\
\text { clase }\end{array}$ & $\begin{array}{l}\text { Estrategias } \\
\text { cognitivista } \\
\text { constructivista }\end{array}$ & $\begin{array}{l}\text { Instrumento } \\
\text { de } \\
\text { Evaluación }\end{array}$ \\
\hline $\begin{array}{l}\text { Inicio (Estrategias } \\
\text { preinstruccionales) }\end{array}$ & $\begin{array}{l}\text { 1. Lluvia de ideas } \\
\text { 2. Propone y } \\
\text { defiende ideas } \\
\text { 3. Preguntar a } \\
\text { otros para } \\
\text { comprender y } \\
\text { clarificar. } \\
\text { 4. Reflexiona, } \\
\text { argumenta, } \\
\text { crea. }\end{array}$ & Rubrica \\
\hline $\begin{array}{l}\text { Desarrollo o } \\
\text { construcción del } \\
\text { conocimiento } \\
\text { (Estrategias } \\
\text { coinstruccionales) }\end{array}$ & $\begin{array}{l}\text { 1. Creatividad. } \\
\text { 2. Participa } \\
\text { activamente en } \\
\text { clase. }\end{array}$ & Rubrica \\
\hline
\end{tabular}




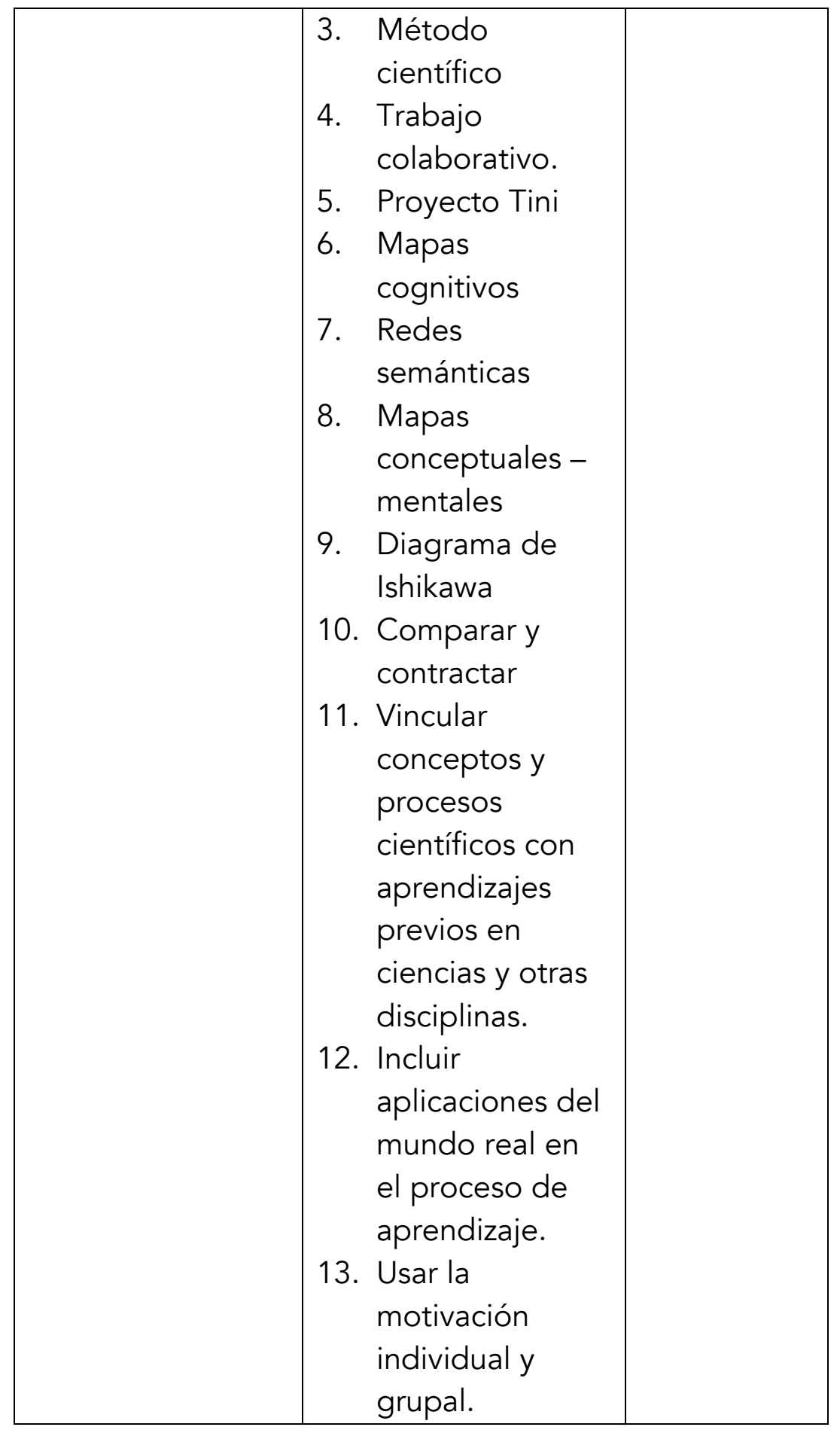




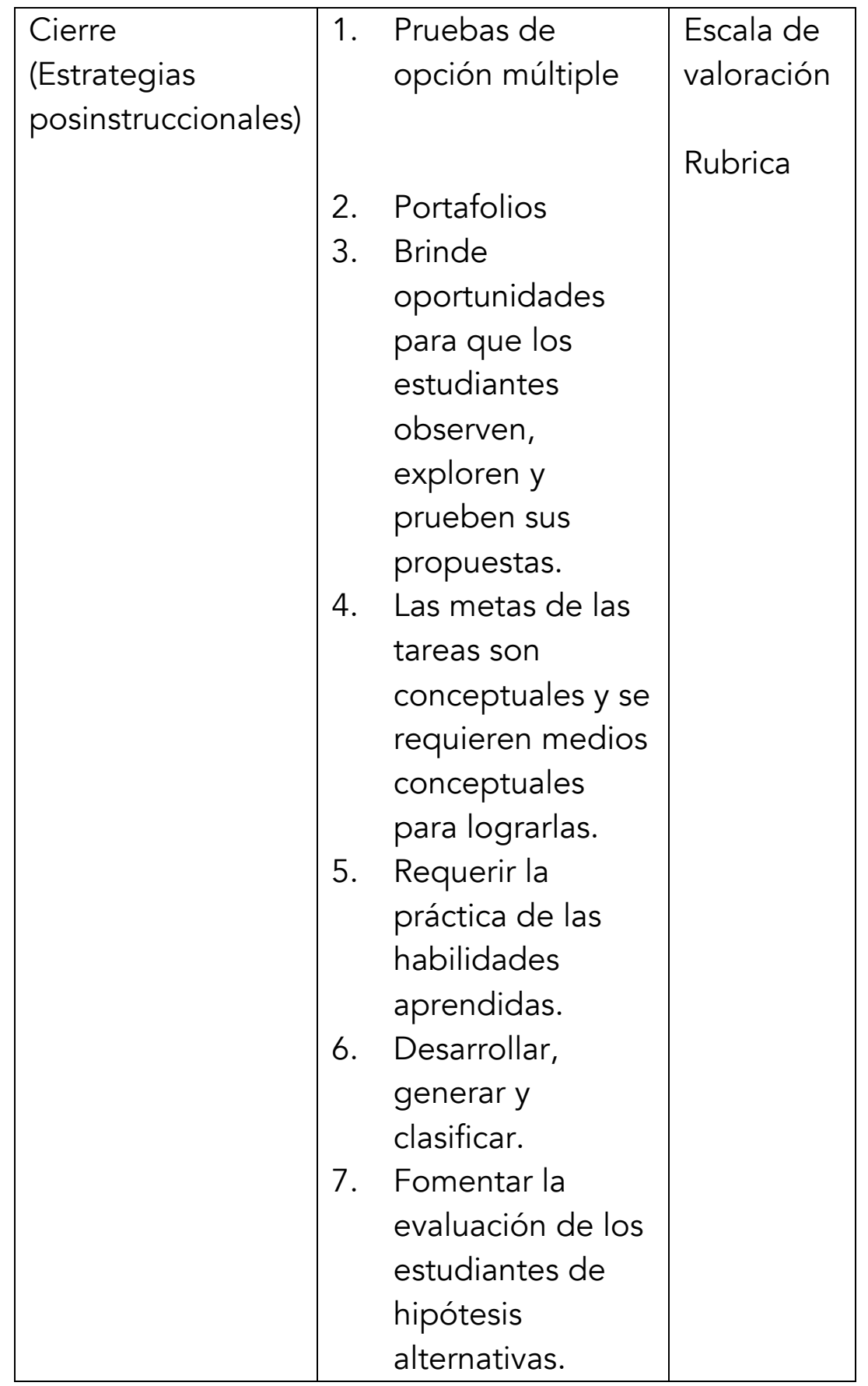




\begin{tabular}{|c|c|c|c|}
\hline & & $\begin{array}{l}\text { Promover el } \\
\text { pensamiento } \\
\text { crítico, lógico y } \\
\text { creativo. }\end{array}$ & \\
\hline $\begin{array}{l}\text { Transferencia del } \\
\text { conocimiento } \\
\text { (Estrategias de } \\
\text { producción) }\end{array}$ & $\begin{array}{l}1 . \\
\\
2 . \\
3 . \\
4 . \\
5 . \\
6 . \\
6 . \\
\\
5 .\end{array}$ & $\begin{array}{l}\text { Proyecto } \\
\text { científico - } \\
\text { humanista, } \\
\text { promueve el } \\
\text { desarrollo y la } \\
\text { autonomía. } \\
\text { Ensayos para que } \\
\text { explica y resuelve } \\
\text { problemas. } \\
\text { Emplear prácticas } \\
\text { de laboratorios } \\
\text { de investigación. } \\
\text { Clase inversa } \\
\text { Foros, para } \\
\text { desarrollar el } \\
\text { pensamiento } \\
\text { lógico y crítico. } \\
\text { Cuadros } \\
\text { comparativos } \\
\text { Elaboración de } \\
\text { maquetas y } \\
\text { videos que } \\
\text { involucre a todos } \\
\text { los alumnos en } \\
\text { tareas científicas } \\
\text { significativas que } \\
\text { desarrollen } \\
\text { habilidades de }\end{array}$ & Rubrica \\
\hline
\end{tabular}




\begin{tabular}{|l|l|l|}
\hline & $\begin{array}{l}\text { pensamiento } \\
\text { creativo. }\end{array}$ & \\
& & \\
& & \\
\hline
\end{tabular}

Las prácticas didácticas del aprendizaje significativo son asociadas con el éxito educativo y es medido con las evaluaciones participativas de los estudiantes, es necesario organizar el contenido para lograr.

La importancia de aprender Ciencias Naturales son estrategias de enseñanza para los educadores de hoy, ser más eficaz en el aula obteniendo buenos resultados con los estudiantes. No siempre es obvio que la ciencia da forma a nuestra vida diaria, pero el hecho es que la ciencia influye en innumerables decisiones que tomamos cada día. Más que nunca, los educadores necesitan emplear estrategias de enseñanza que inspiren y preparen a los estudiantes apreciar la ciencia $y$, potencialmente, perseguirla en sus elecciones académicas. La ciencia con 
la tecnología forma un mecanismo sistemático para la estructura educativa de las ciencias naturales a través de la observación y la experimentación. Es clave para la innovación, la competitividad global y el avance humano. Es importante que el mundo continúe avanzando en el campo de la ciencia, para encontrar alternativas para solucionar lograr buena salud con armonía del medio ambiente.

El valor de aprender ciencias va más allá de los avances científicos, el aprendizaje de la ciencia tiene beneficios individuales, como el desarrollo de nuestra capacidad para hacer preguntas, recopilar información, organizar y probar nuestras ideas, resolver problemas y aplicar lo que aprendemos. Aún más, la ciencia ofrece una plataforma poderosa para generar confianza, desarrollar habilidades de comunicación y dar sentido al mundo que nos rodea, un mundo que está cada vez más moldeado por la ciencia y la tecnología. La ciencia también implica mucha comunicación con otras personas y desarrolla la paciencia y la perseverancia en los estudiantes. Encontrar respuestas a sus innumerables preguntas de "por qué" impulsa a 
investigar y formarse sus propias opiniones en lugar de dar por sentadas las de los demás.

Estrategias de enseñanza para educadores. Existe una necesidad creciente de científicos, ingenieros e innovadores. El futuro de Estados Unidos depende de que los educadores de la nación utilicen actividades prácticas y mentales para hacer que la ciencia sea interesante, atractiva e inspiradora. Sin embargo, una carrera en educación, especialmente en ciencias, puede ser un desafío. El consenso entre estudiantes y educadores es que la ciencia debe ser divertida de aprender y enseñar. Involucrar a los estudiantes en el contenido científico requiere que los educadores ayuden a los estudiantes a verse a sí mismos como científicos e ingenieros en lugar de observar pasivamente a otras personas que realizan el trabajo científico., Se trata de crear oportunidades para que vean la ciencia en aplicación, pero si los estudiantes jóvenes no pueden captar la información y los educadores no están enseñando el contenido de manera efectiva, entonces limita las posibilidades de éxito de los estudiantes. 
Modelo de estrategias de enseñanza para fortalecer el aprendizaje significativo en Ciencias Naturales de la Unidad Educativa Patria-Ecuatoriana, 2020

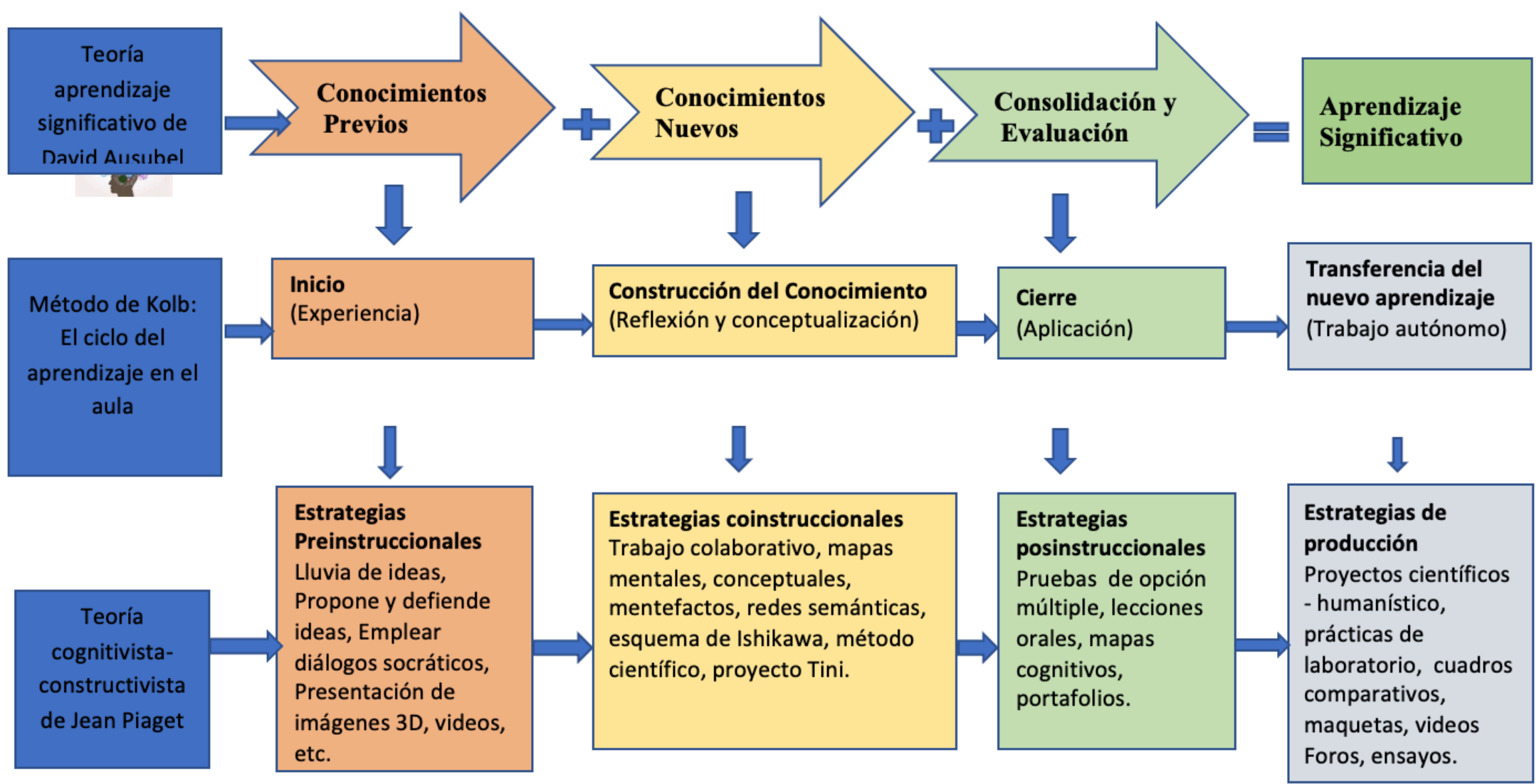

Enfoques

TIC - TAC - TEP - Construir, publicar y difundir

tecnológicas 


\begin{tabular}{|l|l|l|l|}
\hline Organizar temas & Prácticas académico & Prácticas escolares & Prácticas en el aula \\
\hline $\begin{array}{l}\text { Currículo y objetivos } \\
\text { académicos }\end{array}$ & $\begin{array}{l}\text { Alinear el plan de } \\
\text { estudios con los } \\
\text { estándares por área } \\
\text { temática. }\end{array}$ & $\begin{array}{l}\text { Establecer metas } \\
\text { académicas } \\
\text { específicas basadas } \\
\text { en el rendimiento } \\
\text { académico. }\end{array}$ & $\begin{array}{l}\text { Asegura que los puntos de } \\
\text { referencia y metas académicas } \\
\text { impulsen logros por sesión. }\end{array}$ \\
\hline $\begin{array}{l}\text { Selección de docentes } \\
\text { con liderazgo y amplia } \\
\text { capacidad competitiva }\end{array}$ & $\begin{array}{l}\text { Hacer de la enseñanza } \\
\text { yel aprendizaje el } \\
\text { enfoque principal de } \\
\text { los administradores } \\
\text { escolares }\end{array}$ & $\begin{array}{l}\text { Seleccionar } \\
\text { maestros altamente } \\
\text { calificados y brindar } \\
\text { desarrollo } \\
\text { profesional basado } \\
\text { en las necesidades } \\
\text { de los estudiantes }\end{array}$ & $\begin{array}{l}\text { Colaborar enfocándose en } \\
\text { problemas curriculares } \\
\text { instructivos e }\end{array}$ \\
\hline
\end{tabular}




\begin{tabular}{|c|c|c|c|}
\hline $\begin{array}{l}\text { Programas, prácticas y } \\
\text { arreglos de instrucción }\end{array}$ & 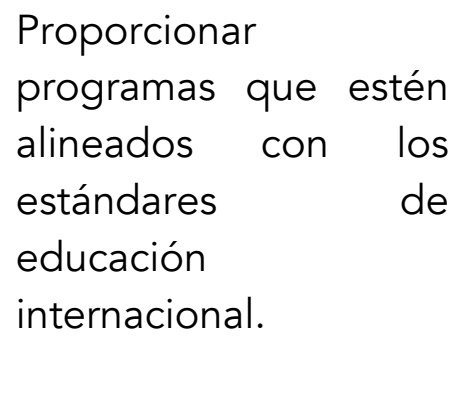 & $\begin{array}{l}\text { Adaptar programas, } \\
\text { prácticas y arreglos } \\
\text { para abordar las } \\
\text { necesidades } \\
\text { aprendizaje de } \\
\text { población la } \\
\text { estudiantil. }\end{array}$ & $\begin{array}{l}\text { Utilizar los datos de la } \\
\text { evaluación para informar las } \\
\text { prácticas de instrucción. }\end{array}$ \\
\hline $\begin{array}{l}\text { Seguimiento: } \\
\text { cumplimiento, análisis } \\
\text { y uso de datos }\end{array}$ & $\begin{array}{l}\text { Analizar evaluaciones } \\
\text { para monitorear las } \\
\text { brechas en el } \\
\text { rendimiento. }\end{array}$ & $\begin{array}{lr}\text { Monitorear } & \text { el } \\
\text { desempeño } & \text { de } \\
\text { maestros } & \text { y } \\
\text { estudiantes } & \text { usando } \\
\text { datos de evaluación } \\
\text { y observaciones en } \\
\text { el aula }\end{array}$ & $\begin{array}{l}\text { Utilice varios métodos de } \\
\text { evaluación para monitorear } \\
\text { continuamente el aprendizaje } \\
\text { de los estudiantes }\end{array}$ \\
\hline
\end{tabular}




\begin{tabular}{|l|l|l|l|}
\hline Reconocimiento, & Los éxitos personales & Intervenir según las & Identificar a los estudiantes \\
intervención y ajustes & son reconocidos en las & necesidades y \\
intervenciones. & que necesitan intervenciones \\
reconocer los logros & académicos y de alcanzar las metas \\
pamportamiento. & académicas.
\end{tabular}


El papel que deberían desempeñar los educadores de ciencias es guiar a los estudiantes a desarrollando destrezas con criterio de desempeño en lugar de centrarse únicamente en la memorización de hechos. La ciencia debería ser un verbo en lugar de un sustantivo". Algunas de las estrategias de enseñanza que los educadores están utilizando para promover la ciencia incluyen el aprendizaje basado en problemas, la incorporación de tecnología educativa en la lección y el aprendizaje basado en proyectos. Tener una base de calidad en principios científicos y un plan para entregar planes de lecciones atractivos y fáciles de entender puede ser increíblemente impactante. Los educadores armados con estrategias y técnicas nuevas y diferentes para la enseñanza de la ciencia pueden plantar las semillas de futuros científicos que podrían hacer cosas asombrosas por la sociedad y el mundo. Uno de los grandes desafíos de la gestión del aula es descubrir cómo calmar a los estudiantes exuberantemente locuaces y redirigir esa energía (no querrás reprimirla por completo) hacia un fin académico más productivo. Si bien existen técnicas que puede emplear para silenciar un aula ruidosa, vale la pena tomarse un momento para escuchar el ruido en sí e 
identificar su fuente. A continuación un vistazo de una estrategia simple que se puede utilizar para fomentar debates productivos en el aula. Los estudiantes más comunicativos como estudiantes extrovertidos y / o auditivos que disfrutan discutiendo asuntos que son significativos para ellos. A continuación se ofrecen el proceso, sobre cómo desarrollar el aprendizaje significativo desde la estrategia de trabajo colaborativo.

- Identifica el objetivo de la actividad.

- Organizar grupos de estudiantes.

- Establecer pautas y parámetros claros para una comunicación asertiva en clase.

- Docente es el tutor que guía desde el principio y después dejar a los grupos que construyan aprendizajes nuevos.

- Brindar oportunidades para preparar discusiones sobre el tema.

- Incorporar estrategias de discusión atractivas para los estudiantes.

- Afirmar, resumir y redirigir según sea necesario.

- Ofrezca tiempos necesarios para discusiones fuera del tema. 
- Invitar a los estudiantes más tranquilos a compartir con los otros alumnos.

- Incentivar la autoevaluación y la Coevaluación como técnicas de medición de aprendizajes.

- Valorar los conocimientos previos, sacar conclusiones y fomentar la creatividad para difundir su trabajo por medios de recursos físicos o digitales. 


\section{REFERENCIAS}

Acosta, F. S. \& Andrade, B. A. (2014). Estrategias de enseñanza para promover el aprendizaje significativo de la biología en la Escuela de Educación. Multiciencias. Universidad del Zulia Punto Fijo, Venezuela. 14(1), 67-73. https://www.redalyc.org/articulo.oa?id=904/90430 816010

Acosta, S. \& García, M. (2011). Estrategias constructivistas para promover el aprendizaje significativo de las ciencias biológicas en la Universidad del Zulia. Revista Venezolana de Tecnología y Sociedad. 4(1), 27-

http://www.revencyt.ula.ve/storage/repo/ArchivoD ocumento/rvtsoc/v4n1/art03.pdf

Adame, T. A. (2017). Medios audiovisuales en el aula. Material de trabajo, Universidad de Córdoba, Escuela de Biología, Tenerife, España. http://online.aliat.edu.mx/Desarrollo/Maestria/Tec EducV2/Sesion5/txt/ANTONIO_ADAME_TOMASO 1.pdf

Agresti, A. (2007). An Introduction to categorical data analysis. $2^{\mathrm{a}}$ Ed. New York: John Wiley \& Sons. ISBN 978-0-471-22618-5

Alvarado, A.; Gil, A.; Rojas, A.; Gómez, M.; Gastelo, G.; Sánchez, W. \& Estela, K. (2018). Estrategia para el aprendizaje autónomo. Universidad Católica "Santo Toribio de Mogrovejo", Chiclayo, Perú. https://sites.google.com/site/portafoliodeestrategi 
asklen/estrategias-de-aprendizaje/estrategias-

cognitivas

Aquino, Clará Adrián Ernesto; Ortiz, Hernández Nehemías; Yanes, Hernández Douglas Vladimir (2013). Incidencia de la formación docente en el aprendizaje de la asignatura de la matemática en los estudiantes de los primeros años de bachillerato, de los centros educativos centro escolar "República del Ecuador" y liceo "Nuestra Señora de los Ángeles, del Distrito Educativo 06 - 07 del municipio de San Salvador, durante el año lectivo 2012". (Tesis de grado, Universidad de El Salvador). http://ri.ues.edu.sv/id/eprint/4844/

Ausubel, D., Joseph, N. \& Hanesian, H. (1991). Psicología educativa: Un punto de vista cognoscitivo. Editorial Trillas, S. A. México.

Ausubel, D., Novak, J. \& Hanesian, H. (1997). Psicología Educativa. Un punto de vista cognoscitivo. México, Trillas.

Barrón, Tirado María Concepción (2009). Docencia universitaria y competencias didácticas. Perfiles Educativos. Instituto de Investigaciones sobre la Universidad y la Educación. XXXI. Distrito Federal, México.

76-87. https://www.redalyc.org/pdf/132/13211980006.pdf

Bartolomé A. (2016): Preparando para un nuevo modo de conocer. EDUTEC. Revista electrónica de Tecnología Educativa, 4. http://www.uib.es/depart/gte/revelec4.htm . 
Biggs, J. (2007). Teaching for Quality Learning at University. New York: Open University Press.

Blurton, C. (2000). Nuevas direcciones del uso de las TIC en la educación. Organización Nacional Unida de Educación, Ciencia y Cultura (UNESCO). https://en.unesco.org/themes/education/

Bolat, Y. (2016). Ters yüz edilmiş sınıflar ve eğitim bilişim ağı (EBA) [Aulas invertidas y red de información educativa (EIN). Journal of Human Sciences, 13(2), 3373-3388. Doi:10.14687/jhs.v13i2.3952

Caballero, C. C. A. \& Recio, M. P. P. (2017). Las tendencias de la Didáctica de las Ciencias Naturales en el Siglo XXI. VARONA, 1(44), pp. 34-41 Universidad Pedagógica Enrique José Varona. La Habana, Cuba. http://www.redalyc.org/articulo.oa?id=3606355640 07

Carriazo, S. M. H. (2009a). ¿Cómo hacer el aprendizaje significativo? Quito, Ecuador: Editorial Santillana. Quito. Ecuador. ISBN: 978-9978-29-567-0

Carriazo, S. M. H. (2009b). El curso para docentes: Conocimientos previos y prerrequisitos. 74 pág. Ediciones Santillana. Quito. Ecuador. ISBN: 9789978-29-572-4.

https://www.uenma.edu.ec/recursos/santillana\%20 archivos/conocimientos\%20previos.pdf

Clark, J., \& White, G. (2010). "Experiential Learning: A Definitive Edge In The Job Market". American Journal of Business Education, 3(2), 115-118. 
Cobo, G.E.A. (2008). Una propuesta para el aprendizaje significativo de los estudiantes de la escuela San José La Salle, de la ciudad de Guayaquil. (Tesis de doctoral, Universidad Andina Simón Bolívar. Guayaquil, Ecuador). https://core.ac.uk/download/pdf/159774007.pdf

Coll, C (2007). Una encrucijada para la educación escolar. Cuadernos de Pedagogía, Nº 370. España.

Concytec (2018). Reglamento de calificación, clasificación y registro de los investigadores del sistema nacional de ciencia, tecnología e innovación tecnológica reglamento RENACYT. Consejo Nacional de Ciencia, Tecnología e Innovación Tecnológica. Lima Perú.

https://portal.concytec.gob.pe/images/renacyt/regl amento_renacyt_version_final.pdf

De-Conti, M. (2018). Teoría del conocimiento pedagógico. Pedagogía y Saberes, 49, 177-188. https://doi.org/0000-0003-4777-732X

De-Pablos, J. (2018): Una perspectiva sociocultural sobre las nuevas tecnologías. Granada, Force Grupo editorial de la Universidad de Granada. 1(3), 457473.

Dobbs-Oates, Jennifer \& Arnold, David. (2009). The Relationship Between Preschool Teachers' Reports of Children's Behavior and Their Behavior Toward Those Children. School psychology quarterly: the official journal of the Division of School Psychology, American Psychological Association. 24. 95-105. 10.1037/a0016157. 
Educación (2020). Modelo del Sistema de Educación Intercultural Bilingüe - MOSEIB. Quito - Ecuador. https://educacion.gob.ec/modelo-y-curriculo-delsistema-de-educacion/

Escobar-Pérez, J. y Cuervo-Martínez, A. (2008). Validez de contenido y juicio de expertos: una aproximación a su utilización. En avances en medición. 2(6), 27-36. http://www.humanas.unal.edu.co/psicometria/files/ 7113/8574/5708/Articulo3_Juicio_de_expertos_2736.pdf

Gabriela, L. M. (2015). Comunicar para enseñar y aprender Ciencias Naturales. Centro de Investigación y Apoyo a la Educación Científica (CIAEC). Facultad de Farmacia y Bioquímica. Universidad de Buenos Aires.

CONICET.

Argentina. https://seminariorepensarlabioquimica.files.wordpr ess.com/2011/11/lorenzo-mg-unlar.pdf

Gallego, M. J. (2017): La tecnología educativa en acción. Granada, Force, Universidad de Granada.

Gamarra, D. C. (2017). Aproximación de un modelo teórico que fortalezca la intervención del trabajo en el contexto escolar. (Tesis Doctoral, Universidad Nacional de San Agustín de Arequipa). http://repositorio.unsa.edu.pe/handle/UNSA/2522

García, H. M. L., Porto, C. M., \& Hernández, V. F. J. (2019). El aula invertida con alumnos de primero de magisterio: fortalezas y debilidades. REDU. Revista de Docencia Universitaria, 17(2), 89-104. https://doi.org/10.4995/redu.2019.11076 
García, H., Navarro, L., López, M., Rodríguez, M. D. (2014). Tecnologías de la Información y la Comunicación en salud y educación médica. Revista Edumecentro; 6(2), pp.

253-265. http://scielo.sld.cu/scielo.php?script=sci_arttext\&pi $d=$ S2077-28742014000100018

García, P. K.A. \& Vélez, Z.P.L. (2015). El Aprendizaje Basado en Problemas como estrategia innovadora en Educación General Básica. (Tesis de grado, Universidad de Cuenca. Ecuador). https://dspace.ucuenca.edu.ec/bitstream/1234567 89/22472/1/tesis.pdf

García-Valcárcel, A. (2009). Modelos y estrategias de enseñanza. [Video]. Disponible en la Escuela de Graduados en Educación de la Universidad Virtual del Tecnológico de Monterrey. https://www.youtube.com/watch?v=V2d42hNMyfY

Goodwin, K. (2012). Uso de la tecnología de tabletas en el aula. Strathfield, Nueva Gales del Sur: Centro de Innovación Curricular y de Aprendizaje de NSW. https://fad.teluq.ca/teluqDownload.php?file=2013/ 11/iPad_Evaluation_Sydney_Region_v2.pdf

Gros, B. (2010). El ordenador invisible. Hacia la apropiación del ordenador en la enseñanza. Barcelona, Gedisa. España.

Guerrero Z, Tivisay M, \& Flores H, Hazel C. (2009). Teorías del aprendizaje y la instrucción en el diseño de materiales didácticos informáticos. Educere, 13(45), 317-329. 
http://ve.scielo.org/scielo.php?script=sci_arttext\&p id $=$ S1316-49102009000200008\&lng=es\&tlng=es.

Gutiérrez, A. (2019). Formación del profesorado en nuevas tecnologías multimedia. Revista Electrónica Interuniversitaria de Formación del Profesorado, 2(1). http://www.uva.es/aufop/publica/revelfop/99v2n1.htm

Hayırsever, F. \& Orhan, A. (2018). Ters Yüz Edilmiş Öğrenme Modelinin Kuramsal Analizi (Análisis teórico del modelo de aprendizaje invertido). Mersin Üniversitesi Eğitim Fakültesi Dergisi, 2018; 14(2):

572-596.

https://doi.org/10.17860/mersinefd. 431745

Hernández, G. (2015). La zona de desarrollo próximo comentarios en torno a su uso en los contextos escolares.

http://www.cesu.unam.mx/iresie/revistas/perfiles/p erfiles/85-86-html/85-04.htm

Hernández, G., Moriel, C. B. L., Seañez, O. M. \& Armendariz, O. A. M. (2014). Modelo innovador de formación docente en la enseñanza-aprendizaje del cuidado de enfermería. Revista Cubana de Enfermería, 30(4). http://scielo.sld.cu/scielo.php?script=sci_arttext\&pi $d=$ S0864-03192014000400005\&lng=es\&ting=es.

Hernández, P. F., Maquilón J.\& Soriano E. (2010). Evaluación de programas educativos. Granada, Grupo editorial Universitario, 95-101. 
Hernández, S. R., Fernández, C. C., \& Baptista, L. M. (2014). Metodología de la Investigación (6ta ed.) 2(1). México DF.: McGranw-Hill. ISBN: 9781456223960

Lacerda, A. (2019). Competencias académicas. Conferencia: XXV conferencia interna del Hospital Universitario "Roberto Rodríguez". Morón, Ciego de Ávila, Cuba. https://doi.org/10.13140/RG.2.2.10066.61123.

Lamas, H. A. (2016). Sobre el rendimiento escolar. Propósitos y Representaciones 3(1), 313-386. https://doi.org/10.20511/pyr2015.v3n1.74

Martínez-Olvera, W., Esquivel-Gámez, I., \& MartínezCastillo, J. (2015). Acercamiento teórico-práctico al modelo del aprendizaje invertido. II Congreso Internacional de Transformación Educativa. https://doi.org/10.13140/RG.2.1.2653.6087

Mashburn, A. J., Opfer, V. D. \& Henry, G. T. (2008). The district effect: Systemic responses to high stakes accountability. The American Journal of Education. 114 (2), 299-332.

Mayorga, F. M. \& Madrid-Vivar, D. (2010). Modelos didácticos y Estrategias de enseñanza en el Espacio Europeo de Educación Superior. Tendencias pedagógicas,15(1), https://www.researchgate.net/publication/4422722 1_Modelos_didacticos_y_Estrategias_de_ensenanz a_en_el_Espacio_Europeo_de_Educacion_Superior

Medina, L. O. (2018). Los estilos de aprendizaje y su relación con el nivel de logro de aprendizaje en la 
Facultad de Administración de la Universidad Nacional Mayor de San Marcos. (Tesis de Maestría, - Universidad Nacional de Educación Enrique Guzmán y Valle. Lima, Perú). http://repositorio.une.edu.pe/handle/UNE/2519

Medina, R. A. \& Salvador, M. F. (2009). Didáctica General del Aprendizaje. Pearson Educación, Madrid. ISBN UNED: 978-84-362-5884-4. http://ceummorelos.edu.mx/libros/didacticageneral.pdf

Monserrat, C. G. (2020). Currículo Priorizado para la Emergencia. 2020-2021. (Módulo de Planificación). Ministerio de educación. 279 p. Ecuador. https://educacion.gob.ec/wpcontent/uploads/downloads/2020/09/CurriculoPriorizado-Costa-Galapagos-para-la-Emergencia2020-2021.pdf

Muir, T. (2017). Flipping the mathematics classroom: affordances and motivating factors (Cambiando el aula de matemáticas: posibilidades y factores motivadores). The Mathematics Educator, 17(1-2), 105-130.

http://math.nie.edu.sg/ame/matheduc/tme/tmeV1 7_1/paper5.pdf

O'Connor, M. (9 de 3 de 2015). Ten powerful concepts for inspired teaching and learning. (A. T. ATS, Ed.) Stanford Teaching Commons , 12. https://teachingcommons.stanford.edu/teachingtalk/ten-powerful-concepts-inspired-teaching-andlearning 
Orellana, A. (2008). Estrategias en educación. Ediciones Mc Graw Hill. Venezuela.

Parra, A. H., López, L. J., González, C., Eliazar, M. C., Leticia, V. A., Alma, D. \& González, Z. N. C. (2019). Las tecnologías del aprendizaje y del conocimiento (TAC) y la formación integral y humanista del médico. Investigación en educación médica, 8(31), 72-81.

10.22201/facmed.20075057e.2019.31.18128

Ponce, de León Elizabeth (2018). Factores que intervienen en el aprendizaje. [Internet]. http://doctoraponcedeleonsicoedu.blogspot.com/ 2018/04/factores-que-intervienen-en.html

Prieto, V., Quiñones, I., Ramírez, G., Fuentes, Z., Labrada, T., Pérez, O., \& Montero, M. (2016). Impacto de las tecnologías de la información y las comunicaciones en la educación y nuevos paradigmas del enfoque educativo. Educ Med Super. 25(5), pp. 102. http://scielo.sld.cu/scielo.php?script=sci_arttext\&pi $d=$ S0864-21412011000100009 [ Links ]

Project, T. y Flipped, L. N. (2015). Speak Up 2014 National Research Project Findings Flipped Learning continues to trend for third year [Hallazgos del Proyecto Nacional de Investigación Speak Up 2014: Flipped Learning continúa siendo tendencia por tercer año]. http://www.tomorrow.org/speakup/2015_FlippedL earningReport.html

Reinoso, L.G.G., Barzola, M.K., Caguana, M.D., López, P.R. \& López, P.J.C. (2019). Alternate title: M-learning, a 
path to ubiquitous learning in higher education in Ecuador (M- learning, un camino hacia aprendizaje ubicuo en la educación superior del Ecuador). Revista Ibérica de Sistemas e Tecnologías de Información. Lousada. E (18), 47-59. https://search.proquest.com/openview/547824842

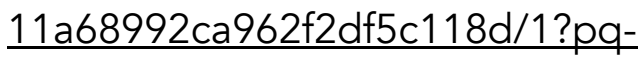
origsite $=$ gscholar $\& \mathrm{cbl}=1006393$

Robles Garrote, P. y Rojas, M. D. C. (2015). La validación por juicio de expertos: dos investigaciones cualitativas en Lingüística aplicada. Revista Nebrija de Lingüística Aplicada 18 (2), 12-33.

Rodrigo-cano, D., De-casas-moreno, P., \& Aguaded, I. (2020). Aprendizaje móvil (m-learning) como recurso formativo. Revista Mediterránea de Comunicación. 11(1), 61-74. https://doi.org/10.14198/MEDCOM2020.11.1.18

Rojas, B. L. (2005). Influencia del entorno familiar en el rendimiento de niños y niñas con diagnóstico de maltrato de la escuela Calarca de Ibagué. (Tesis de Doctoral, Pontificia Universidad Javeriana). http://www.javeriana.edu.co/biblos/tesis/medicina/ tesis24.pdf

Salas, B. M. (2019). Estrategias de enseñanza que usan los docentes y el rendimiento académico de los estudiantes del nivel secundario de la Institución Educativa \# 40177, "Divino Corazón de Jesús de Paucarpata", Arequipa. Universidad Nacional de San Agustin de Arequipa. Paucarpata, Arequipa. 
Salinas, J. (2004). Innovación docente y uso de las TIC en la enseñanza universitaria. Revista de Universidad y Sociedad del Conocimiento, 1(1). Recuperado de http://www.uoc.edu/rusc/dt/esp/salinas1 104.pdf

Sánchez, R.J., Ruiz, P.J., \& Sánchez, V.E. (2014). Las Clases invertidas: beneficios y estrategias para su puesta en práctica en la educación superior. (Tesis de doctoral. Universidad de Málaga). https://riuma.uma.es/xmlui/handle/10630/7821

Santelices, María Verónica, Taut, Sandy, Araya, Carolina, \& Manzi, Jorge (2013). Consecuencias a nivel local de un sistema de evaluación de profesores: El Caso de Chile. Estudios Pedagógicos, XXXIX(2),299-328.. https://www.redalyc.org/articulo.oa?id=173529673 018

Santos-Guevara, Brenda N. (2010). Competencias docentes para la enseñanza de ciencias naturales en una institución privada de nivel medio superior en el área metropolitana de Monterrey, N.L.. https://doi.org/10.13140/RG.2.1.1139.2489.

Sarmiento, S.M. (2017). La enseñanza de las matemáticas y las NTIC. una estrategia de formación permanente. (Tesis de Doctoral, Universitat Rovira I Virgili). http://hdl.handle.net/10803/8927

Say, F.S. \& Yıldırım, F.S (2020). Flipped Classroom Implementation in Science Teaching (Implementación del aula invertida en la enseñanza de ciencias).International Online Journal of Education and Teaching. 7(2), 606-620. http://iojet.org/index.php/IOJET/article/view/759 
Serrano, M. (2010). El proceso de enseñanza aprendizaje. Mérida, Talleres gráficos universitarios ULA.

Silva J. (2017). Una propuesta de modelo para introducir metodologías activas en educación superior. Innovación Educativa, 17(73), 117-132. http://www.scielo.org.mx/scielo.php?script=sci_artt ext\&pid=S1665-26732017000100117

Simón, L. J.; Ojando, P. E. S.; Ávila, M. X.; Miralpeix, B. A.; López, V. P. y Prats, F. M. Á. (2018). Reformulación de los roles del docente y del discente en la educación. El caso práctico del modelo de la Flipped Classroom en la Universidad. Revista de Estudios y Experiencias en Educación. 1(2), 53-73. https://doi.org/10.21703/rexe.Especial2_20185373 3

Stavenga de Jong, J. A., Wierstra, R. F. A. and Hermanussen, J. (2006) "An exploration of the relationship between academic and experiential learning approaches in vocational education", British Journal of Educational Psychology. 76(1). 155-169.

Tjur, T. (2009). Coefficients of determination in logistic regression models. A new proposal: The coefficient of discrimination. The American Statistician, 6(3), 366-372.

Tregón, M.N. (2017). Orientación educativa para la diversidad funcional visual en Nicaragua. Diseño y evaluación de un programa de formación para el profesorado. (Tesis doctoral, 456 p.). Universitat Jaume I y el Instituto Interuniversitario de Desarrollo 
Local. Xarxa, Nicaragua.

https://doi.org/10.6035/14003.2017.214069

Unesco (2013). Enfoques estratégicos sobre las TIC en Educación en América Latina y el Caribe. Santiago de Chile: OREAL/Unesco;

UNESCO (2015). Treviño et al. "Tercer Estudio Regional Comparativo y Explicativo (TERCE). Factores Asociados". Publicado por la Oficina Regional de Educación para América Latina y el Caribe (OREALC/UNESCO Santiago). http://www.unesco.org/new/fileadmin/MULTIMEDI

A/FIELD/Santiago/pdf/TERCE-Cuadernillo3Factores-Asociados.pdf

Uribe, C. S. E. (2018). Lógica matemática en el aprendizaje significativo en niños de séptimo año de Educación General Básica de la Unidad Educativa "Dr. José Ricardo Chiriboga" parroquia Manuel Cornejo Astorga, Tandapi. Período 2016 -2017. (Tesis de grado. Universidad Central del Ecuador). http://www.dspace.uce.edu.ec/handle/25000/1641 0

Yépez-Reyes, V. (2018). Posibilidades y facilidades de uso (Affordances) del aprendizaje móvil en la educación superior. Revista Andina de Educación Quito,

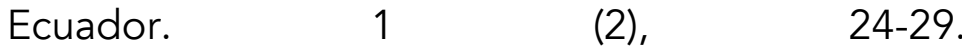
https://doi.org/10.32719/26312816.2018.1.1.3

Zambrano, Farías J., Balladares, Ponguillo K. A. (2017). Sociedad del Conocimiento y las TEPs. INNOVA Research Journal UIDE extensión Guayaquil, 2(10), 169-177. 

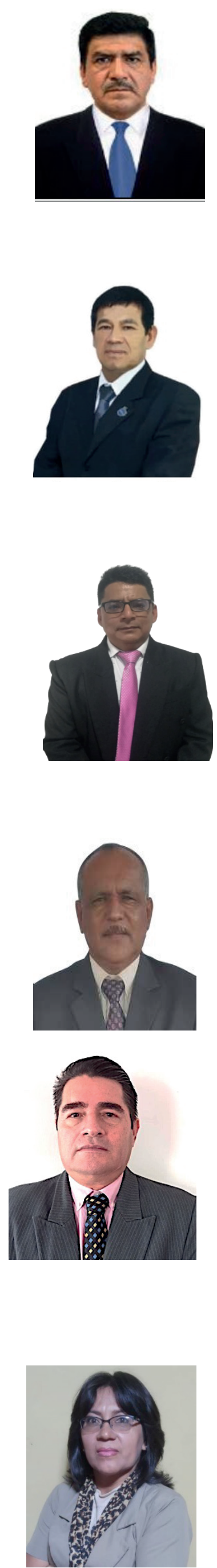

Milton Doroteo Cayambe Guachilema

https://orcid.org/0000-0003-4772-894X

cayambe1970@hotmail.com

Doctorado en Educación, Magister en Diseño Curricular, Diploma Superior en Diseño Curricular por Competencias, Licenciado en las Ciencias de la Educación Mención Químico - Biológicas. Docente de la Facultad de Filosofía, Letras y Ciencias de la Educación de la Universidad de Guayaquil, Consultor académico de trabajos de titulación, Gestor de prácticas pre-profesionales; Docente de la Unidad Educativa Patria Ecuatoriana; Vicerrector del Colegio Particular San Andrés, Formación de Formadores.

\section{Manuel Jesús Sánchez Chero}

https://orcid.org/0000-0003-1646-3037

manuelsanchezchero@gmail.com

Ingeniero de Sistemas, Magister en docencia universitaria, doctorado en educación, Docente de posgrado del doctorado de Educación de la Universidad César Vallejo Filial Piura, docente asociado de la Universidad Nacional de Frontera, Investigador Renacyt con registro P0011796, en el grupo de Carlos Monge Medrano, Nivel III. Con amplia experiencia en proyectos y publicaciones en el área de Ingeniería y tecnología de información.

\section{Jaime Amado Rosero Rojas}

https://orcid.org/0000-0003-1161-2822

amadorojas1977@hotmail.com

jroseror@uteq.edu.ec

Licenciado en Física Matemáticas, Magister en Enseñanza de las Matemáticas en la UNAE Universidad Nacional del Ecuador, Docente con amplia experiencia en Educación Técnica en Electricidad, Docente del Instituto Siete de Octubre y en la actualidad Docente de la Universidad Técnica Estatal de Quevedo.

\section{Manuel Valentín Bermúdez Pacheco}

https://orcid.org/0000-0003-3582-0079

maberpa10@hotmail.com

Licenciado en ciencias de la educación, magister universitario en formación del profesorado de educación secundaria de ecuador en la especialidad de matemáticas, doctorado en educación, ex docente de nivelación universidad estatal de Quevedo, docente de matemáticas de la unidad educativa el empalme.

\section{Walter Geovanni Valero Zambrano \\ https://orcid.org/0000-0001-7960-8569 \\ geovannyvalero@hotmail.com}

Magister en Gerencia en Innovación Educativa, Ingeniero en Gestión Empresarial, Tecnólogo en Administración de Empresas, Licenciado en Ciencias de la Educación, Profesor Segunda Enseñanza, Docente Academia Naval Guayaquil extensión Quevedo, Docente Ciencias Naturales Unidad Educativa 24 de Mayo, Docente Nivelación Universidad Técnica Estatal de Quevedo.

\section{Danette Pintado García}

https://orcid.org/0000-0002-7151-5154

danettepintadogarcia@gmail.com

Licenciado en Matemáticas, Magister en docencia universitaria, estudios concluidos de doctorado en educación, en la Universidad Nacional Pedro Ruiz Gallo, docente Auxiliar de la Universidad Nacional de Jaén 

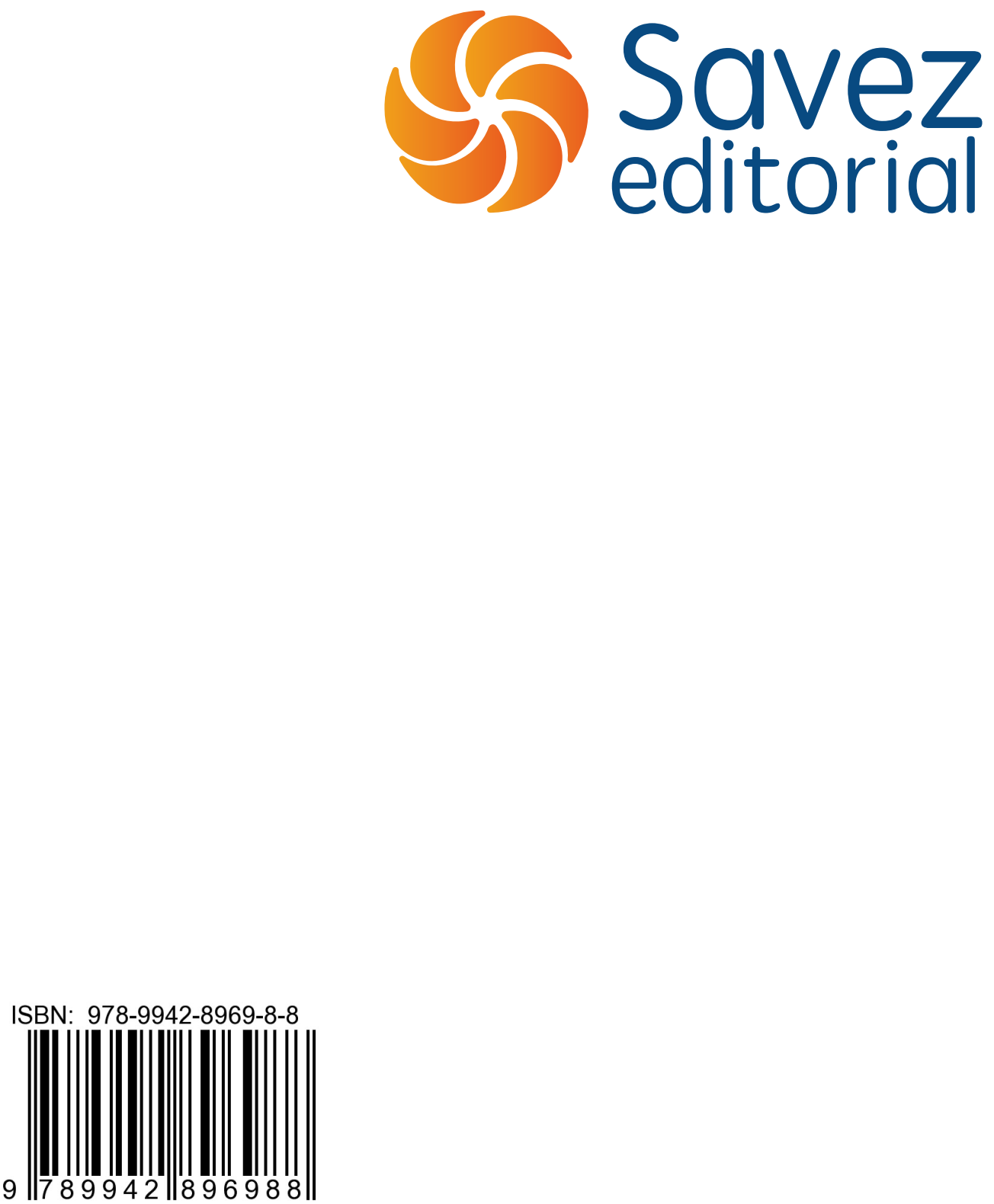